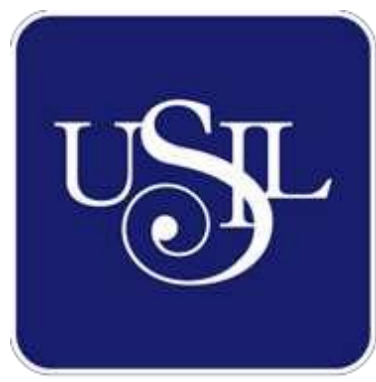

UNIVERSIDAD

SAN IGNACIO

DE LOYOLA

ESCUELA DE POSTGRADO

Maestría en Administración de Negocios - Executive MBA

\title{
ESTUDIO DE FACTIBILIDAD TÉCNICO Y ECONÓMICO DE UNA EMPRESA AJUSTADORA DE SEGUROS EN RIESGOS GENERALES
}

Tesis para optar el Grado de Maestro en Administración de Negocios - Executive MBA

\author{
ARTEMIO MARCELO MORENO VALVERDE \\ CRISTHI EMMA PACORA MURGUEYTIO
}

Asesor:

Ana Hospina Schaefer

$$
\text { Lima - Perú }
$$




\section{"ESTUDIO DE FACTIBILIDAD TECNICO Y ECONOMICO DE UNA EMPRESA AJUSTADORA DE SEGUROS EN RIESGOS GENERALES"}




\title{
DEDICATORIA
}

\author{
A mi esposa e hijos por su comprensión, paciencia y apoyo \\ incondicional. \\ Artemio Marcelo Moreno Valverde
}

\begin{abstract}
A la memoria de mis amados padres.
Cristhi Emma Pacora Murgueytio
\end{abstract}




\section{AGRADECIMIENTOS}

Agradecer a todos los que de una u otra manera nos apoyaron para la elaboración de este proyecto, durante el estudio preliminar, durante el proceso y desarrollo, a través de su experiencia, conocimiento, asesoría, información, así como también a las personas relacionadas al sector empresarial y de seguros.

- A la Mg. Ana Hospina, nuestra asesora.

- Al personal del Sistema de Bibliotecas USIL, por su disposición, brindándonos la información solicitada.

- A todas aquellas personas que han colaborado para el desarrollo de este proyecto. 


\section{RESUMEN EJECUTIVO}

El presente documento fundamenta la implementación y rentabilidad de una empresa ajustadora de seguros, profundizando en las características más importantes del mercado asegurador, además de sus factores clave. A la vez, contempla información analizada y proyectada para basar los indicadores financieros abordados y sustentar de manera técnica las conclusiones logradas.

En el primer capítulo además de ahondar en una explicación minuciosa del mercado, se detalla la idea y modelo de negocio y se establece la misión, visión y objetivos de la empresa, la cual estará dedicada a brindar un servicio integral de ajuste de seguros en Riesgos Generales (Multiriesgo, robo, deshonestidad, responsabilidad civil, lucro cesante, rotura de maquinaria, CAR, TREC, EAR, equipo electrónico) con honestidad, profesionalismo, ética y responsabilidad; enfocada a Compañías de Seguros.

El mercado asegurador está compuesto por 4 tipos de integrantes: El Asegurado, el Corredor o Bróker de Seguros, la Compañía de Seguros y la Empresa Ajustadora de Seguros; y su actividad inicia con el asegurado, quién contrata la póliza a una compañía de seguros a través de un corredor. En el caso que suceda un siniestro que afecte al asegurado o los bienes asegurados, el corredor de seguros que es un intermediario y asesor del asegurado, informará de la ocurrencia a la compañía de seguros, la cual a su vez, contactará una empresa ajustadora 
de seguros. La empresa ajustadora de seguros será la responsable de analizar de manera imparcial el siniestro y determinar el monto o siniestralidad que la compañía deberá abonar al asegurado. Cabe señalar que a cambio del servicio proveído por la ajustadora de seguros, la compañía definirá y le pagará una comisión o porcentaje de la siniestralidad indemnizada al asegurado.

El segundo capítulo comprende el análisis de la industria y el mercado, en él se demuestra que en los últimos años en el Perú, el mercado de seguros generales ha crecido considerablemente, ya sea por los montos de primas pagadas que incrementan a una razón anual de $10 \%$ (Superintendencia de Banca, Seguros y Administradoras de Fondos de Pensiones, 2017); o por las siniestralidades pagadas que aumentan en promedio de 13\% por año (Asociación Peruana de Empresas de Seguros, 2017). También mediante el análisis se demuestra la facturación para el mercado de empresas ajustadoras de seguros se incrementa en un promedio anual de $14 \%$, valor que representa en promedio, el $1.189 \%$ de los pagos de siniestralidades realizados por las compañías de seguros.

En el tercer capítulo se analizan las estrategias del marketing mix, donde se aprecia que debido a la estandarización del servicio, el canal de distribución y el precio (comisión fijada por la compañía sin negociación); solo es posible establecer estrategias de promoción que permitan la consolidación de las ventas. Asimismo con la información del análisis del mercado se pronostica las ventas para los 5 primeros años de funcionamiento de la empresa, considerando el comportamiento de las empresas ajustadoras de seguros en sus primeros años de operación. 
En el cuarto y quinto capítulo se especifica el plan de operaciones y de recursos humanos de la empresa, estableciendo su ubicación, proceso productivo y costos de producción; además de su organización funcional, organigrama, política de contratación y políticas salariales.

En el capítulo seis se detalla el plan financiero, el cual contempla que en la etapa de implementación de la empresa, se requerirá una inversión inicial de S/. 95,756.00 para cubrir la inversión en gastos activos fijos, pre-operativos y capital de trabajo. La inversión estará compuesta en un $30 \%$ de capitales propios y en $70 \%$, con un préstamo financiado a tres años con un interés anual y mensual de $13.30 \%$ y $1.046 \%$ respectivamente.

La TIRF del proyecto bajo un escenario moderado es de $51.10 \%$ y el costo de oportunidad asciende a $12.85 \%$. Además se ha realizado un análisis de sensibilidad considerando una variación de $\pm 5 \%$ en la comisión pagada por las compañías de seguros, obteniendo una evaluación en escenarios pesimista, regular y optimista.

El periodo de recuperación es de 5.20 años con una Tasa de Inflación esperada de $2.88 \%$ y una Tasa Real (Ec.Fisher) de 9.70\%. El índice de rentabilidad es de 2.26 con un Valor Presente de S/. 120,191.75.

Finalmente se concluye el crecimiento del mercado, la factibilidad de la implementación de la empresa y su correspondiente rentabilidad. 


\section{ÍNDICE}

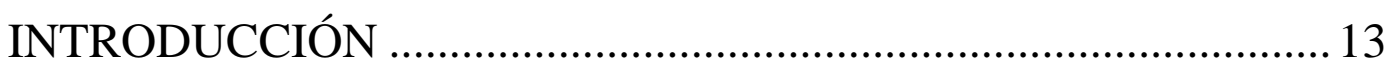

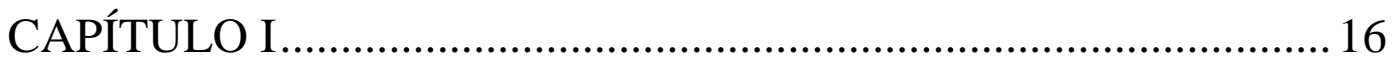

1. FORMULACION DE LA IDEA DE NEGOCIO Y MODELO DE

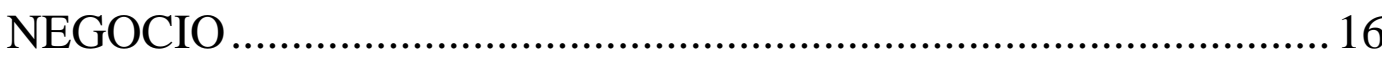

1.1. DESCRIPCIÓN GENERAL DE LA IDEA DE NEGOCIO Y MODELO DE NEGOCIO ……........................................ 16

1.1.1. Marco Conceptual.......................................................... 22

1.1.2. Marco Normativo de las Empresas Ajustadoras de Seguros

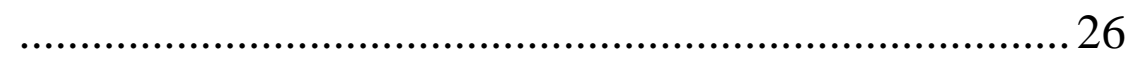

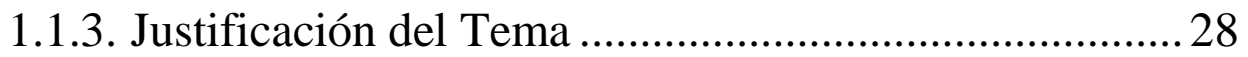

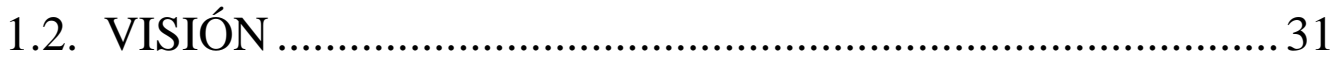

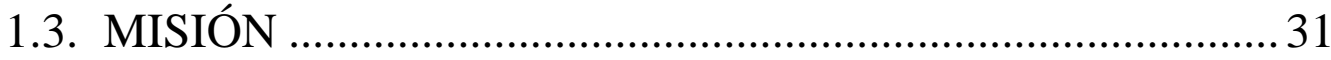

1.4. OBJETIVOS DE LA EMPRESA ……………......................... 31

1.4.1. Objetivo General............................................................. 31

1.4.2. Objetivos Específicos ..................................................... 31

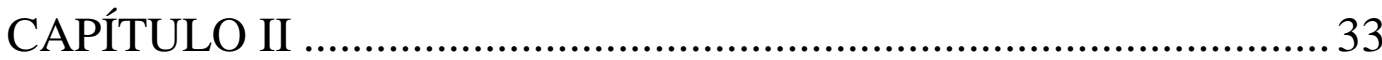

2. ANÁLISIS DE LA INDUSTRIA Y DEL MERCADO ................... 33

2.1. ANÁLISIS DE LA INDUSTRIA: LAS 5 FUERZAS DE

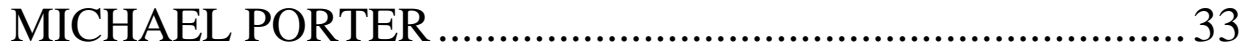

2.1.1. Poder de Negociación de los Clientes ........................... 33

2.1.2. Nivel de Rivalidad entre los Competidores ................... 34

2.1.3. Amenaza de Nuevos Ingresantes ..................................... 35

2.1.4. El poder de los Proveedores ........................................... 37

2.1.5. Amenaza de Productos Sustitutos.................................. 37

2.2. ANÁLISIS DEL MERCADO …............................................ 37

2.2.1. Análisis de las Compañías de Seguros .......................... 38 
2.2.2. Análisis de los Ajustadores de Seguros .......................... 46

2.3. ANÁLISIS DE LA DEMANDA ….......................................... 48

2.4. ANALISIS DE LA COMPETENCIA ……...........................52

2.4.1. Empresas Ajustadoras de Seguros ................................. 52

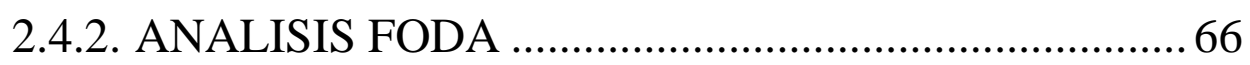

2.5. ANALISIS DE LA CADENA DE VALOR ............................68

2.5.1. Definición de Cadena de Valor....................................... 68

2.5.2. Cadena de Valor de Empresa.......................................... 70

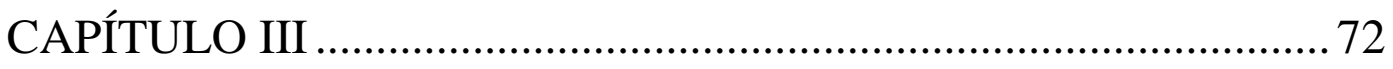

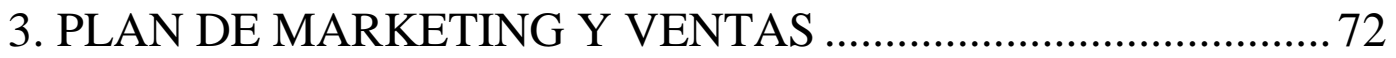

3.1. ESTRATEGIA DEL PRODUCTO O SERVICIO ................. 72

3.2. ESTRATEGIA DE DISTRIBUCIÓN ................................... 73

3.3. ESTRATEGIA DE PRECIO …........................................... 74

3.4. ESTRATEGIA DE PROMOCIÓN …….................................. 74

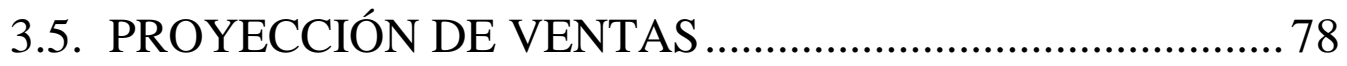

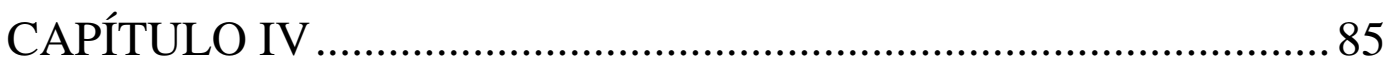

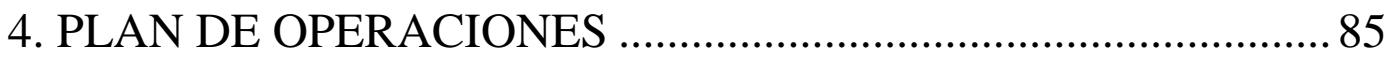

4.1. UBICACIÓN GEOGRÁFICA ………………………............. 85

4.1.1. Macro localización........................................................... 85

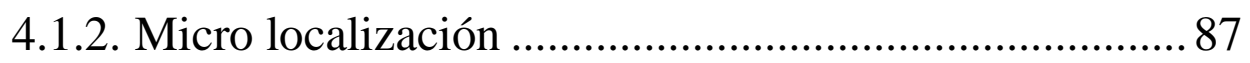

4.2. INFRAESTRUCTURA …................................................... 92

4.3. PROCESO PRODUCTIVO ................................................. 93

4.4. REGULACIÓN DE LICENCIAS Y POLÍTICAS .................. 94

4.1.1. Análisis del marco legal............................................... 94

4.1.2. Forma societaria.............................................................. 97

4.1.3. Creación y funcionamiento ............................................. 99

4.1.4. Requisitos para postular al Registro de Intermediarios y Auxiliares de Seguros - SBS Y AFP............................. 99

4.1.5. Requisitos del Municipio de Pueblo Libre .................... 102 


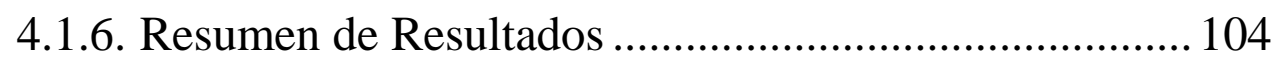

4.5. COSTOS DE PRODUCCIÓN .................................................. 104

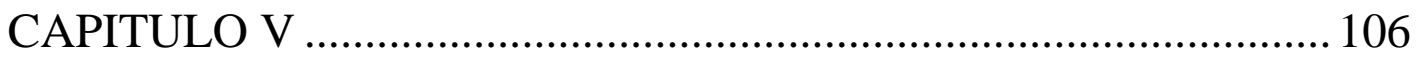

5. PLAN DE RECURSOS HUMANOS ........................................... 106

5.1. ORGANIZACIÓN FUNCIONAL_............................................ 106

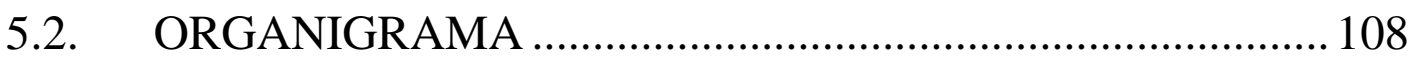

5.3. POLÍTICA DE CONTRATACIÓN …..................................... 112

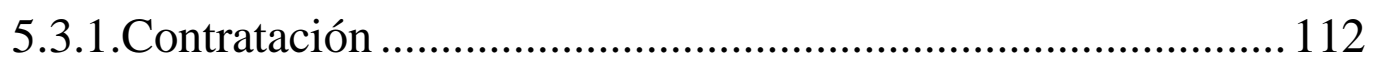

5.3.2.Política de Contratación del Personal ...................................... 113

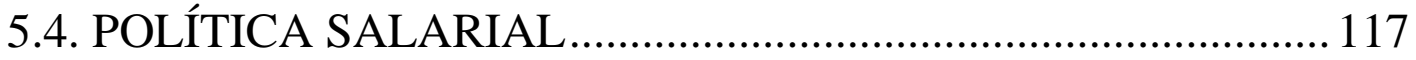

5.4.1.Consideraciones de la Política Salarial ................................... 117

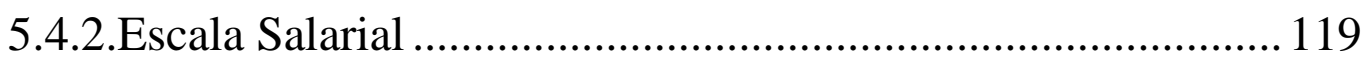

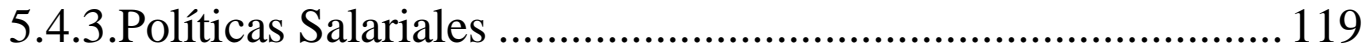

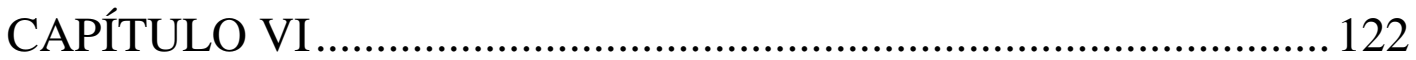

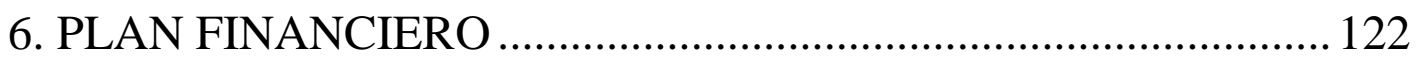

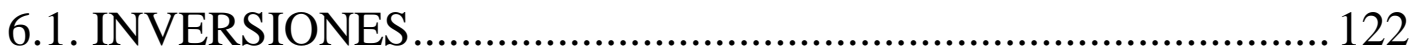

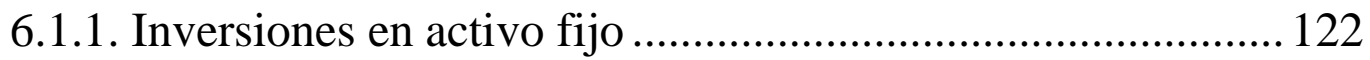

6.1.2. Inversiones en Capital de Trabajo........................................... 123

6.1.3. Inversiones en Activos Intangibles ....................................... 123

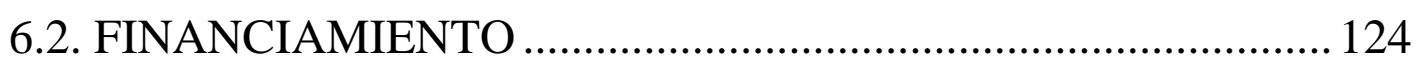

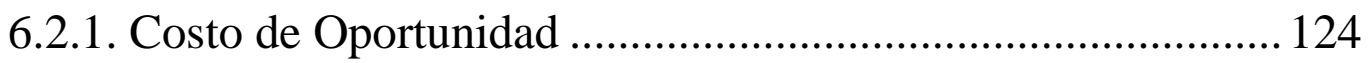

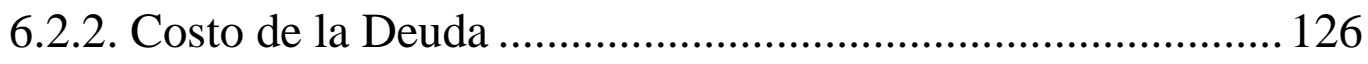

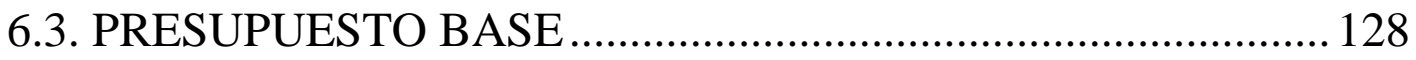

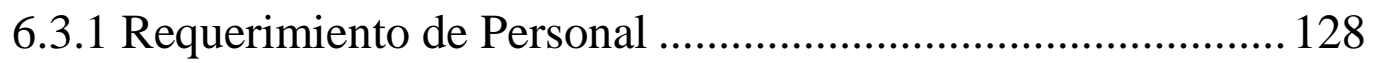

6.3.2. Costos Indirectos al Servicio................................................ 129

6.3.3. Gastos de Administración ..................................................... 130

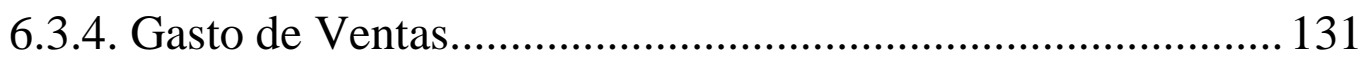

6.3.5. Cálculo de la Depreciación ................................................... 132

6.4. ESTADOS FINANCIEROS PROYECTADOS .......................... 132 


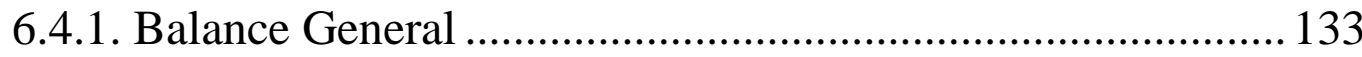

6.4.2. Estado de Pérdidas y Ganancias Proyectado ......................... 134

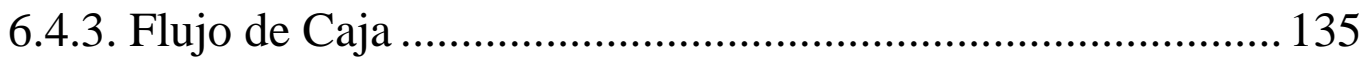

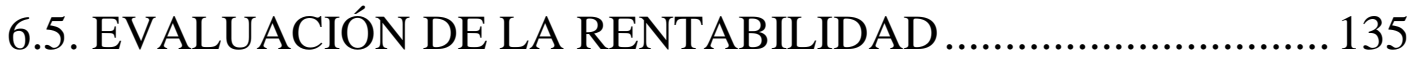

6.5.1. Valor Actual Neto y Tasa Interna de Retorno (VAN y TIR) 137

6.5.2. Período de Recuperación: Pay Back corriente....................... 138

6.5.3. Índice de Rentabilidad o Índice de Deseabilidad.................. 139

6.6. ANÁLISIS DE SENSIBILIDAD................................................. 140

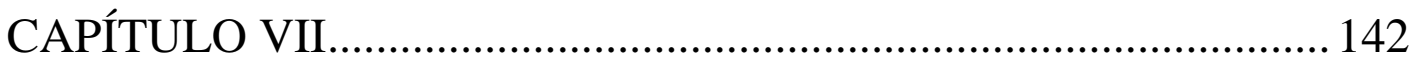

7. CONCLUSIONES Y RECOMENDACIONES ............................ 142

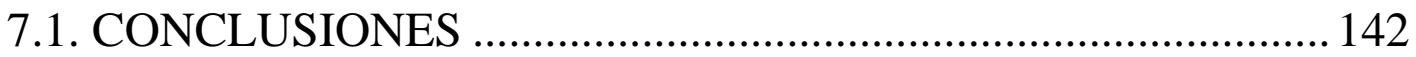

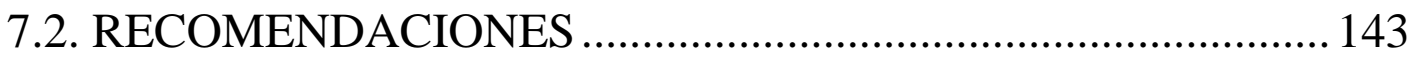

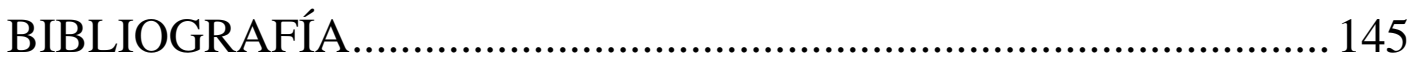




\section{INTRODUCCIÓN}

Hace más de un siglo existen los seguros en el Perú, no obstante la participación de este rubro en el PBI resulta menor al 1\%, porcentaje que en el resto de la región latinoamericana se llega a duplicar, triplicar, o cuadriplicar. En el caso de los países más avanzados la diferencia es aún mayor (Araujo, Escudero, \& Palacios, 2000).

Naturalmente los seguros tienen implicancias positivas en la economía nacional a través de factores como la disminución de los riesgos a los que se exponen las empresas, el fomento tanto nacional como internacional del comercio, el movimiento que presenta el mercado de capitales y de los rubros relacionados a construcción, impulso de la demanda en el mercado laboral, concentración del ahorro interno y dinamización del tipo de cambio vigente en la economía (Araujo et al., 2000).

El seguro es el instrumento a través del cual los tomadores de riesgos transfieren al asegurador, la obligación de indemnizar total o parcialmente sus pérdidas, dependiendo del contexto.

Las compañías aseguradoras cubren los riesgos que podrían afectar a los bienes o a los individuos. Como contraprestación de ello requieren del pago de un monto (prima) y en el caso que suceda un determinado evento que ocasione una pérdida o perjuicio (siniestro) la aseguradora pagará el monto acordado (indemnización), cuyo riesgo de ocurrencia es objeto de cobertura por el seguro.

La actividad del mercado inicia con el asegurado, el cual contrata la póliza de una compañía de seguros a través de un corredor y una vez suscrito el 
contrato que defina los acuerdos del seguro, el asegurado deberá pagar la prima a la compañía a fin de mantener en vigencia del mismo.

De suscitarse un siniestro que afecte al asegurado o los bienes asegurados, el corredor de seguros que es un intermediario y asesor del asegurado, informará de la ocurrencia a la compañía de seguros, la cual a su vez, contactará una empresa ajustadora de seguros. La ajustadora de seguros será la responsable de analizar de manera imparcial el siniestro y determinar el monto o siniestralidad que la compañía deberá abonar al asegurado. Cabe señalar que a cambio del servicio proveído por la ajustadora de seguros, la compañía definirá y le pagará una comisión o porcentaje de la siniestralidad indemnizada al asegurado.

El organismo que representa al gobierno en el conjunto de operaciones relacionadas a la adquisición y regulación de seguros es la Superintendencia de Banca, Seguros y AFP (SBS), cuyas funciones radican en mantener el respeto a las leyes establecidas, además de representar al Estado en las negociaciones donde existan las debidas autorizaciones para que las aseguradoras recauden fondos.

De acuerdo a la Superintendencia de Banca y Seguros y AFP (2017) actualmente el sistema de seguros en el Perú se compone de dos tipos de ramos globales: Seguros de Vida y Seguros Generales. Los Seguros de Vida son los que mitigan los riesgos que afectan la existencia de una persona y, Seguros Generales son aquellos que resguardan el daño sucedido sobre un bien material; siendo además los tipos de seguros de interés en el presente documento. 
El mercado de Seguros Generales se encuentra compuesto por 12 compañías de seguros: 4 están dedicadas simultáneamente a ramos generales y de vida y 8 están dedicadas exclusivamente a ramos generales (Superintendencia de Banca, Seguros y Administradoras de Fondos de Pensiones, 2017).

Adicionalmente, el mercado peruano posee 14 empresas ajustadoras de seguros enfocadas en riesgos generales (Superintendencia de Banca, Seguros y Administradoras de Fondos de Pensiones, 2017). Dado que cada empresa ajustadora puede atender distintos casos de distintas compañías y, que las empresas ajustadoras están lideradas por 5 empresas que concentran el 76\% del mercado; existe una ralentización en la atención y determinación de las siniestralidades suscitadas, generándose una necesidad de nuevas empresas ajustadoras de seguros que brinden un servicio de calidad.

Por todo lo anterior, se ha desarrollado el presente proyecto para demostrar la factibilidad técnico económico en el mediano plazo de establecer una empresa Ajustadora de Seguros en Riesgos Generales en el mercado asegurador peruano, con la finalidad de poder brindar un servicio integral de ajuste de seguros en Riesgos Generales (robo, incendio, deshonestidad, responsabilidad civil, lucro cesante, rotura de maquinaria, CAR, TREC, EAR, equipo electrónico) con honestidad, profesionalismo, ética y responsabilidad enfocada a los clientes (Compañía de Seguros, Corredores de Seguros y Empresas Aseguradas) debido a que existe una necesidad de las compañías de seguros por contar con mayores empresas de ajustes de seguros. 


\section{CAPÍTULO I}

\section{FORMULACION DE LA IDEA DE NEGOCIO Y MODELO DE NEGOCIO}

\subsection{DESCRIPCIÓN GENERAL DE LA IDEA DE NEGOCIO Y MODELO DE NEGOCIO}

El Perú se encuentra dentro de los países con menor cobertura de seguros en la región Latinoamérica, siendo que al 2015 se situó en $1.92 \%$ menor al promedio de la región, lo cual responde a diferentes factores económicos, sociales y culturales. Por tales motivos, resalta las oportunidades de crecimiento del sector basados en la expansión de nichos de mercado no explotados, lo cual sumado a la recuperación gradual de la economía peruana, traería consigo un crecimiento del sector asegurador peruano superior al promedio compuesto de los últimos cuatro años. (Pacific Credit Rating, 2015)

De acuerdo a la Superintendencia de Banca y Seguros y AFP actualmente el sistema de seguros en el Perú se compone de dos tipos de ramos globales: Seguros de Vida y Seguros Generales, atendidos por 21 compañías de seguros, de las cuales 4 están dedicadas a ramos generales y de vida, 8 exclusivamente a ramos generales y 9 exclusivamente a ramos de vida (Superintendencia de Banca, Seguros y Administradoras de Fondos de Pensiones, 2017). 
La SBS define a los Seguros de Vida como aquellos que mitigan los riesgos que afectan la existencia de una persona, mientras que a los Seguros Generales los conceptualiza como aquellos que resguardan el daño sucedido sobre un bien material; siendo además los tipos de seguros de interés del presente documento y de la empresa en implementación. Por lo expuesto, las 12 empresas que se dedican a ramos generales serán materia del presente proyecto, definiéndoseles como clientes potenciales.

El mercado de seguros generales está integrado por 4 participantes fundamentales: El Asegurado, el Corredor o Bróker de Seguros, la Compañía de Seguros y, la Empresa Ajustadora de Seguros.

La actividad del mercado inicia con el asegurado, el cual contrata la póliza a una compañía de seguros a través de un corredor. Una vez suscrito el contrato que defina los acuerdos del seguro, el asegurado deberá pagar la prima de seguros a la compañía a fin de mantener en vigencia del mismo.

De suscitarse un siniestro que afecte al asegurado o los bienes asegurados, el corredor de seguros que es un intermediario y asesor del asegurado, informará de la ocurrencia a la compañía de seguros, la cual a su vez, contactará una empresa ajustadora de seguros. La ajustadora de seguros será la responsable de analizar de manera imparcial el siniestro y determinar el monto o siniestralidad que la compañía deberá abonar al asegurado. Cabe señalar que a cambio del servicio proveído por la ajustadora de seguros, la compañía definirá y le pagará una comisión o porcentaje de la siniestralidad indemnizada al asegurado. Si bien la Compañía de 
Seguros designa a la Ajustadora de Seguros, esta designación también depende de las buenas relaciones de trabajo con los Corredores de Seguros y las Empresas Aseguradas.

El siguiente gráfico define el funcionamiento del mercado:

\section{Figura 1.1. Funcionamiento del Mercado de Seguros}

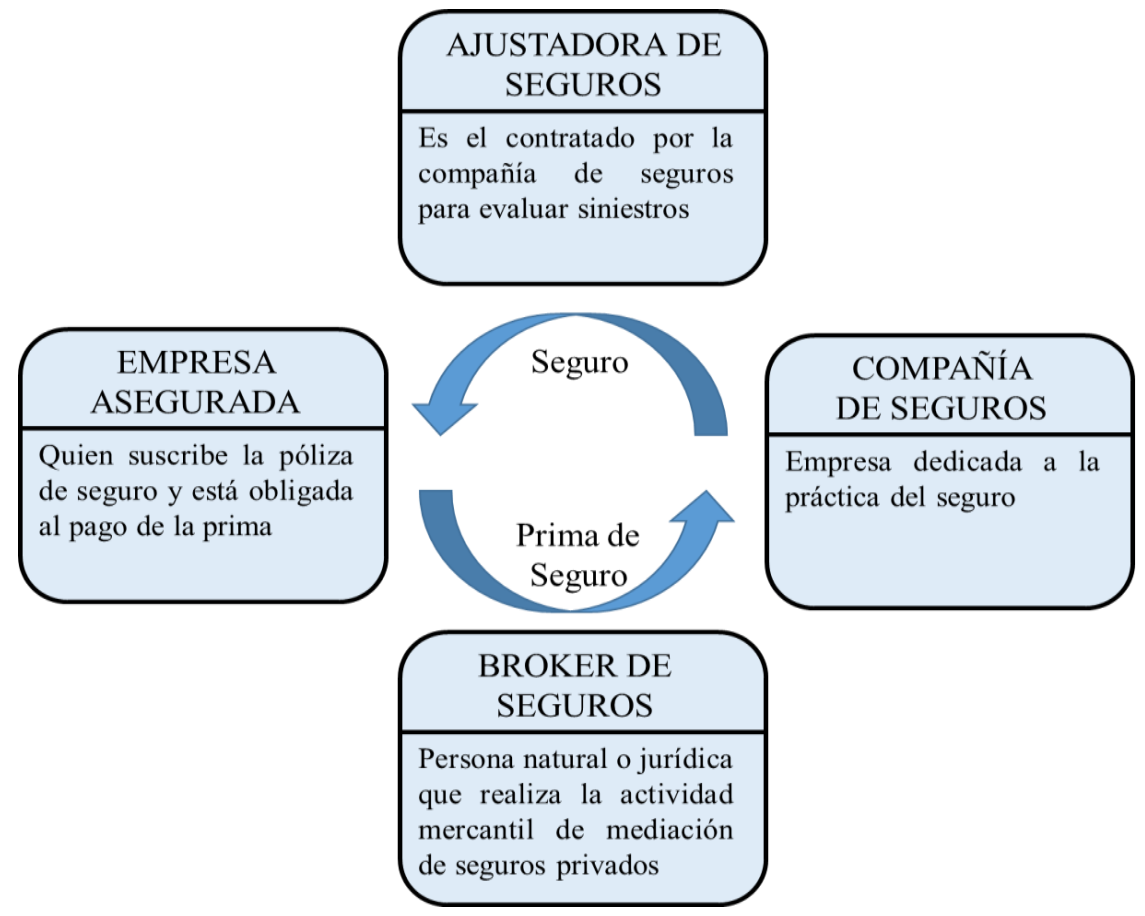

Fuente: Elaboración Propia

De manera objetiva, los clientes de las Empresas Ajustadoras de Seguros son las Compañías de Seguros, las cuales ante la ocurrencia de un Siniestro tendrán la necesidad específica de contar con una empresa ajustadora de seguros que evalúe el siniestro, precise su causa, determine si los reclamos están amparados por la póliza y calcule la indemnización que la Compañía de Seguros deberá pagar al asegurado. 
De acuerdo al ranking de primas de seguros en riesgos generales publicado por la SBS al 31 de diciembre del 2016, el mercado de seguros peruano se encuentra altamente concentrado en cuatro compañías de seguros: Pacifico, Rímac, Mapfre y La Positiva, quienes manejan aproximadamente el $90.9 \%$ del mercado (Superintendencia de Banca, Seguros y Administradoras de Fondos de Pensiones, 2017).

Para complementar, la publicación financiera de las empresas ajustadoras de seguros publicado por la SBS señala que actualmente existen 27 empresas ajustadoras y peritos de seguros en el país. De este grupo 14 empresas ajustadoras de seguros se encargan de riesgos generales, 06 empresas dedicadas a ajustes de seguros de transportes, 1 de cascos, y 6 peritos de seguros (Superintendencia de Banca, Seguros y Administradoras de Fondos de Pensiones, 2017).

Del grupo de las 14 empresas ajustadoras que se encargan de riesgos generales, cinco son las principales: Herrera DKP, Crawford Perú S.A., W Moller, FGR Perú, Iriarte Ajustadores de Seguros; ateniendo al $76 \%$ de los siniestros que afectan a las empresas aseguradas (Superintendencia de Banca, Seguros y Administradoras de Fondos de Pensiones, 2017).

Como consecuencia de esta concentración de mercado y de los eventos catastróficos suscitados, se generan ralentizaciones y falta de respuestas de las Empresas Ajustadoras de Seguros en la solución a los siniestros. 
En resumen, el mercado de seguros generales es un mercado en crecimiento, el cual además posee concentración y ralentización en la atención de los servicios, siendo por tal razón, factible la implementación de una Empresa Ajustadora de Seguros que contribuya a la dinamización del mercado.

La idea de negocio del presente proyecto surge por el conocimiento y la experiencia de más de 10 años del equipo de trabajo en el mercado asegurador, y su relación directa con compañías de seguros, corredores de seguros y ajustadores de seguros.

Analizando la información anteriormente comentada, surge la idea de negocio para implementar una empresa ajustadora de seguros en riesgos generales que participe como actor importante en el mercado de seguros.

El equipo de trabajo identificó una oportunidad de negocio basada en varios aspectos:

a. El potencial desarrollo del mercado de seguros en el Perú, y el ingreso de nuevas compañías generara mayor dinamismo y crecimiento.

b. Las pérdidas económicas de los asegurados a consecuencia de siniestros (siniestralidad) en los últimos años viene incrementándose, y las compañías de seguros vienen pagando indemnizaciones por estos; por lo que existe una necesidad de atención de los siniestros (esto se mostrará a mayor detalle en el Análisis de Mercado del Capítulo II). 
c. La existencia de pocas empresas (14) que brindan el servicio de ajuste de seguros en el ramo de riesgos generales.

d. El $76 \%$ de los siniestros son atendidos por las cinco grandes empresas de ajustes de seguros (Superintendencia de Banca, Seguros y Administradoras de Fondos de Pensiones, 2017).

De acuerdo a los puntos indicados anteriormente, se observa la necesidad del mercado asegurador de contar con nuevas empresas ajustadoras de seguros en riesgos generales. Esto se debe a que si bien existen 14 empresas ajustadoras de seguros que atienden a 12 compañías de seguros, la demanda del mercado no se rige por el número de las compañías, sino por la cantidad de los casos y los montos por ajustar en cada uno (desembolso por siniestralidades).

Dado que una empresa ajustadora de seguros puede atender casos de distintas compañías de seguros y a la vez, una compañía de seguros puede solicitar los servicios de distintas empresas ajustadoras de seguros para diferentes casos; los ingresos de las empresas ajustadoras de seguros dependerán de la comisión cobrada sobre el monto calculado por la siniestralidad de los casos ofrecidos por las compañías de seguros.

Por lo tanto, al existir un incremento en las siniestralidades y montos pagados, se detecta que la demanda de empresas ajustadoras de seguros aumentará. Además, dado que existen 5 empresas ajustadoras que poseen gran parte del mercado (76\%), actualmente existen ralentizaciones en el sistema de atención; lo que conlleva a la necesidad de contar con empresas ajustadoras que brinden un servicio de calidad. 
Por estas razones, el presente documento fundamenta la implementación de la empresa Moreno \& Pacora Ajustadores de Seguros.

\subsubsection{Marco Conceptual}

En esta sección se definirán algunos conceptos relacionados con la terminología utilizada en el mundo de los seguros y de uso frecuente en los ajustes de riesgos generales, asimismo se explicara de manera detallada las funciones del ajustador de seguros:

\section{a. El Ajustador de Seguros}

Es una persona natural o jurídica imparcial, contratada por la aseguradora con la finalidad de evaluar siniestros, analizar su causa, definir si los reclamos se encuentran dentro del ámbito de la póliza y calcular el monto a indemnizar en cada caso.

\section{b. Asegurado}

Contratante y beneficiario del seguro es quién suscribe la póliza de seguro, tiene la obligación del pago de una prima, sus activos constituyen el objeto a asegurar (la vivienda, la empresa, etc.) y es quién tiene derecho a recibir la indemnización económica en caso se produzca el siniestro.

\section{c. Bróker o Corredor de Seguros}


Persona física o jurídica que realiza la actividad mercantil de mediación de seguros privados sin mantener vínculos contractuales que supongan afección con entidades aseguradoras, y que ofrece asesoramiento independiente, profesional e imparcial a quienes demanden la cobertura de los riesgos a que se encuentran expuestos sus personas, sus patrimonios, sus intereses o responsabilidades.

\section{d. Compañía de Seguros}

Compañía, empresa o sociedad dedicada a la práctica del aseguramiento. También conocidas como aseguradoras, se encargan de pagar las indemnizaciones en caso de siniestros.

Asimismo, el ramo de riesgos generales está conformado por una serie de riesgos o pólizas que de acuerdo a LA POSITIVA (2017) presentan cada una las siguientes definiciones:

\section{a. Póliza Multiriesgo}

Seguro combinado que incluye diferentes tipos de garantías y que por tanto cubre, en un único contrato, los diferentes tipos de riesgos y de accidentes imprevistos:

- Incendio y/o rayo.

- Explosión.

- Terrorismo y riesgos políticos.

- Terremoto y riesgos de la naturaleza.

b. Póliza de Robo 
Póliza que protege en el caso de suscitarse algún robo con fractura y/o asalto de bienes tales como: maquinaria, equipos, mercancía, materia prima; mientras estén dentro del local asegurado. También posee cobertura para casos de robo de dinero dentro y/o fuera del local.

\section{c. Póliza de Deshonestidad}

Protege en caso de pérdidas de dinero, valores u otros bienes efectivamente sufridas por el asegurado durante la vigencia de la Póliza, resultante directamente de cualquier Acto de Deshonestidad cometido por cualquier trabajador, sea que éste haya actuado solo o en colusión con otras personas.

\section{d. Póliza de Responsabilidad Civil}

Cubre al asegurado contra las reclamaciones de terceros por concepto de Responsabilidad Civil Extracontractual, a consecuencia de daños personales y/o daños materiales causados involuntariamente a dichos terceros; por un accidente ocurrido como resultado directo de las actividades o negocios declarados.

\section{e. Póliza de Lucro Cesante}

Si los locales que utiliza el asegurado para su negocio o los bienes existentes en ellos, fueran dañados o destruidos por una de las causas especificadas en la definición de riesgo cubierto y, si como consecuencia de ese daño o destrucción, el negocio explotado por el asegurado resultara interrumpido o perturbado, se indemnizará al 
asegurado la pérdida real que resulte de dicha interrupción o perturbación.

\section{f. Póliza de Rotura de Maquinaria}

Cubre la maquinaria contra daños materiales que le ocurran, siempre y cuando dichos daños sucedan en forma accidental, súbita e imprevista como consecuencia directa de cualquiera de los riesgos cubiertos, y hagan necesaria la reparación o reposición de la maquinaria dañada.

g. Póliza CAR - Seguro de Todo Riesgo para

\section{Contratistas}

Cubre la obra contra las pérdidas físicas o daños materiales que le ocurran durante la vigencia de la Póliza, siempre y cuando dichas pérdidas físicas o daños materiales sucedan en forma accidental, súbita e imprevista como consecuencia de cualquier causa, excepto las causas excluidas y/o las que pudiesen ser amparadas con la contratación de las coberturas de riesgos opcionales; y hagan necesaria la reparación o reposición de dichos bienes dañados o perdidos.

\section{h. Póliza TREC - Todo Riesgo Equipo de Contratistas}

Cubre el equipo o maquinaria contra las pérdidas físicas o daños materiales, siempre y cuando dichas pérdidas físicas o daños materiales sucedan en forma accidental, súbita e imprevista como consecuencia de cualquier causa 
no excluida, y hagan necesaria la reparación o reposición del equipo o maquinaria dañada o pérdida.

\section{i. Póliza EAR - Montaje}

Cubre la obra de montaje contra las pérdidas físicas o daños materiales que le ocurran durante la vigencia de la Póliza, siempre y cuando dichas pérdidas físicas o daños materiales sucedan en forma accidental, súbita e imprevista como consecuencia de cualquier causa, excepto las causas excluidas y/o las que pudiesen ser amparadas con la contratación de las coberturas de riesgos opcionales; y hagan necesaria la reparación o reposición de dichos bienes dañados o perdidos.

\section{j. Póliza Equipo Electrónico}

Cubre los equipos electrónicos, contra pérdidas físicas o daños materiales que le ocurran durante la vigencia de la Póliza, siempre y cuando dichas pérdidas físicas o daños materiales sucedan en forma accidental, súbita e imprevista como consecuencia de cualquier causa no excluida, y hagan necesaria la reparación o reposición de los equipos electrónicos perdidos o dañados.

\subsubsection{Marco Normativo de las Empresas Ajustadoras de} Seguros

Con el propósito de ahondar en el funcionamiento de las Empresas Ajustadoras de Seguros se detallan los artículos de la Ley $N^{\circ}$ 26702, Ley General del Sistema Financiero y Sistema de Seguros y la Ley No 29946, Ley del Contrato de 
Seguros; las cuales regulan la participación y funciones de los Ajustadores de Seguros en los siguientes artículos:

\section{Artículo 38. Ajustador (Ley $\mathbf{N}^{\circ}$ 29946)}

La actuación del ajustador debe ser técnica, independiente e imparcial. La Superintendencia adoptará las medidas necesarias para garantizar dichas características, incluyendo las sanciones que corresponda. Toda conducta que evidencie la violación reiterada de dichas medidas dará lugar a la revocación definitiva de la autorización del ajustador involucrado.

Es nula toda cláusula que prohíba o restrinja el derecho del asegurado a participar en la designación del ajustador una vez producido el siniestro."

\section{“Artículo 75. Participación del ajustador (Ley N²9946)}

El ajustador de siniestros o el perito deben ser designados de común acuerdo por las partes.

La opinión del ajustador no obliga a las partes y es independiente de ellas. Los informes del ajustador deben ser proporcionados simultáneamente a ambas partes. En caso de que cualquiera de las partes no esté de acuerdo, podrán designar a otro ajustador para elaborar un nuevo ajuste del siniestro, de lo contrario podrán recurrir al medio de solución de controversias que corresponda."

“Artículo 343". Funciones del Ajustador de seguros (Ley $N^{\circ}$ 26702) 
Son funciones del ajustador de siniestros:

a. Estimar el valor de los objetos asegurados antes de la ocurrencia del siniestro, en el caso de que éste se encontrase cubierto por la póliza.

b. Examinar, investigar y determinar las causas conocidas o presuntas del siniestro.

c. Calificar, informar y opinar si el siniestro se encuentra amparado por las condiciones de la póliza.

d. Establecer el monto de las pérdidas o daños amparados por la póliza.

e. Señalar el importe que corresponde indemnizar con arreglo a las condiciones de la póliza.

f. Establecer el valor del salvamento para deducirlo de la cifra de daños, o su comercialización por la empresa de seguros. El peritaje del ajustador no obliga a las partes y es independiente a ellos."

Asimismo, en la página web de la SBS, muestra la relación de Ajustadores de Seguros tanto personas naturales como jurídicas que se encuentran autorizados y habilitados para realizar la labor como Ajustadores de seguros.

\subsubsection{Justificación del Tema}

Con el presente proyecto se intenta demostrar la factibilidad técnico económico en el mediano plazo de una empresa Ajustadora de Seguros en Riesgos Generales en el mercado asegurador peruano, con la finalidad de poder brindar un servicio integral de ajuste de seguros en Riesgos Generales 
(Multiriesgo, robo, deshonestidad, responsabilidad civil, lucro cesante, rotura de maquinaria, CAR, TREC, EAR, equipo electrónico) con honestidad, profesionalismo, ética y responsabilidad enfocada a Compañías de Seguros, Corredores de Seguros y Empresas Aseguradas; debido a que existe una necesidad de las compañías de seguros por contar con mayores empresas de ajustes de seguros que brinden un servicio de calidad.

Como ya se ha comentado (Formulación de la idea de Negocio del Capítulo I), existe en el mercado asegurador la necesidad de contar con Ajustadores de Seguros en Riesgos Generales ya sea por el incremento de la siniestralidad en los últimos años, o por la existencia de pocas empresas que atienden estos riesgos generales (la demanda del mercado no se rige por el número de las compañías, sino por la cantidad de los casos y los montos por ajustar en cada uno). Asimismo el ingreso de nuevas compañías de seguros dinamizara el mercado.

El mercado objetivo de las empresas Ajustadoras de Seguros son las compañías de seguros, quienes son las que nombran a los ajustadores para encargarse de la atención de los siniestros, pero a la par dependen de las buenas relaciones de trabajo con los corredores de seguros y las empresas aseguradas. 
Esta investigación pretende demostrar la factibilidad de nuestro proyecto, para ponerlo en ejecución en el mediano plazo. 


\subsection{VISIÓN}

Ser reconocido en el largo plazo como una de las empresas ajustadoras de seguros más importantes y solido del Perú.

\subsection{MISIÓN}

Brindar un servicio oportuno y eficiente para la atención de siniestros, mejorando los procesos para la atención de los siniestros, en concordancia con las condiciones de la póliza.

\subsection{OBJETIVOS DE LA EMPRESA}

\subsubsection{Objetivo General}

Brindar un servicio integral de ajuste de seguros en Riesgos Generales (Multiriesgo, robo, deshonestidad, responsabilidad civil, lucro cesante, rotura de maquinaria, CAR, TREC, EAR, equipo electrónico) con honestidad, profesionalismo, ética y responsabilidad enfocada a Compañías de Seguros, Corredores de Seguros y Empresas Aseguradas.

\subsubsection{Objetivos Específicos}

\section{- Empresarial}

Ser parte del proceso de crecimiento y desarrollo del mercado asegurador peruano.

\section{- Comercial}

Satisfacer las necesidades de las compañías de seguros, corredores y empresas aseguradas. 
- Operativo

Mejora permanente de procesos, innovación, búsqueda de valor, alianzas estratégicas y calidad de servicio.

- Financiero

Maximizar el valor de la inversión. 


\section{CAPÍTULO II}

\section{ANÁLISIS DE LA INDUSTRIA Y DEL MERCADO}

\subsection{ANÁLISIS DE LA INDUSTRIA: LAS 5 FUERZAS DE MICHAEL PORTER}

Se analiza al detalle a continuación:

\subsubsection{Poder de Negociación de los Clientes}

Conforme a la información que proporciona la SBS, actualmente existen 21 compañías de seguros; de las cuales 12 están dedicadas al ramo de riesgos generales. Además en el mercado de Riesgos Generales, 4 compañías concentran el 91\% de participación en las primas pagadas, siendo: Rímac, Pacifico, Mapfre y La Positiva (Superintendencia de Banca, Seguros y Administradoras de Fondos de Pensiones, 2017).

Dado que los clientes son pocos (12) y que además 4 de ellos concentran el $91 \%$ del mercado, su poder de negociación es elevado, pudiendo exigir mejores servicios, mejores tecnologías o staffs de especialistas en riesgos a las empresas proveedoras de este servicio (Superintendencia de Banca, Seguros y Administradoras de Fondos de Pensiones, 2017). 


\subsubsection{Nivel de Rivalidad entre los Competidores}

Entre los años 2011 y 2015 aparecieron 4 nuevas empresas ajustadoras de seguros las cuales, como es de esperarse, han tenido un crecimiento en su participación en el mercado. De estas 4 empresas, 2 han tenido un crecimiento considerable (FGR Perú Ajustadores de Seguros y Baukost Ajustadores y Peritos de Seguros), mientras que las 2 restantes (GD Ajustadores de Seguros SAC y Perú Veritas Ajustadores de Seguros SAC) obtuvieron un crecimiento pasivo (Ver Tabla 2.1).

De las 10 empresas que no iniciaron operaciones entre el 2011 y 2015 podemos observar que 8 han venido reduciendo su participación en el mercado, mientras que las 2 restantes tuvieron crecimientos sumamente pasivos (Ver Tabla 2.1).

Por lo tanto podemos concluir la rivalidad entre los competidores es moderada, ya que existen 14 empresas en un sector creciente. Además para el periodo 2011-2015, 6 han incrementado su participación; especialmente FGR Perú Ajustadores de Seguros y Baukost Ajustadores y Peritos de Seguros, empresas que han tenido un incremento de participación notable. 


\section{Tabla 2.1. Pendiente de crecimiento de la participación de las}

\section{empresas ajustadoras de seguros}

\begin{tabular}{|c|c|c|c|c|c|c|}
\hline PROVEEDORES & 2011 & 2012 & 2013 & 2014 & 2015 & $\begin{array}{l}\text { Pendiente de } \\
\text { Crecimiento }\end{array}$ \\
\hline HERRERA D.K.P. - AJUSTADORES DE SEGUROS & $37.0 \%$ & $42.3 \%$ & $35.3 \%$ & $41.7 \%$ & $32.5 \%$ & $-1.0 \%$ \\
\hline CRAWFORD PERU S.A. AJUSTADORES Y PERITOS DE SEGUROS & $23.5 \%$ & $18.8 \%$ & $23.5 \%$ & $19.6 \%$ & $21.4 \%$ & $-0.3 \%$ \\
\hline W. MOLLER AJUSTADORES Y PERITOS DE SEGUROS S.A.C. & $6.0 \%$ & $7.1 \%$ & $10.4 \%$ & $6.9 \%$ & $7.9 \%$ & $0.4 \%$ \\
\hline FGR PERU AJUSTADORES DE SEGUROS & - & - & $0.4 \%$ & $4.9 \%$ & $7.5 \%$ & $3.5 \%$ \\
\hline IRIARTE Y ASOCIADOS S.A. AJUSTADORES Y PERITOSDE SEGUROS & $7.1 \%$ & $7.2 \%$ & $6.3 \%$ & $5.7 \%$ & $7.2 \%$ & $-0.1 \%$ \\
\hline BAUKOST AJUSTADORES Y PERITOS DE SEGUROS & - & - & - & $2.0 \%$ & $4.9 \%$ & $2.9 \%$ \\
\hline MASTER AJUSTADORES DE SEGUROS S.A.C. & $4.0 \%$ & $4.2 \%$ & $4.0 \%$ & $3.6 \%$ & $3.9 \%$ & $-0.1 \%$ \\
\hline MCLARENS TOPLIS PERU AJUSTADORES Y PERITOS DE SEGUROS S.A. & $10.0 \%$ & $9.8 \%$ & $6.9 \%$ & $4.7 \%$ & $3.7 \%$ & $-1.8 \%$ \\
\hline BISI \& ROMERO ASOCIADOS S.A. AJUSTADORES DE SEGUROS & $3.1 \%$ & $2.3 \%$ & $1.7 \%$ & $3.1 \%$ & $2.8 \%$ & $0.0 \%$ \\
\hline BARRON AJUSTADORES DE SEGUROS S.A.C. & $5.6 \%$ & $3.3 \%$ & $3.5 \%$ & $2.8 \%$ & $2.2 \%$ & $-0.7 \%$ \\
\hline GD AJUSTADORES DE SEGUROS S.A.C. & - & $0.9 \%$ & $1.9 \%$ & $1.8 \%$ & $2.0 \%$ & $0.3 \%$ \\
\hline OSBERK AJUSTADORES DE SEGUROS S.A. & $2.2 \%$ & $2.6 \%$ & $4.4 \%$ & $1.1 \%$ & $1.8 \%$ & $-0.2 \%$ \\
\hline PERU VERITAS AJUSTADORES DE SEGUROS S.A.C. & - & - & $0.7 \%$ & $1.2 \%$ & $1.3 \%$ & $0.3 \%$ \\
\hline ACM AJUSTADORES Y PERITOS DE SEGUROS S.A.C. & $1.4 \%$ & $1.5 \%$ & $1.0 \%$ & $0.9 \%$ & $1.0 \%$ & $-0.1 \%$ \\
\hline TOTAL & $100.0 \%$ & $100.0 \%$ & $100.0 \%$ & $100.0 \%$ & $100.0 \%$ & \\
\hline
\end{tabular}

Fuente: Superintendencia de Banca, Seguros y Administradoras de Fondos de Pensiones, 2017, Intermediarios y Auxiliares de Seguros. Recuperado de https://www.sbs.gob.pe/app/stats_net/stats/EstadisticaBoletinEstadistico.aspx?p=26\#. Elaboración propia.

\subsubsection{Amenaza de Nuevos Ingresantes}

La amenaza de nuevos ingresantes es moderada, ya que si bien no existen limitantes para la creación de nuevas empresas ajustadoras de seguros, estas necesitan de ajustadores profesionales (personal) para poder realizar su labor $\mathrm{y}$; en el caso de los ajustadores de seguros (profesionales) existen ciertas barreras que limitan su ingreso al mercado.

De manera específica, para que un profesional pueda desempeñarse como ajustador de seguros, debe contar con la licencia respectiva (Licencia de Ajustador de Seguros), la cual se obtiene única y exclusivamente aprobando el examen de Ajustador de Seguros realizado por la SBS. Este examen es solo una vez al año, limitando las cantidades de nuevos ingresos; ya sea por la reducida frecuencia en su realización 
o por las dificultades y exigencias del mismo para ser aprobado.

Otro factor a tener en cuenta es que los aspirantes a ajustadores de seguros son principalmente graduados de la Asociación Peruana de Empresas de Corredores de Seguros (APECOSE), la cual posee pocos centros de capacitación en todo el país.

También, se debe considerar que el inicio de las operaciones de toda empresa ajustadora de seguros está muy ligada al conocimiento del mercado por parte de sus integrantes, pues como ya se ha mencionado anteriormente, pese a que es la compañía de Seguros la que designa a las Empresa Ajustadoras de Seguros para la atención de los siniestros, la decisión también depende de las buenas relaciones de trabajo que la Ajustadoras de Seguros poseen con los corredores de seguros y las empresas aseguradas.

En el caso de empresas extranjeras de Ajuste de Seguros, el ingreso se limita dado que estas prefieren la sociedad con empresas ajustadoras peruanas que ya operan en el mercado, formando sociedades para el inicio de sus operaciones comerciales. 


\subsubsection{El poder de los Proveedores}

Se estima que el poder de los proveedores, compuesto principalmente por ajustadores de seguros naturales y peritos especializados, es alto. El requerimiento de una alta especialización para brindar los servicios de temas especializados en evaluación de riesgos, peritaje y siniestros involucra cierto poder para exigir ciertos beneficios y mejores condiciones laborales y salariales.

\subsubsection{Amenaza de Productos Sustitutos}

No existen productos sustitutos para el servicio que se busca brindar, puesto que este se basa en actividades muy específicas tanto para la compañía de seguros como para los asegurados.

\subsection{ANÁLISIS DEL MERCADO}

Considerando que el servicio consiste en una propuesta integral de ajuste de seguros en Riesgos Generales (robo, incendio, deshonestidad, responsabilidad civil, lucro cesante, rotura de maquinaria, CAR, TREC, EAR, equipo electrónico) basada en la honestidad, profesionalismo, ética y responsabilidad; enfocada además, a cubrir las necesidades de los clientes (Compañía de Seguros), analizaremos las características más importantes del mercado, considerando tanto a las compañías de seguros como a los Ajustadores de Seguros. 


\subsubsection{Análisis de las Compañías de Seguros}

En la actualidad la Superintendencia de Banca, Seguros y Administradoras de Fondos de Pensiones (2017) señala que el sistema de seguros en el Perú se divide en dos tipos de ramos globales (Ver Tabla 2.2):

\section{Tabla 2.2. Tipos de Seguro}

\begin{tabular}{cl}
\hline Tipos de Seguro & \multicolumn{1}{c}{ Definición } \\
\hline Seguros Generales & $\begin{array}{l}\text { Aquellos que resguardan un daño } \\
\text { sucedido sobre un bien material. }\end{array}$
\end{tabular}

Seguros de Vida

Aquellos que mitigan los riesgos que afectan la existencia de una persona.

Fuente: Superintendencia de Banca, Seguros y Administradoras de Fondos de Pensiones, 2017, Evolución del Sistema Asegurador. Recuperado de

https://www.sbs.gob.pe/app/stats_net/stats/EstadisticaBoletinEstadistico.aspx?p=27\#

Elaboración propia.

Este sistema tuvo al cierre 2016 un ingreso total en primas de seguros superior a once mil millones (Ver Tabla 2.3), resultante del pago de Primas de Seguros de Vida y Pago de Primas de Seguros por Ramos Generales, valorizados en más de cinco mil millones y seis mil millones de soles respectivamente (Ver Tabla 2.3). 


\section{Tabla 2.3. Primas Pagadas}

\begin{tabular}{|c|c|c|c|c|c|c|}
\hline \multirow{2}{*}{$\begin{array}{l}\text { Año } \\
2011\end{array}$} & \multicolumn{2}{|c|}{$\begin{array}{c}\text { Primas de Seguros } \\
\text { de Vida } \\
\text { (En Millones) }\end{array}$} & \multicolumn{2}{|c|}{$\begin{array}{c}\text { Primas de Seguros } \\
\text { por Ramos } \\
\text { Generales } \\
\text { (En Millones) }\end{array}$} & \multicolumn{2}{|c|}{$\begin{array}{c}\text { Primas de Seguros } \\
\text { Netas por Ramos } \\
\text { (En Millones) }\end{array}$} \\
\hline & S/. & 3,407 & S/. & 3,805 & S/. & 7,212 \\
\hline 2012 & S/. & 3,676 & S/. & 4,230 & S/. & 7,906 \\
\hline 2013 & S/. & 4,184 & S/. & 4,885 & S/. & 9,069 \\
\hline 2014 & S/. & 4,929 & S/. & 5,225 & S/. & 10,154 \\
\hline 2015 & S/. & 5,618 & S/. & 6,126 & S/. & 11,744 \\
\hline 2016 & S/. & 5,113 & S/. & 6,143 & S/. & 11,256 \\
\hline
\end{tabular}

Fuente: Superintendencia de Banca, Seguros y Administradoras de Fondos de Pensiones, 2017, Boletín Estadístico de Seguros. Recuperado de https://www.sbs.gob.pe/app/stats_net/stats/EstadisticaBoletinEstadistico.aspx?p=25\#). Elaboración propia.

Lo que evidencia un crecimiento anual promedio de $10 \%$ en el mercado de pago de Primas de Seguros (Ver Tabla 2.4).

\section{Tabla 2.4. Incremento Anual de las Primas Pagadas}

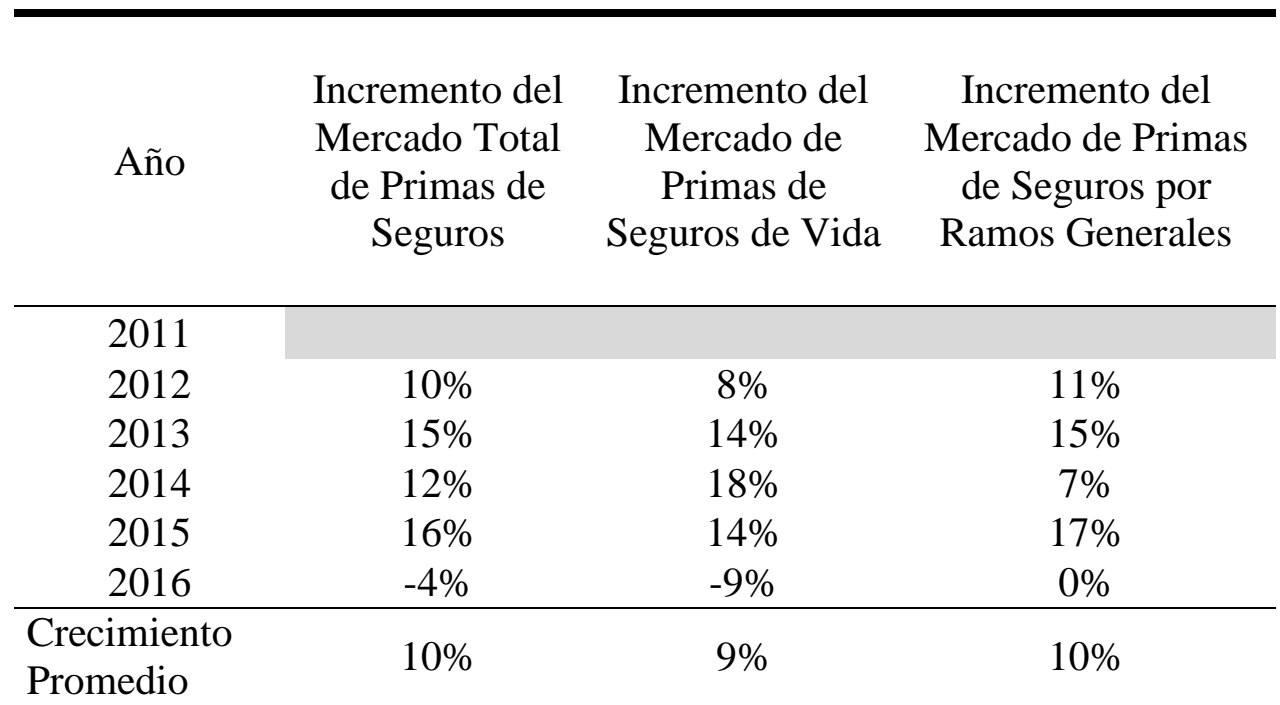

Fuente: Superintendencia de Banca, Seguros y Administradoras de Fondos de Pensiones, 2017, Boletín Estadístico de Seguros. Recuperado de https://www.sbs.gob.pe/app/stats_net/stats/EstadisticaBoletinEstadistico.aspx?p=25\#). Elaboración propia.

Particularmente en el caso del mercado de Seguros Generales, la Superintendencia de Banca, Seguros y 
Administradoras de Fondos de Pensiones (2017) señala que hasta el segundo trimestre del 2016, el sector estuvo conformado por 21 empresas, de las cuales cuatro están dedicadas a ramos generales y de vida, 8 exclusivamente a ramos generales y 9 exclusivamente a ramos de vida (Ver Tabla 2.5).

\title{
Tabla 2.5. Empresas de Seguros Autorizadas
}

\begin{tabular}{ccc}
\hline $\begin{array}{c}\text { Ramos Generales y de } \\
\text { Vida }\end{array}$ & Ramos Generales & Ramos de Vida \\
\hline Chubb Perú & Pacífico Seguros & El Pacífico Vida \\
Cardif & La Positiva & Sura \\
Interseguro & Mapfre Perú & La Positiva Vida \\
Rímac & Secrex & Mapfre Perú Vida \\
& Insur & Rigel \\
& HDI Seguros & Vida Cámara \\
& Aval Perú & Ohio National Vida \\
& Coface & Crecer Seguros \\
& Protecta \\
\hline
\end{tabular}

Fuente: Superintendencia de Banca, Seguros y Administradoras de Fondos de Pensiones, 2017, Evolución del Sistema Asegurador. Recuperado de https://www.sbs.gob.pe/app/stats_net/stats/EstadisticaBoletinEstadistico.aspx?p=27\# Elaboración propia.

\begin{abstract}
Analizando la participación que poseen las Compañías de Seguros Generales, según la información de la SBS; podemos apreciar que el $91 \%$ de las Primas Pagadas se concentran en 4 empresas, posicionándolas como las más importantes del sector (Ver Tabla 2.6).
\end{abstract}


Tabla 2.6. Ranking de Primas de Seguros en Ramos Generales

\begin{tabular}{lrcc}
\hline \multicolumn{1}{c}{ Compañ́a de Seguro } & $\begin{array}{c}\text { Monto } \\
\text { (En Millones) }\end{array}$ & $\begin{array}{c}\text { Participación } \\
\text { (\%) }\end{array}$ & $\begin{array}{c}\text { Participación } \\
\text { Acumulada } \\
\text { (\%) }\end{array}$ \\
\hline Rímac & 2,272 & $37 \%$ & $37 \%$ \\
Pacífico Seguros Generales & 1,449 & $24 \%$ & $61 \%$ \\
Mapfre Perú & 1,093 & $18 \%$ & $78 \%$ \\
La Positiva & 771 & $13 \%$ & $91 \%$ \\
Chubb Seguros & 160 & $3 \%$ & $94 \%$ \\
Cardif & 113 & $2 \%$ & $95 \%$ \\
Interseguro & 84 & $1 \%$ & $97 \%$ \\
El Pacífico Vida & 64 & $1 \%$ & $98 \%$ \\
Insur & 44 & $1 \%$ & $98 \%$ \\
Secrex & 41 & $1 \%$ & $99 \%$ \\
HDI Seguros & 25 & $0 \%$ & $100 \%$ \\
AVLA Perú & 13 & $0 \%$ & $100 \%$ \\
Protecta & 8 & $0 \%$ & $100 \%$ \\
Coface Seguros & 4 & $0 \%$ & $100 \%$ \\
Mapfre Perú Vida & 3 & $0 \%$ & $100 \%$ \\
La Positiva Vida & 1 & $0 \%$ & $100 \%$ \\
Seguros Sura & 0 & $0 \%$ & $100 \%$ \\
\hline TOTAL & $\mathbf{6 , 1 4 3}$ & $\mathbf{1 0 0 \%}$ & \\
\hline
\end{tabular}

Fuente: Superintendencia de Banca, Seguros y Administradoras de Fondos de Pensiones, 2017, Boletín Estadístico de Seguros. Recuperado de

https://www.sbs.gob.pe/app/stats_net/stats/EstadisticaBoletinEstadistico.aspx?p=25\#).

Elaboración propia.

Respecto a las siniestralidades pagadas por las compañías de seguros, estas se han venido incrementando en un promedio de $13 \%$ anual (Ver Tabla 2.7). 


\section{Tabla 2.7. Siniestralidades Pagadas e Incremento Anual}

\begin{tabular}{|c|c|c|c|c|}
\hline \multicolumn{2}{|l|}{ Año } & \multicolumn{2}{|c|}{$\begin{array}{c}\text { Siniestralidad Pagada en } \\
\text { Ramos Generales por las } \\
\text { Compañías de Seguros } \\
\text { (En Millones) }\end{array}$} & \multirow[t]{2}{*}{ Incremento } \\
\hline & 2011 & $\mathrm{~S} /$. & 1,520 & \\
\hline & 2012 & $\mathrm{~S} /$. & 1,891 & $24 \%$ \\
\hline & 2013 & $\mathrm{~S} /$ & 2,264 & $20 \%$ \\
\hline & 2014 & $\mathrm{~S} /$. & 2,112 & $-7 \%$ \\
\hline & 2015 & $\mathrm{~S} /$ & 2,558 & $21 \%$ \\
\hline & 2016 & $\mathrm{~S} /$. & 2,727 & $7 \%$ \\
\hline \multicolumn{4}{|c|}{ Crecimiento Promedio Anual } & $13 \%$ \\
\hline
\end{tabular}

Además las 4 Compañías de Seguros más importantes, componen en promedio el $96 \%$ del monto total pagado por siniestralidades en los últimos años por el mercado (Ver Tabla 2.8).

Tabla 2.8. Participación en Pago de Siniestralidades por Año

\begin{tabular}{lcccccc}
\hline $\begin{array}{l}\text { Compañía de } \\
\text { Seguro }\end{array}$ & $\mathbf{2 0 1 2}$ & $\mathbf{2 0 1 3}$ & $\mathbf{2 0 1 4}$ & $\mathbf{2 0 1 5}$ & $\mathbf{2 0 1 6}$ & Promedio \\
\hline RIMAC & $35 \%$ & $35 \%$ & $36 \%$ & $40 \%$ & $34 \%$ & $36 \%$ \\
PACIFICO & $27 \%$ & $29 \%$ & $28 \%$ & $24 \%$ & $24 \%$ & $26 \%$ \\
MAPFRE & $15 \%$ & $19 \%$ & $16 \%$ & $15 \%$ & $23 \%$ & $17 \%$ \\
LA POSITIVA & $20 \%$ & $14 \%$ & $16 \%$ & $17 \%$ & $14 \%$ & $16 \%$ \\
OTROS & $3 \%$ & $3 \%$ & $5 \%$ & $5 \%$ & $6 \%$ & $4 \%$ \\
\hline TOTAL & $\mathbf{1 0 0 \%}$ & $\mathbf{1 0 0 \%}$ & $\mathbf{1 0 0 \%}$ & $\mathbf{1 0 0 \%}$ & $\mathbf{1 0 0 \%}$ & $\mathbf{1 0 0 \%}$ \\
\hline
\end{tabular}

Fuente: Superintendencia de Banca, Seguros y Administradoras de Fondos de Pensiones, 2017, Boletín Estadístico de Seguros. Recuperado de https://www.sbs.gob.pe/app/stats_net/stats/EstadisticaBoletinEstadistico.aspx?p=25\#). Elaboración propia. 
En resumen sobre la participación de mercado de las compañías de seguros en primas y siniestralidades pagadas, se tiene el siguiente resultado:

\section{Tabla 2.9. Participación de las Principales Compañías de Seguros}

\begin{tabular}{llcc}
\hline Empresas en Riesgos Generales & $\begin{array}{c}\text { Participación de } \\
\text { mercado por } \\
\text { primas pagadas \% }\end{array}$ & $\begin{array}{c}\text { Siniestralidad } \\
\text { pagada \% }\end{array}$ \\
\hline 1 & Rímac & & \\
2 & Pacífico Seguros Generales & $91 \%$ & $96 \%$ \\
3 & Mapfre Perú & & \\
4 & La Positiva & & \\
\hline
\end{tabular}

Fuente: Superintendencia de Banca, Seguros y Administradoras de Fondos de Pensiones, 2017, Boletín Estadístico de Seguros. Recuperado de

https://www.sbs.gob.pe/app/stats_net/stats/EstadisticaBoletinEstadistico.aspx?p=25\#).

Elaboración propia.

\section{a. Segmentación de Mercado}

Dadas las características de partición en el mercado, por parte de las compañías de seguros; segmentaremos el mercado en Clientes Premium y Clientes Regulares. Los Clientes Premium serán las 4 compañías que desembolsan en promedio por año, el $96 \%$ de las siniestralidades pagadas, mientras que los Clientes Regulares serán el resto de las compañías de Ramos Generales o Ramos Generales y de Vida. 


\section{Tabla 2.10. Segmentación del Mercado}

\section{Clientes Premium}

Rímac, Pacífico Seguros Generales, Mapfre Perú y La Positiva

\section{Clientes Regulares}

Chubb Perú, Cardif, Interseguro, Secrex, Insur, HDI Seguros, Aval Perú, Coface.

Fuente: Elaboración propia.

\section{b. Mercado Potencial - Mercado Disponible - Mercado Efectivo y Mercado Objetivo}

De la segmentación del mercado, podemos observar que los Clientes Grandes y Medianos poseen la necesidad de contar con los servicios de las empresas ajustadoras de seguros, motivo por el cual acceden a los servicios dependiendo de las ventajas que ofrece o negocia el ajustador, generándose una frecuencia de consumo.

El mercado de ajuste de seguros posee una característica muy particular. Debido a que existe un reducido número de compañías de seguros, el mercado potencial, el mercado disponible, el mercado efectivo y el mercado objetivo; resultan ser iguales para este caso.

A continuación se demuestra la afirmación, mediante el análisis de cada mercado.

Mercado Potencial: Se considerará como mercado potencial a las 12 compañías de seguros dedicadas a 
ramos generales, ya que todas podrían necesitar el

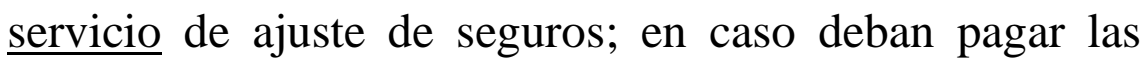
siniestralidades que puedan sufrir sus asegurados.

Mercado Disponible: Se considerará como mercado disponible a todas las compañías de seguros dedicadas a ramos generales, ya que en la realidad, se observa que todas realizan desembolsos por siniestralidades y por ende, demandan el servicio de ajuste de seguros (Ver Tablas 2.8 y 2.9$)$.

Mercado Efectivo: Se considerará como mercado efectivo a todas las compañías de seguros dedicadas a ramos generales, ya que al hacer desembolsos por las $\underline{\text { siniestralidades que sufren sus asegurados, todas tienen la }}$ intención de comprar el servicio de ajuste de seguros.

Mercado Objetivo: Debido a que existen solo 12 compañías que demandarán el servicio de ajuste de seguros, la Empresa Moreno \& Pacora Ajustadores de Seguros, al igual que las otras empresas ajustadoras del mercado, considerará a todas como su mercado objetivo. Esto además se plantea con el propósito dar competitividad a la empresa y proporcionarle las mismas expectativas que poseen sus competidoras. 
Tabla 2.11. Mercado Potencial, Disponible, Efectivo y Objetivo

$($ Mercado Potencial $)=($ Mercado Disponible $)=($ Mercado Efectivo $)=$ $($ Mercado Objetivo $)=($ Clientes Grandes + Clientes Medianos $)$

Fuente: Elaboración propia.

\subsubsection{Análisis de los Ajustadores de Seguros}

La composición de los principales ajustadores del mercado de seguros peruano está conformado por 14 empresas dedicadas al rubro de Ramos Generales, según la SBS (Superintendencia de Banca, Seguros y Administradoras de Fondos de Pensiones, 2017).

El total de ingresos de las empresas ajustadoras al cierre del 2015 corresponde a S/.31,620,239.00 resultado de un crecimiento anual promedio de $14 \%$ (Ver Tabla 2.12) para este sector (Superintendencia de Banca, Seguros y Administradoras de Fondos de Pensiones, 2017). Estos ingresos se basan en comisiones pagadas por las Compañías de Seguros a los Ajustadores, después de fijar el pago por siniestralidad. 


\section{Tabla 2.12. Ingresos Anuales de las Empresas Ajustadoras de Seguros en Riesgos Generales}

\begin{tabular}{cccc}
\hline Año & & Monto & Incremento \\
\hline 2011 & S/. & $18,988,084$ & \\
2012 & S/. & $19,335,127$ & $2 \%$ \\
2013 & S/. & $23,454,468$ & $21 \%$ \\
2014 & S/. & $29,573,104$ & $26 \%$ \\
2015 & S/. & $31,620,239$ & $7 \%$ \\
\hline \multicolumn{4}{l}{} \\
$\begin{array}{l}\text { Promedio de Crecimiento Anual de } \\
\text { Mercado }\end{array}$
\end{tabular}

Fuente: Asociación Peruana de Empresas de Seguros, 2017, Siniestros de Primas de Seguros

Netas. Recuperado de http://www.apeseg.org.pe/php/sicsa/sinianual.php

Elaboración propia.

En este sector, 5 empresas concentran la mayor participación en los ingresos; teniéndose para el 2015 una participación del $76 \%$ (Ver Tabla 2.14):

\section{Tabla 2.13. Participación de las Empresas Ajustadoras de Seguros en Soles}

\begin{tabular}{|c|c|c|c|c|c|c|c|c|c|c|}
\hline PROVEEDORES & & 2011 & & 2012 & & 2013 & & 2014 & & 2015 \\
\hline HERRERA D.K.P. - AJUSTADORES DE SEGUROS & $\mathrm{S} /$. & $7,032,171$ & $\mathrm{~S} /$. & $8,181,878$ & $\mathrm{~S} /$. & $8,276,202$ & S/. & $12,329,070$ & $\mathrm{~S} /$. & $10,284,998$ \\
\hline CRAWFORD PERU S.A. AJUSTADORES Y PERITOS DE SEGUROS & $\mathrm{S} /$. & $4,466,390$ & S/. & $3,637,929$ & $\mathrm{~S} /$. & $5,502,652$ & $\mathrm{~S} /$. & $5,791,712$ & $\mathrm{~S} /$. & $6,781,631$ \\
\hline W. MOLLER AJUSTADORES Y PERITOS DE SEGUROS S.A.C. & $\mathrm{S} /$. & $1,139,692$ & $\mathrm{~S} /$. & $1,365,297$ & $\mathrm{~S} /$. & $2,436,395$ & S/. & 2,032,202 & $\mathrm{S} /$. & $2,488,446$ \\
\hline FGR PERU AJUSTADORES DE SEGUROS & & - & & - & $\mathrm{S} /$. & 89,419 & $\mathrm{~S} /$. & $1,435,149$ & $\mathrm{~S} /$. & $2,360,066$ \\
\hline IRIARTE Y ASOCIADOS S.A. AJUSTADORES Y PERITOSDE SEGUROS & $\mathrm{S} /$. & $1,356,412$ & $\mathrm{~S} /$. & $1,396,069$ & $\mathrm{~S} /$. & $1,482,858$ & S/. & $1,697,385$ & $\mathrm{~S} /$. & $2,260,962$ \\
\hline BAUKOST AJUSTADORES Y PERITOS DE SEGUROS & & - & & - & & - & S/. & 592,166 & $\mathrm{~S} /$ & $1,544,755$ \\
\hline MASTER AJUSTADORES DE SEGUROS S.A.C. & $\mathrm{S} /$. & 759,049 & $\mathrm{~S} /$. & 813,475 & $\mathrm{~S} /$. & 947,696 & $\mathrm{~S} /$. & $1,075,629$ & $\mathrm{~S} /$. & $1,235,326$ \\
\hline MCLARENS TOPLIS PERU AJUSTADORES Y PERITOS DE SEGUROS S.A. & $\mathrm{S} /$. & $1,896,761$ & S/. & $1,895,220$ & $\mathrm{~S} /$. & $1,616,051$ & $\mathrm{~S} /$. & $1,385,854$ & $\mathrm{~S} /$. & $1,175,401$ \\
\hline BISI \& ROMERO ASOCIADOS S.A. AJUSTADORES DE SEGUROS & 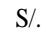 & 592,303 & S/. & 442,313 & S/. & 404,043 & S/. & 911,368 & S/. & 879,239 \\
\hline BARRON AJUSTADORES DE SEGUROS S.A.C. & $\mathrm{S} /$. & $1,057,855$ & S/. & 636,937 & $\mathrm{~S} /$. & 810,903 & $\mathrm{~S} /$. & 841,270 & $\mathrm{~S} /$. & 687,969 \\
\hline GD AJUSTADORES DE SEGUROS S.A.C. & & - & $\mathrm{S} /$. & 169,471 & S/. & 454,062 & $\mathrm{~S} /$. & 544,758 & $\mathrm{~S} /$. & 618,598 \\
\hline OSBERK AJUSTADORES DE SEGUROS S.A. & $\mathrm{S} /$. & 425,881 & S/. & 509,776 & $\mathrm{~S} /$. & $1,027,908$ & $\mathrm{~S} /$. & 332,234 & $\mathrm{~S} /$. & 576,447 \\
\hline PERU VERITAS AJUSTADORES DE SEGUROS S.A.C. & & & & & S/. & 172,683 & $\mathrm{~S} /$. & 347,343 & $\mathrm{~S} /$. & 415,440 \\
\hline ACM AJUSTADORES Y PERITOS DE SEGUROS S.A.C. & $\mathrm{S} /$. & 261,570 & S/. & 286,762 & $\mathrm{~S} /$. & 233,596 & S/. & 256,963 & $\mathrm{~S} / \mathrm{.}$ & 310,961 \\
\hline TOTAL & $\mathrm{S} /$. & $8,988,084$ & $\mathrm{~S} /$. & $19,335,127$ & $\mathrm{~S} /$. & $23,454,468$ & $\mathrm{~S} /$. & $29,573,104$ & $\mathrm{~S} /$. & $31,620,239$ \\
\hline
\end{tabular}

Fuente: Superintendencia de Banca, Seguros y Administradoras de Fondos de Pensiones, 2017, Intermediarios y Auxiliares de Seguros. Recuperado de https://www.sbs.gob.pe/app/stats_net/stats/EstadisticaBoletinEstadistico.aspx?p=26\#. Elaboración propia. 
Tabla 2.14. Participación de las Empresas Ajustadoras de Seguros en Porcentaje

\begin{tabular}{|c|c|c|c|c|c|}
\hline PROVEEDORES & 2011 & 2012 & 2013 & 2014 & 2015 \\
\hline HERRERA D.K.P. - AJUSTADORES DE SEGUROS & $37.0 \%$ & $42.3 \%$ & $35.3 \%$ & $41.7 \%$ & $32.5 \%$ \\
\hline CRAWFORD PERU S.A. AJUSTADORES Y PERITOS DE SEGUROS & $23.5 \%$ & $18.8 \%$ & $23.5 \%$ & $19.6 \%$ & $21.4 \%$ \\
\hline W. MOLLER AJUSTADORES Y PERITOS DE SEGUROS S.A.C. & $6.0 \%$ & $7.1 \%$ & $10.4 \%$ & $6.9 \%$ & $7.9 \%$ \\
\hline FGR PERU AJUSTADORES DE SEGUROS & - & - & $0.4 \%$ & $4.9 \%$ & $7.5 \%$ \\
\hline IRIARTE Y ASOCIADOS S.A. AJUSTADORES Y PERITOSDE SEGUROS & $7.1 \%$ & $7.2 \%$ & $6.3 \%$ & $5.7 \%$ & $7.2 \%$ \\
\hline BAUKOST AJUSTADORES Y PERITOS DE SEGUROS & - & - & - & $2.0 \%$ & $4.9 \%$ \\
\hline MASTER AJUSTADORES DE SEGUROS S.A.C. & $4.0 \%$ & $4.2 \%$ & $4.0 \%$ & $3.6 \%$ & $3.9 \%$ \\
\hline MCLARENS TOPLIS PERU AJUSTADORES Y PERITOS DE SEGUROS S.A. & $10.0 \%$ & $9.8 \%$ & $6.9 \%$ & $4.7 \%$ & $3.7 \%$ \\
\hline BISI \& ROMERO ASOCIADOS S.A. AJUSTADORES DE SEGUROS & $3.1 \%$ & $2.3 \%$ & $1.7 \%$ & $3.1 \%$ & $2.8 \%$ \\
\hline BARRON AJUSTADORES DE SEGUROS S.A.C. & $5.6 \%$ & $3.3 \%$ & $3.5 \%$ & $2.8 \%$ & $2.2 \%$ \\
\hline GD AJUSTADORES DE SEGUROS S.A.C. & - & $0.876 \%$ & $1.9 \%$ & $1.8 \%$ & $2.0 \%$ \\
\hline OSBERK AJUSTADORES DE SEGUROS S.A. & $2.2 \%$ & $2.6 \%$ & $4.4 \%$ & $1.1 \%$ & $1.8 \%$ \\
\hline PERU VERITAS AJUSTADORES DE SEGUROS S.A.C. & - & - & $0.736 \%$ & $1.2 \%$ & $1.3 \%$ \\
\hline ACM AJUSTADORES Y PERITOS DE SEGUROS S.A.C. & $1.4 \%$ & $1.5 \%$ & $1.0 \%$ & $0.9 \%$ & $1.0 \%$ \\
\hline TOTAL & $100.0 \%$ & $100.0 \%$ & $100.0 \%$ & $100.0 \%$ & $100.0 \%$ \\
\hline
\end{tabular}

Fuente: Superintendencia de Banca, Seguros y Administradoras de Fondos de Pensiones, 2017, Intermediarios y Auxiliares de Seguros. Recuperado de https://www.sbs.gob.pe/app/stats_net/stats/EstadisticaBoletinEstadistico.aspx?p=26\#. Elaboración propia.

\subsection{ANÁLISIS DE LA DEMANDA}

Para hacer un adecuado análisis de demanda debemos considerar todos los parámetros que intervienen en el mercado de Seguros de Ramos Generales.

a. El proceso inicia con el pago de las Primas a las Compañías de Seguros, las cuales serán nuestros clientes y además pagarán las Siniestralidades que correspondan

b. La Siniestralidades se pagarán solo a empresas aseguradas, por lo tanto, el pago por siniestralidades es una variable dependiente de las Primas de Seguros pagadas. 
c. Las empresas ajustadoras de seguros cobran una comisión de la siniestralidad pagada. Asimismo los ingresos de la aseguradora dependerá del posicionamiento que tenga en el sector.

Con la información analizada tenemos que en los últimos años, el mercado de Primas de Seguros de Ramos Generales viene creciendo en un promedio anual de 10\% (Tabla 2.4).

Figura 2.1. Primas Pagadas por Ramos Generales

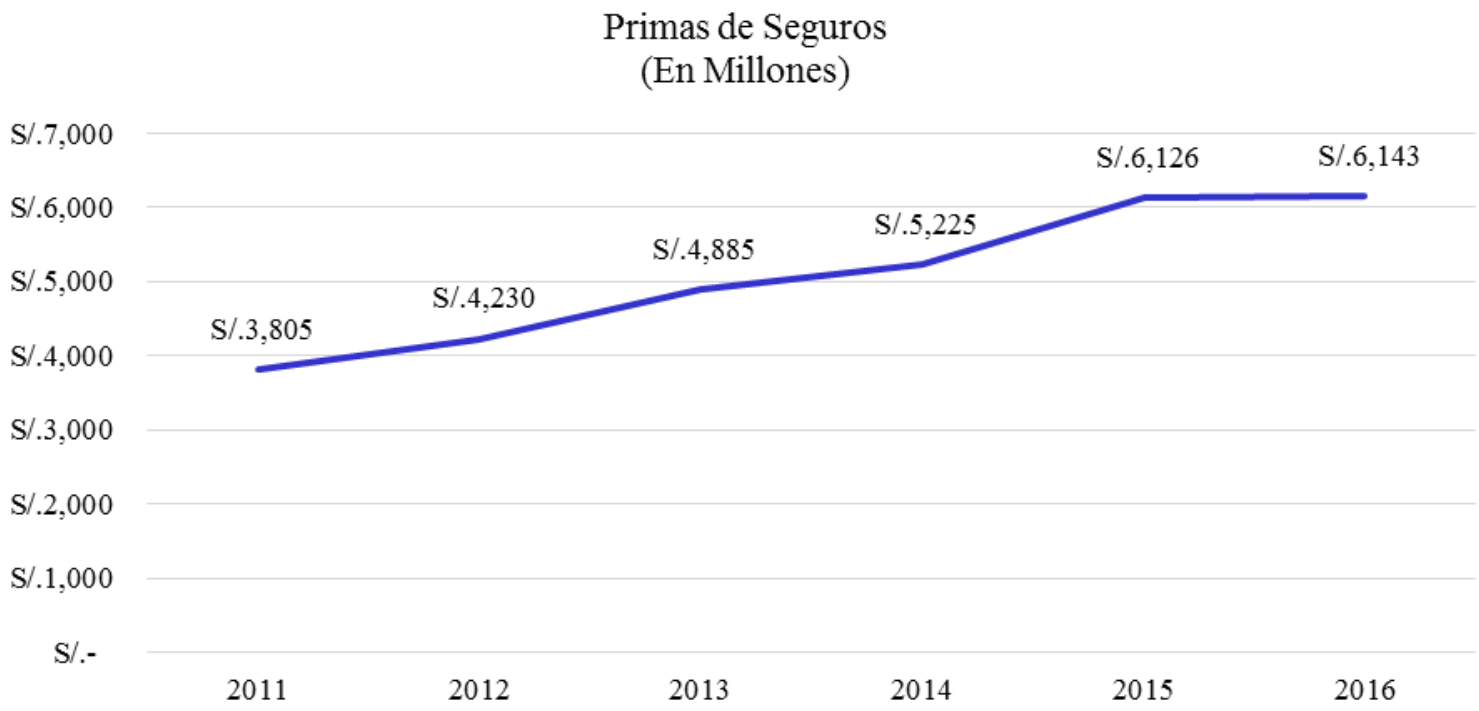

Fuente: Superintendencia de Banca, Seguros y Administradoras de Fondos de Pensiones, 2017, Boletín Estadístico de Seguros. Recuperado de

https://www.sbs.gob.pe/app/stats_net/stats/EstadisticaBoletinEstadistico.aspx?p=25\#

Elaboración propia.

Asimismo, las siniestralidades que son una variable dependiente de las Primas de Seguros contratadas o pagadas, se incrementan; representando un $43 \%$ promedio de las Primas de Seguros (Ver Tabla 2.15): 


\section{Tabla 2.15. Relación entre Siniestralidad y Primas Pagadas}

\begin{tabular}{cccccc}
\hline Año & $\begin{array}{c}\text { Primas de } \\
\text { Seguros } \\
\text { (En } \\
\text { Millones) }\end{array}$ & $\begin{array}{c}\text { Siniestralidad } \\
\text { Pagada } \\
\text { (En Millones) }\end{array}$ & $\begin{array}{c}\text { Siniestralidad } \\
\text { / Primas }\end{array}$ \\
\hline 2011 & S/. & 3,805 & S/. & 1,520 & $40 \%$ \\
2012 & S/. & 4,230 & S/. & 1,891 & $45 \%$ \\
2013 & S/. & 4,885 & S/. & 2,264 & $46 \%$ \\
2014 & S/. & 5,225 & S/. & 2,112 & $40 \%$ \\
2015 & S/. & 6,126 & S/. & 2,558 & $42 \%$ \\
2016 & S/. 6,143 & S/. & 2,727 & $44 \%$ \\
\hline \multicolumn{5}{c}{ Promedio de Crecimiento } & $43 \%$ \\
\hline
\end{tabular}

Fuente: Superintendencia de Banca, Seguros y Administradoras de Fondos de Pensiones, 2017, Boletín Estadístico de Seguros. Recuperado de https://www.sbs.gob.pe/app/stats_net/stats/EstadisticaBoletinEstadistico.aspx?p=25\#

Asociación Peruana de Empresas de Seguros, 2017, Siniestros de Primas de Seguros Netas. Recuperado de http://www.apeseg.org.pe/php/sicsa/sinianual.php

Elaboración propia.

Además, las indemnizaciones por siniestralidad han significado un ingreso para las empresas ajustadoras de seguros en un ratio de $1.189 \%$ en promedio (Tabla 2.16).

\section{Tabla 2.16. Ratio entre la Siniestralidad Pagada y el Ingreso para las Empresas Ajustadoras de Seguros}

\begin{tabular}{ccccccc}
\hline AÑO & $\mathbf{2 0 1 1}$ & $\mathbf{2 0 1 2}$ & $\mathbf{2 0 1 3}$ & $\mathbf{2 0 1 4}$ & $\mathbf{2 0 1 5}$ & Promedio \\
\hline $\begin{array}{c}\text { TOTAL DE INGRESOS PARA } \\
\text { AJUSTADORAS } \\
\text { (En millones) }\end{array}$ & S/. 19.0 & S/. 19.3 & S/. 23.5 & S/. 29.6 & S/. 31.6 & -- \\
$\begin{array}{c}\text { SINIESTRALIDAD } \\
\text { PAGADA POR LAS } \\
\text { COMPANIÍAS DE SEGUROS } \\
\text { (En millones) }\end{array}$ & S/. $1,519.9$ & S/. $1,890.9$ & S/. 2,263.6 & S/. 2,112.4 & S/. $2,558.4$ & -- \\
\hline RATIO & $\mathbf{1 . 2 4 9 \%}$ & $\mathbf{1 . 0 2 3 \%}$ & $\mathbf{1 . 0 3 6 \%}$ & $\mathbf{1 . 4 0 0 \%}$ & $\mathbf{1 . 2 3 6 \%}$ & $\mathbf{1 . 1 8 9 \%}$ \\
\hline
\end{tabular}

Fuente: Asociación Peruana de Empresas de Seguros, 2017, Siniestros de Primas de Seguros

Netas. Recuperado de http://www.apeseg.org.pe/php/sicsa/sinianual.php

Superintendencia de Banca, Seguros y Administradoras de Fondos de Pensiones, 2017, Intermediarios y Auxiliares de Seguros. Recuperado de

https://www.sbs.gob.pe/app/stats_net/stats/EstadisticaBoletinEstadistico.aspx?p=26\#.

Elaboración propia. 
De este ratio, 5 empresas concentran un $76 \%$ de los ingresos, mientras que las empresas restantes poseen una participación entre $1 \%$ y $5 \%$ (Tabla 2.17 ).

Además se observa que el mercado está liderado por HERRERA DKP Y CRAWFORD PERU quienes concentran más del 50\% de participación del mercado

\section{Tabla 2.17. Participación de los Competidores en el Mercado durante el 2015}

\begin{tabular}{clc}
\hline $\mathbf{N}^{\circ}$ & \multicolumn{1}{c}{ AJUSTADORES DE SEGUROS } & $\begin{array}{c}\text { \% de } \\
\text { Mercado }\end{array}$ \\
\hline 1 & HERRERA D.K.P. - AJUSTADORES DE SEGUROS & $32.53 \%$ \\
2 & CRAWFORD PERU S.A. AJUSTADORES Y PERITOS DE & $21.45 \%$ \\
3 & SEGUROS & $7.87 \%$ \\
4 & W. MOLLER AJUSTADORES Y PERITOS DE SEGUROS S.A.C. & $7.46 \%$ \\
5 & IRIARTE Y ASOCIADOS S.A. AJUSTADORES Y PERITOSDE & $7.15 \%$ \\
6 & SEGUROS & $4.89 \%$ \\
7 & BAUKOST AJUSTADORES Y PERITOS DE SEGUROS & $3.91 \%$ \\
8 & MASTER AJUSTADORES DE SEGUROS S.A.C. & $3.72 \%$ \\
9 & SELARENS TOPLIS PERU AJUSTADORES Y PERITOS DE & $2.78 \%$ \\
10 & BISI \& ROMERO ASOCIADOS S.A. AJUSTADORES DE & $2.18 \%$ \\
11 & BARRONOS AJUSTADORES DE SEGUROS S.A.C. & $1.96 \%$ \\
14 & GD AJUSTADORES DE SEGUROS S.A.C. & $1.82 \%$ \\
\hline
\end{tabular}

Fuente: Superintendencia de Banca, Seguros y Administradoras de Fondos de Pensiones, 2017, Intermediarios y Auxiliares de Seguros. Recuperado de https://www.sbs.gob.pe/app/stats_net/stats/EstadisticaBoletinEstadistico.aspx?p=26\#.

Elaboración propia. 


\subsection{ANALISIS DE LA COMPETENCIA}

A continuación se realiza el análisis competitivo de las principales empresas ajustadores de seguros que participan en el mercado asegurador peruano.

\subsubsection{Empresas Ajustadoras de Seguros}

\section{a. Herrera DKP}

De acuerdo a la página constitucional de HERRERA DKP (2017) es una empresa que inició sus actividades en 1997 como resultado de la fusión de Herrera y Asociados SRL con DKP Peritos de Seguros Sociedad Civil de Responsabilidad Limitada. Actualmente cuenta con 68 trabajadores

Entre las fortalezas de la empresa se encuentran:

$\checkmark$ HERRERA DKP se encuentra ya consolidada tanto en el mercado nacional como internacional, logrando satisfacer con sus recursos humanos y materiales las necesidades de atención de los siniestros en la variedad de los seguros.

$\checkmark$ Está asociado con Cunningham Lindsey International Loss Adjuster, Comisariado Español Marítimo S.A. Comismar, Pannell \& Co Average Adjusters.

$\checkmark$ Forma parte de una red mundial de oficinas que dan soporte en caso de siniestros de gran envergadura.

$\checkmark$ La empresa está compuesta por personal con experiencia y profesionalismo. 
25 años de experiencia como ajustadores de seguros.

$\checkmark$ Posicionamiento en el mercado de seguros

Tiene el 33\% de participación del mercado, siendo el líder.

$\checkmark$ Elabora boletines especializados para conocimiento del mercado.

$\checkmark$ Página web al servicio del cliente.

Entre las debilidades de la empresa se encuentran:

$\checkmark$ Gran concentración de siniestros asignados por las aseguradoras.

$\checkmark$ Demora en la atención de algunos siniestros.

$\checkmark$ Enfoque mayormente a siniestros grandes.

\section{b. Crawford Perú S.A. Ajustadores y Peritos de Seguros.}

Crawford Perú S.A. Inicio operaciones en Perú el 02 de abril de 1984 y pertenece a la red mundial Crawford \& Company, con sede en Atlanta, USA. Está formada por un equipo de profesionales especializados en la atención de siniestros de Robo, Incendio, Terremoto, Casco, Acuicultura, Transporte Marítimo, Transporte Aéreo, Transporte Terrestre, Transporte de Carga Nacional, STP (Stock ThroughPut) y Responsabilidad Civil Internacional.

Es una empresa sólida con más de 35 años en el mercado asegurador nacional e internacional y cuenta con 39 trabajadores. 
Entre las fortalezas de la empresa se encuentran

$\checkmark$ Tienen el respaldo de Crawford \& Company International.

$\checkmark$ Experiencia de 70 años en el mercado internacional.

La empresa está compuesta por personal con experiencia y profesionalismo.

$\checkmark$ Forma parte de una red mundial de oficinas que dan soporte en caso de siniestros de gran envergadura.

$\checkmark$ Cuenta con posicionamiento en el mercado.

$\checkmark$ Tiene el 21\% de participación del mercado.

$\checkmark$ Página web al servicio del cliente.

$\checkmark$ Crawford \& Company proporciona a sus empleados y clientes el conjunto más avanzado de herramientas de Tecnología de la Información y Comunicación (TIC) en la industria para realizar los ajustes de siniestros.

Entre las debilidades de la empresa se encuentran:

$\checkmark$ Gran concentración de siniestros asignados por las aseguradoras.

$\checkmark$ Demora en la atención de algunos siniestros.

$\checkmark$ Enfoque mayormente a siniestros grandes. 


\section{c. W. Moller Ajustadores y peritos de Seguros S.A.C.}

Fundada el 11 de octubre de 1963, W.Moller S.A.C., es una de las principales empresas de ajuste y liquidación de seguros en el Perú.

La experiencia de más de 50 años, siendo protagonista en la historia del mercado de seguros peruano, sumada a su red nacional conformada por Ajustadores, Peritos, Expertos y Consultores, le permite atender los reclamos de manera inmediata en cualquier ciudad de la república y del extranjero.

En el año 2013, W.Moller S.A.C., se integra a Addvalora Global Loss Adjusters, la red mundial de ajustadores de seguros más extensa en el globo.

La empresa cuanta con 17 trabajadores.

Entre sus fortalezas se encuentran:

$\checkmark$ Tiene 54 años de experiencia en ajuste de seguros.

$\checkmark$ Socio de Addvalora - Global Loss Adjuster, red mundial de ajustadores más extensa en el mundo.

$\checkmark$ Tiene Red de oficinas en todo el Perú.

$\checkmark$ Cuentan con posicionamiento en el mercado.

$\checkmark$ La empresa está compuesta por personal con experiencia y profesionalismo.

$\checkmark$ Desarrollan foros y eventos sobre diversos riesgos 
Tiene el $8 \%$ de participación del mercado.

$\checkmark$ Página web al servicio del cliente.

Entre las debilidades de la empresa se encuentran:

Gran concentración de siniestros asignados por las aseguradoras.

$\checkmark$ Demora en la atención de algunos siniestros.

$\checkmark$ Enfoque mayormente a siniestros grandes.

$\checkmark$ Poca penetración en el mercado.

\section{d. FGR PERU Ajustadores de Seguros}

FGR PERU es una empresa ajustadora de seguros subsidiaria de FGR CHILE, empresa con más de 25 años en la industria de seguros en Chile, expertos en liquidación de seguros de Vida y Generales.

Actualmente la empresa cuenta con 17 trabajadores.

Entre las fortalezas de la empresa se encuentran:

$\checkmark 25$ años de experiencia como ajustadores de seguros.

$\checkmark$ Presencia Internacional - Chile, Perú y Colombia.

$\checkmark 270$ profesionales en Chile, Perú y Colombia.

$\checkmark$ Tiene el 7\% de participación del mercado.

$\checkmark$ Página web de la casa matriz al servicio del cliente.

Entre las debilidades de la empresa se encuentran: 
$\checkmark$ No cuenta con una página web directa, utiliza la web de la matriz.

$\checkmark$ Poca penetración en el mercado.

$\checkmark$ No cuentan con oficinas en provincias

\section{e. IRIARTE Y ASOCIADOS S.A. Ajustadores y Peritos de Seguros}

Inicio operaciones el 21 de abril de 1993.

Participación del mercado del 7\%.

Cantidad de trabajadores $=7$

Entre las fortalezas de la empresa se encuentran

$\checkmark$ Experiencia de 27 años como empresa de ajuste de seguros.

$\checkmark$ Personal con experiencia.

$\checkmark$ Especializados en Responsabilidad Civil

$\checkmark$ Tienen una participación del mercado de 7\%

$\checkmark$ Cuenta con posicionamiento en el mercado

Entre las debilidades de la empresa se encuentran:

$\checkmark$ Son especializados en Responsabilidad Civil, pocos casos de siniestros generales.

$\checkmark$ No cuenta con una página web de servicio al cliente.

$\checkmark$ La empresa es reconocida por la experiencia del fundador, próximo a jubilarse. 


\section{f. BAUKOST Ajustadores y Peritos de Seguros}

Inicio operaciones en Perú el 22 de junio de 1999.

De acuerdo al portal institucional de BAUKOST (2017) la Empresa es española con una Oficina Técnica integrada por profesionales de diferentes campos, especializados en distintas áreas relacionadas con la valoración de proyectos de obra y proyectos industriales.

Fundada en 1992, cuenta además con un conocimiento profundo de las exigencias de los Servicios Técnicos relacionados con el Sector Asegurador, y una dilatada experiencia en el tratamiento integral de los Siniestros.

Número de trabajadores: 15

Entre las fortalezas de la empresa se encuentran

$\checkmark$ Subsidiaria de BAUKOST ESPAÑA, con presencia internacional.

$\checkmark 25$ años de experiencia como ajustadores de seguros.

$\checkmark$ Empresa compuesta por experiencia y profesionalismo

$\checkmark$ Tiene experiencia con clientes europeos.

$\checkmark$ Servicio en el área pericial como el de consultoría.

$\checkmark$ Tiene el 5\% de participación del mercado

$\checkmark$ Página web al servicio del cliente

Entre las debilidades de la empresa se encuentran: 
$\checkmark$ No cuenta con una página web de servicio al cliente enfocado al mercado de Perú.

$\checkmark$ Poca penetración de mercado.

$\checkmark$ No cuentan con oficinas en provincias

g. Master Ajustadores de Seguros S.A.C.

Inicio operaciones el 08 de enero de 1999.

Participación de mercado: $4 \%$

Número de trabajadores: 8

h. MCLAREnS Toplis Perú Ajustadores y Peritos de Seguros S.A

Inicio de operaciones el 08 de enero de 1999.

Participación de mercado: $4 \%$

Número de trabajadores: 8

i. BISI \& Romero Asociados S.A. Ajustadores de Seguros.

Inicio de operaciones: 04 de diciembre de 1995.

Participación de mercado: 3\%

Número de trabajadores: 6

j. Barrón Ajustadores de Seguros S.A.C.

Inicio de Operaciones: 05 de junio del 2007.

Participación de mercado: 2\%

Número de trabajadores: 5

k. GD Ajustadores de Seguros S.A.C.

Fecha de inicio: 01 de marzo del 2012. 
Participación de mercado: 2\%

Número de trabajadores: 3

\section{OSBERK AJUSTADORES DE SEGUROS S.A.}

OSBERK, inició operaciones en el sector seguros desde el mes de abril de 1988, dándole al mercado asegurador un servicio profesional de ajuste y liquidación de pérdidas.

En la actualidad tienen suscrito un convenio con la empresa Miller International, Ingeniero Jurgen Kolbe, creando un valor agregado a sus operaciones. OSBERK cuenta con un grupo de asesores en ingeniera que nos permiten atender de manera profesional y eficiente en cualquier parte del Perú.

Número de trabajadores: 4

Entre las fortalezas de la empresa se encuentran:

$\checkmark$ Acuerdo con un ajustador internacional de prestigio

$\checkmark 25$ años de experiencia como ajustadores de seguros.

$\checkmark$ Empresa sólida que no tiene deudas en el sistema financiero.

$\checkmark$ Funcionarios son profesionales que gozan de buena reputación.

$\checkmark$ Cuenta con la infraestructura necesaria para un servicio de calidad.

$\checkmark$ Tienen una participación del mercado del $2 \%$ 
Asesores en ingeniería para atención a nivel nacional.

$\checkmark$ Página web al servicio del cliente.

\section{m. PERU VERITAS AJUSTADORES DE SEGUROS} S.A.C.

Fecha de inicio: 16 de diciembre del 2011.

Participación de mercado: $1 \%$

Número de trabajadores: 7

\section{n. ACM AJUSTADORES Y PERITOS DE SEGUROS} S.A.C.

Fecha de inicio: 06 de noviembre del 2006.

Participación de mercado: $1 \%$

Número de trabajadores: 6

Tabla 2.18. Resumen de fortalezas y debilidades de las empresas ajustadoras de seguros

\begin{tabular}{ccc}
\hline EMPRESAS & DEBILIDADES & FORTALEZAS \\
\hline & & Basta experiencia (desde 1992 \\
& operando) \\
& Concentración de & Gran número de Trabajadores \\
& siniestros & $(68)$ \\
1.- HERRERA & Puede generar demora en \\
D.K.P. & la atención de siniestros \\
menores. & Asociaciones internacionales. \\
& Personal con experiencia \\
& & Tienen una red mundial de \\
& & oficinas. \\
& & Página Web al servicio del \\
& & cliente \\
\hline
\end{tabular}




\begin{tabular}{|c|c|c|}
\hline EMPRESAS & DEBILIDADES & FORTALEZAS \\
\hline $\begin{array}{l}\text { 2.- CRAWFORD } \\
\text { PERU S.A. }\end{array}$ & $\begin{array}{l}\text { Concentración de } \\
\text { siniestros. } \\
\text { Puede generar demora en } \\
\text { la atención de siniestros } \\
\text { menores. }\end{array}$ & $\begin{array}{c}\text { Basta experiencia (desde } 1984 \\
\text { operando) } \\
\text { Un numeroso grupo de } \\
\text { trabajadores (39) } \\
\text { Una participación de mercado } \\
\text { del } 21 \% \\
\text { Asociaciones internacionales } \\
\text { Personal con experiencia } \\
\text { Página web al servicio del } \\
\text { cliente } \\
\end{array}$ \\
\hline 3.- W. MOLLER & $\begin{array}{l}\text { Concentración de } \\
\text { siniestros. } \\
\text { Puede generar demora en } \\
\text { la atención de siniestros } \\
\text { menores. }\end{array}$ & $\begin{array}{c}\text { Basta experiencia (desde } 1963 \\
\text { operando) } \\
\text { Un grupo de } 17 \text { trabajadores } \\
\text { Una participación de mercado } \\
\text { del } 8 \% \\
\text { Asociaciones internacionales } \\
\text { Personal con experiencia } \\
\text { Red mundial de oficinas } \\
\text { Página web al servicio del } \\
\text { cliente }\end{array}$ \\
\hline 4.- FGR PERU & $\begin{array}{c}\text { Pocos años en el mercado } \\
\text { peruano. }\end{array}$ & $\begin{array}{c}\text { Un grupo de } 17 \text { trabajadores } \\
\text { Una participación de mercado } \\
\text { importante del } 7 \% \\
\text { Tiene socios internacionales } \\
\text { Red de oficinas Colombia, } \\
\text { Chile y Perú. } \\
\text { Página web al servicio del } \\
\text { cliente }\end{array}$ \\
\hline
\end{tabular}

No cuenta con página

Web

5.- IRIARTE Y ASOCIADOS S.A
No tiene socios internacionales

La especialización limita la designación de siniestros de otros ramos.
Basta experiencia (desde 1993 operando)

Importante participación de mercado del $7 \%$ Especializados en Responsabilidad Civil 
6.- BAUKOST

Poca participación de mercado
Sólida experiencia en el mercado (desde 1999)

Un grupo de 15 trabajadores

Asociaciones internacionales

Página web al servicio del cliente

\begin{tabular}{|c|c|c|}
\hline EMPRESAS & DEBILIDADES & FORTALEZAS \\
\hline 7.- MASTER & $\begin{array}{c}\text { Pocos años en el mercado } \\
\text { peruano } \\
\text { Poca participación de } \\
\text { mercado } \\
\text { No tiene socios } \\
\text { internacionales } \\
\text { Limitación de } \\
\text { profesionales } \\
\text { No Tienen página web al } \\
\text { servicio del cliente }\end{array}$ & $\begin{array}{c}\text { Cuentan con } 18 \text { años de } \\
\text { experiencia en el mercado } \\
\text { Número de trabajadores }=8\end{array}$ \\
\hline $\begin{array}{l}\text { 8.- MCLARENS } \\
\text { TOPLIS PERU }\end{array}$ & $\begin{array}{c}\text { Pocos años en el mercado } \\
\text { peruano } \\
\text { Poca participación de } \\
\text { mercado } \\
\text { No tiene socios } \\
\text { internacionales } \\
\text { Limitación de } \\
\text { profesionales } \\
\text { No Tienen página web al } \\
\text { servicio del cliente }\end{array}$ & Número de trabajadores $=8$ \\
\hline $\begin{array}{l}\text { 9.- BISI \& } \\
\text { ROMERO }\end{array}$ & $\begin{array}{c}\text { Pocos años en el mercado } \\
\text { peruano } \\
\text { Poca participación de } \\
\text { mercado } \\
\text { No tiene socios } \\
\text { internacionales } \\
\text { Limitación de } \\
\text { profesionales } \\
\text { No Tienen página web al } \\
\text { servicio del cliente }\end{array}$ & Número de trabajadores $=6$ \\
\hline
\end{tabular}




\begin{tabular}{|c|c|c|}
\hline 10.- BARRON & $\begin{array}{c}\text { Pocos años en el mercado } \\
\text { peruano } \\
\text { Poca participación de } \\
\text { mercado } \\
\text { No tiene socios } \\
\text { internacionales } \\
\text { Limitación de } \\
\text { profesionales } \\
\text { No Tienen página web al } \\
\text { servicio del cliente }\end{array}$ & Número de trabajadores $=5$ \\
\hline EMPRESAS & DEBILIDADES & FORTALEZAS \\
\hline $\begin{array}{c}\text { 11.- GD } \\
\text { AJUSTADORES }\end{array}$ & $\begin{array}{c}\text { Pocos años en el mercado } \\
\text { peruano } \\
\text { Poca participación de } \\
\text { mercado } \\
\text { No tiene socios } \\
\text { internacionales } \\
\text { Limitación de } \\
\text { profesionales } \\
\text { No Tienen página web al } \\
\text { servicio del cliente }\end{array}$ & Número de trabajadores $=3$ \\
\hline 12.- OSBERK & $\begin{array}{c}\text { Pocos años en el mercado } \\
\text { peruano } \\
\text { Poca participación de } \\
\text { mercado } \\
\text { No tiene socios } \\
\text { internacionales } \\
\text { Limitación de } \\
\text { profesionales } \\
\text { No Tienen página web al } \\
\text { servicio del cliente }\end{array}$ & Número de trabajadores $=4$ \\
\hline $\begin{array}{l}\text { 13.- PERU } \\
\text { VERITAS }\end{array}$ & $\begin{array}{c}\text { Pocos años en el mercado } \\
\text { peruano } \\
\text { Poca participación de } \\
\text { mercado } \\
\text { No tiene socios } \\
\text { internacionales } \\
\text { Limitación de } \\
\text { profesionales } \\
\text { No Tienen página web al } \\
\text { servicio del cliente }\end{array}$ & Número de trabajadores $=7$ \\
\hline
\end{tabular}




\begin{tabular}{cc}
\hline & Pocos años en el mercado \\
peruano \\
Poca participación de \\
mercado \\
No tiene socios \\
14.- ACM & internacionales \\
Limitación de \\
profesionales \\
\\
No Tienen página web al \\
servicio del cliente
\end{tabular}

Fuente: Elaboración propia.

Adicionalmente se ha considerado dentro del análisis de la competencia la Matriz de Perfil Competitivo (MPC) con la finalidad de una mejor comprensión del entorno externo y la competencia en esta industria. A continuación se presenta la tabla, junto a los respectivos puntajes para 03 empresas competidoras:

Tabla 2.19. Matriz de Perfil Competitivo

\begin{tabular}{lrcccccc}
\hline $\begin{array}{c}\text { FACTORES CRÍTICOS DE ÉXITO } \\
\text { (FCE) }\end{array}$ & \multirow{2}{*}{ PESO } & \multicolumn{2}{c}{ HERRERA D.K.P. } & CRAWFORD PERÚ S.A. & \multicolumn{2}{c}{ W. MOLLER } \\
Rtg & Puntaje & Ratg & Puntaje & Rtg & Puntaje \\
\hline Experiencia y trayectoria en el Mercado & $35 \%$ & 2 & 0.70 & 3 & 1.05 & 4 & 1.40 \\
Asociaciones Internacionales & $5 \%$ & 3 & 0.15 & 3 & 0.15 & 1 & 0.05 \\
Desarrollo de Páginas Web & $25 \%$ & 2 & 0.50 & 2 & 0.50 & 3 & 0.75 \\
Numeroso grupo de trabajadores & $15 \%$ & 4 & 0.60 & 2 & 0.30 & 1 & 0.15 \\
Nivel de especialización & $5 \%$ & 2 & 0.10 & 2 & 0.10 & 1 & 0.05 \\
Red mundial de oficinas & $15 \%$ & 4 & 0.60 & 1 & 0.15 & 3 & 0.45 \\
\hline TOTAL & $\mathbf{1 0 0 \%}$ & - & $\mathbf{2 . 6 5}$ & - & $\mathbf{2 . 2 5}$ & - & $\mathbf{2 . 8 5}$ \\
\hline
\end{tabular}

Fuente: Elaboración propia.

Como se puede apreciar la empresa con mayor score es W. MOLLER seguida por HERRERA D.K.P. por lo que las estrategias que se listan en la Matriz FODA a continuación estarán considerando prioritariamente a estas 02 empresas que resulta la principal competencia. 


\title{
2.4.2. ANALISIS FODA
}

\section{A continuación se desarrolla el marco general para la formulación de las estrategias a adoptar.}

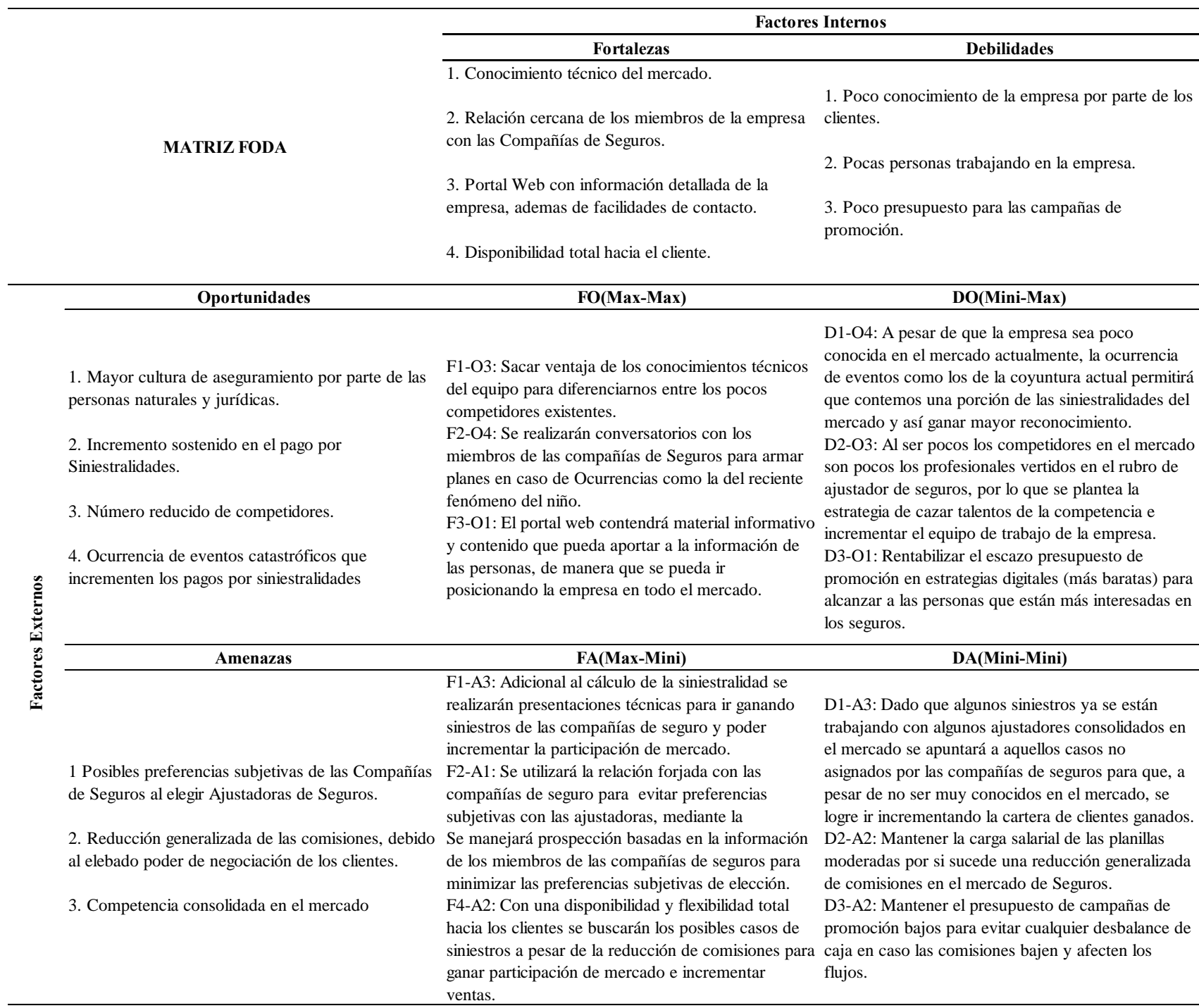

\section{Tabla 2.20. Análisis FODA de la Empresa}

Fuente: Elaboración propia.

\author{
De toda la cartera de estrategias aquí formuladas las que se \\ implementarán en el corto plazo del cuadrante FO son la F1- \\ O3 y F3-O1, dado que ambas son vitales para el inicio de
}


operaciones; para una siguiente etapa se estaría aplicando la F2-O4.

Dentro del cuadrante DO es fundamental la adopción de estrategias digitales que permitan rentabilizar la inversión en publicidad que se está realizando. En línea a esto se encuentra la inversión en la Página web que detallamos en el acápite de Promoción.

Adicionalmente la estrategia D2-O3 es vital para el desarrollo de la compañía, ya que los talentos en el rubro de ajustadoras de seguros son escasos. Para la correcta implementación de esta estrategia se dependerá del conocimiento que se posee del mercado y los contactos que se han ido generando con las compañías de seguros por los socios de la compañía. En esta misma línea es importante notar que la empresa FGR ha logrado en muy poco tiempo posicionarse con un importante $7 \%$ en el mercado, impulsado fundamentalmente por la red de contactos que maneja cada uno de sus ajustadores; por lo que a fin de implementar esta estrategia de forma más exitosa se empezará realizando la caza de talentos empezando con este competidor.

Para el caso de los cuadrantes FA y DA se utilizarán las estrategias F4-A2 y D1-A3 respectivamente para adoptar una estrategia agresiva de crecimiento. Por un lado apuntaremos a aquellas cuentas que actualmente no estén asociadas a alguna ajustadora ya posicionada, por otro se aceptarán los casos de siniestralidades, a pesar de que existan reducciones 
en las comisiones; la finalidad de esta estrategia es posicionar a la compañía e incrementar su participación de una forma acelerada.

\subsection{ANALISIS DE LA CADENA DE VALOR}

\subsubsection{Definición de Cadena de Valor}

La cadena de valor es el instrumento propuesto por Porter (2015) que permite la identificación de habilidades críticas para la obtención de ventajas competitivas a largo plazo. Esta herramienta de gestión hace factible el análisis interno de la empresa mediante la desagregación de las principales actividades que generan valor. Con esta desagregación, la empresa es capaz de identificar sus fortalezas y debilidades, sobre todo en lo que concierne a ventajas competitivas y los costos asociados a las actividades.

En toda empresa, la cadena de valor clasifica las actividades de valor en 2 :

\section{a. Actividades Primarias o de Línea}

Son aquellas actividades que están directamente relacionadas con la producción y comercialización del producto:

Logística interior (de entrada): actividades relacionadas con la recepción, almacenaje y distribución de los insumos necesarios para fabricar el producto. 
$\checkmark$ Operaciones: actividades relacionadas con la transformación de los insumos en el producto final. Logística exterior (de salida): actividades relacionadas con el almacenamiento del producto terminado, y la distribución de éste hacia el consumidor.

$\checkmark$ Mercadotecnia y ventas: actividades relacionadas con el acto de dar a conocer, promocionar y vender el producto.

$\checkmark$ Servicios: actividades relacionadas con la provisión de servicios complementarios al producto tales como la instalación, reparación y mantenimiento del mismo. (www.crecenegocios.com/la-cadena-de-valor-deporter, 2014)

\section{b. Actividades de Apoyo o de Soporte}

Son aquellas actividades que agregan valor al producto pero que no están directamente relacionadas con la producción y comercialización de éste, sino que más bien sirven de apoyo a las actividades primarias:

$\checkmark$ Infraestructura de la empresa: actividades que prestan apoyo a toda la empresa, tales como la planeación, las finanzas y la contabilidad.

$\checkmark$ Gestión de recursos humanos: actividades relacionadas con la búsqueda, contratación, entrenamiento $\mathrm{y}$ desarrollo del personal.

$\checkmark$ Desarrollo de la tecnología: actividades relacionadas con la investigación y desarrollo de la tecnología necesaria para apoyar a las demás actividades. 
Aprovisionamiento: actividades relacionadas con el proceso de compras. (www.crecenegocios.com/lacadena-de-valor-de-porter, 2014).

\subsubsection{Cadena de Valor de Empresa}

\section{Tabla 2.21. Cadena de Valor de la Empresa}

\begin{tabular}{|c|c|c|c|c|}
\hline \multicolumn{5}{|c|}{$\begin{array}{l}\text { Infraestructura de la Empresa } \\
\text { - Planificación Estratégica }\end{array}$} \\
\hline \multicolumn{5}{|c|}{$\begin{array}{l}\text { Gestión de Recursos Humanos } \\
\text { - Gestión por Competencias } \\
\text { - Formación } \\
\text { - Retribución }\end{array}$} \\
\hline \multicolumn{5}{|c|}{$\begin{array}{l}\text { Desarrollo de tecnología } \\
\text { - Implantación del Programa C.R.M. }\end{array}$} \\
\hline \multicolumn{5}{|c|}{$\begin{array}{l}\text { Compras } \\
\text { - Gestión de Relaciones con Compañías Aseguradoras }\end{array}$} \\
\hline $\begin{array}{l}\text { Logística de } \\
\text { Entrada } \\
\text { - Análisis de } \\
\quad \text { Datos }\end{array}$ & $\begin{array}{l}\text { Operaciones } \\
\text { - Proyectos } \\
\text { - Suscripción } \\
\text { - Suplementos }\end{array}$ & $\begin{array}{l}\text { Logística de } \\
\text { Entrada } \\
\text { - Cobro } \\
\text { - Entrega de } \\
\text { Documentos }\end{array}$ & $\begin{array}{l}\text { Marketing y } \\
\text { Ventas } \\
\text { - Construir } \\
\text { equipo ventas } \\
\text { - Renovación de } \\
\text { Pólizas } \\
\text { - Gestión de } \\
\text { Relaciones } \\
\text { - Construcción } \\
\text { de Marca }\end{array}$ & $\begin{array}{l}\text { Servicios } \\
\text { - Gestión de } \\
\text { Siniestros } \\
\text { - Revisión de } \\
\text { Riesgo }\end{array}$ \\
\hline
\end{tabular}

Fuente: Elaboración propia

En el entendido que la cadena de Valor es un concepto utilizado por las empresas que ya se encuentran en marcha, la finalidad de definir este punto en el presente Proyecto de Factibilidad apunta directamente a un enfoque estratégico y conceptual, de modo que al momento de iniciar operaciones la Empresa Moreno \& Pacora Ajustadores de Seguros ya tendrá un marco al cual alinear o basar su cadena de valor. 


\section{CAPÍTULO III}

\section{PLAN DE MARKETING Y VENTAS}

En el presente capítulo, se analizara las estrategias del marketing mix: producto o servicio, distribución, precio y promoción que realizara Moreno \& Pacora Ajustadores de Seguros en sus actividades, culminando con la proyección de ventas.

\subsection{ESTRATEGIA DEL PRODUCTO O SERVICIO}

El servicio a ofrecer por el Ajustador de Seguros en Riesgos Generales es estandarizado y específico, está basado en evaluar siniestros, analizar su causa, definir si los reclamos se encuentran en el ámbito cubierto por la póliza y calcular el monto correspondiente a indemnizar.

La empresa ajustadora de seguros debe ser especializada e imparcial, siendo contratada por las Compañías de Seguros para:

a. Diagnosticar la cobertura de un siniestro

b. Definir el monto correspondiente a la perdida

c. Definir el monto correspondiente a la indemnización.

Se toma en cuenta para el cálculo de la pérdida y de la indemnización los procedimientos incluidos en una póliza respecto a puntos tales como: 

a. Valor de la pérdida.
b. Comprobación de las sumas aseguradas.
c. Aplicación de penalidades.
d. Aplicación de deducibles.

Por lo tanto, el Servicio de Ajuste de Seguros no puede ser diferenciado a nivel de empresas ajustadoras; sin embargo la estrategia a utilizar implicará el valor agregado que pueda adicionarse a este servicio estandarizado.

De manera específica, la Empresa Moreno \& Pacora Ajustadores de Seguros S.A.C. adicionará como valor agregado, las siguientes ventajas sobre sus competidores:

a. Conocimiento del Mercado

b. Nivel de especialización y experticia de los miembros del equipo de la empresa

c. Eficiencia en la atención de los casos, dada la ralentización que actualmente existe en el Sistema.

\subsection{ESTRATEGIA DE DISTRIBUCIÓN}

La cadena de distribución del servicio ofrecido está relacionado a la decisión para la designación de un ajustador de seguros en caso de un siniestro, es decir de ocurrir un siniestro la elección de ajustador de seguros está en la decisión de la compañía de seguros que es quien contrata y paga los servicios, pero a la par depende de las buenas relaciones de trabajo con los corredores de seguros y los 
asegurados quien en múltiples casos es quien deciden el nombramiento del ajustador.

Por estas condiciones o características del mercado, el proyecto no contempla una estrategia de distribución, ya que al igual que con el servicio, la distribución del mismo es estandarizada y específica, no pudiendo distinguirse o diferenciarse a nivel de Empresas Ajustadoras de Seguros.

\subsection{ESTRATEGIA DE PRECIO}

Los ajustadores de seguros reciben una comisión por cada siniestro cerrado e indemnizado, esta comisión es fijada según la tarifa de cada compañía de seguros, cada una de ellas mantiene comisiones distintas, el rango de comisiones que en promedio pagan las principales compañías de seguros se encuentran entre 1,5\% y 3,0\% del monto del siniestro.

Por estas características, no es factible establecer una estrategia de precios; ya que los servicios son pagados conforme a las comisiones establecidas (y no negociadas) por la compañía de seguros.

\subsection{ESTRATEGIA DE PROMOCIÓN}

Dadas las características del mercado, no ha sido factible determinar estrategias de servicio, distribución y precio. Sin embargo es factible establecer una estrategia de promoción que 
permita la penetración en el mercado a través de difusión y venta del servicio, además de la fidelización de los clientes obtenidos.

La Estrategia de Promoción consistirá en comunicar, dar a conocer, informar y/o hacer recordar la existencia de la empresa y su servicio; así como persuadir, estimular e inducir la compra del mismo.

El objetivo comunicacional es dar a conocer la empresa, la filosofía de la organización, el staff de profesionales y su experiencia en el mercado asegurador, a través de:

a. Dictar cursos de seguros, atención de siniestros.

b. Participar en talleres organizados por la Escuela de Seguros APECOSE.

c. Foros, charlas, seminarios.

d. Participar en el encuentro asegurador peruano todos los años.

e. Organizar eventos sobre riesgos.

La Estrategia de Promoción será conforme a la siguiente tabla: 


\section{Tabla 3.1. Estrategia de Promoción}

\begin{tabular}{|c|c|c|}
\hline Etapa & Acciones & Objetivos \\
\hline Etapa 01 & $\begin{array}{l}\text { Se realizarán eventos, charlas, } \\
\text { foros, seminarios, etc. dirigidos } \\
\text { a compañías de seguros, } \\
\text { corredores y asegurados } \\
\text { En los eventos se realizarán las } \\
\text { siguientes actividades: } \\
\text { - Mostrar los conocimientos } \\
\text { técnicos y especializados del } \\
\text { equipo a través de los temas } \\
\text { desarrollados. } \\
\text { - Mostrar la disponibilidad } \\
\text { total del equipo con los } \\
\text { potenciales clientes } \\
\text { - Entrega de merchandising, } \\
\text { boletines, etc. } \\
\text { - Promocionar la página web } \\
\text { - Registrar a los invitados, } \\
\text { solicitando información de } \\
\text { contacto }\end{array}$ & $\begin{aligned} & \text { Branding y Difusión de la } \\
& \text { Empresa } \\
& \text { Mostrar el nivel de } \\
& \text { especialización y experticia del } \\
& \text { equipo de la empresa } \\
&>\text { Tener una base de datos con la } \\
& \text { información de contacto de los } \\
& \text { asistentes a los foros, charlas y } \\
& \text { todo tipo de evento realizado } \\
& \text { por la empresa. Esto permitirá } \\
& \text { hacer contacto estratégico con } \\
& \text { los miembros clave de las } \\
& \text { compañías de seguros, } \\
& \text { corredores de seguros y } \\
& \text { asegurados. }\end{aligned}$ \\
\hline Etapa 02 & $\begin{array}{l}\text { La base de datos de clientes será } \\
\text { utilizada para realizar una } \\
\text { segmentación de la siguiente } \\
\text { forma: } \\
\text { - Compañías de Seguros: que a } \\
\text { su vez serán segmentados en } \\
\text { Clientes Premium y Clientes } \\
\text { Regulares (como se definió } \\
\text { la segmentación de mercado } \\
\text { del punto 2.2.1, Análisis de } \\
\text { Compañías de Seguros) } \\
\text { - Corredores de Seguros } \\
\text { - Empresas Aseguradas }\end{array}$ & $\begin{array}{l}\text { Ordenar la base de datos a fin de } \\
\text { diferenciar las estrategias. El } \\
\text { propósito de la diferenciación es } \\
\text { que con las compañías de } \\
\text { seguros (potenciales clientes) se } \\
\text { debe persuadir, estimular e } \\
\text { inducir la compra; mientras que } \\
\text { las estrategias a realizar con los } \\
\text { corredores de seguros y } \\
\text { asegurados apunta a lograr la } \\
\text { comunicación y recomendación } \\
\text { de la empresa ante las } \\
\text { compañías de seguros. }\end{array}$ \\
\hline
\end{tabular}




\begin{tabular}{|c|c|c|}
\hline Etapa & Acciones & Objetivos \\
\hline Etapa 03 & $\begin{array}{l}\text { Con las compañías de seguros } \\
\text { (potenciales clientes) se harán } \\
\text { actividades diferenciadas según } \\
\text { su segmentación: } \\
\text { - Premium: Contacto } \\
\text { constante a fin de generar } \\
\text { vínculos comerciales } \\
\text { promocionado la empresa, el } \\
\text { servicio y la especialización } \\
\text { técnica del equipo. } \\
\text { - Regulares: Contacto } \\
\text { moderado y envió de mailing } \\
\text { Con los corredores de seguros y } \\
\text { asegurados se realizarán visitas } \\
\text { y envío de mailing, ofreciendo a } \\
\text { estos como valor agregado el } \\
\text { conocimiento técnico y } \\
\text { experticia del equipo. }\end{array}$ & $\begin{array}{l}\text { El objetivo del contacto con } \\
\text { los potenciales clientes es } \\
\text { realizar la difusión de la } \\
\text { empresa concentrando la } \\
\text { atención en los clientes con } \\
\text { mayores pagos de } \\
\text { siniestralidades y por ende con } \\
\text { mayor posibilidad de ingresos } \\
\text { para la empresa. } \\
\text { El objetivo del contacto con } \\
\text { los corredores de seguros y } \\
\text { asegurados es desarrollar } \\
\text { relaciones de comunicación y } \\
\text { recomendación que permita a } \\
\text { la empresa, enterarse con } \\
\text { mayor facilidad de los } \\
\text { siniestros ocurridos y aś } \\
\text { acudir de manera oportuna y } \\
\text { precisa a las compañías de } \\
\text { seguros para ofrecer los } \\
\text { servicios. Adicionalmente se } \\
\text { busca a través de las } \\
\text { relaciones con los corredores y } \\
\text { asegurados, lograr su } \\
\text { recomendación con la } \\
\text { compañía de seguros ante la } \\
\text { ocurrencia de un siniestro. }\end{array}$ \\
\hline
\end{tabular}

Fuente: Elaboración propia

Las acciones de difusión y seguimiento permitirán conseguir a nuevos clientes además de fidelizarlos, logrando el posicionamiento de la empresa en el mercado.

Con esto se podrán cubrir las necesidades de los clientes (compañías de seguros) los cuales ante la ocurrencia de siniestros, demandan la determinación del monto o siniestralidad que se deberá abonar a favor del asegurado. 


\subsection{PROYECCIÓN DE VENTAS}

Del análisis de demanda hemos observado que:

a. El mercado de Primas de Seguros tiene una tendencia creciente

b. Las siniestralidades representan un $43 \%$ en promedio de las Primas Pagadas

c. El ingreso para el mercado de empresas ajustadoras de seguros de riesgos generales representa un $1.189 \%$ de la siniestralidad pagada

Por lo tanto proyectando las Primas de Seguros tenemos:

\section{Figura 3.1. Proyección de Primas y Siniestralidades (En Millones de}

\section{Nuevos Soles)}

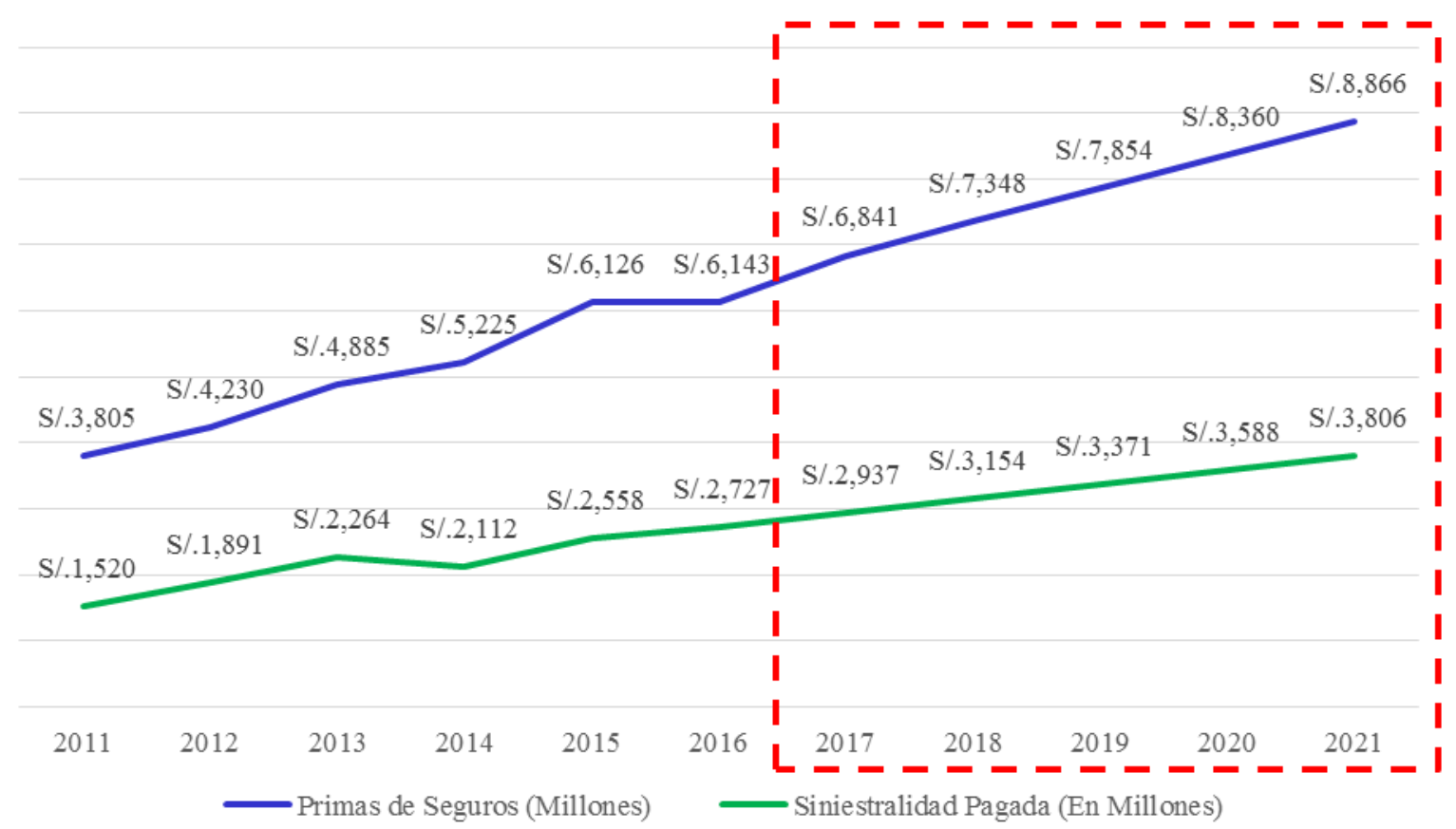

Fuente: Superintendencia de Banca, Seguros y Administradoras de Fondos de Pensiones, 2017, Boletín Estadístico de Seguros. Recuperado de

https://www.sbs.gob.pe/app/stats_net/stats/EstadisticaBoletinEstadistico.aspx?p=25\#

Asociación Peruana de Empresas de Seguros, 2017, Siniestros de Primas de Seguros Netas. Recuperado de http://www.apeseg.org.pe/php/sicsa/sinianual.php

Elaboración propia. 
Adicionalmente se establecen los siguientes criterios:

a. Considerando un escenario estricto y por ende realista, la empresa no formará parte de las 5 ajustadoras top del mercado (que concentran $76 \%$ de los ingresos del mercado). Por lo tanto su análisis comparativo y referencial estará relacionado a las 9 empresas fuera del top 5.

b. En la Tabla 2.14. (Participación de las Empresas Ajustadoras de Seguros en Porcentaje) se observa que entre los años 2011 y 2015, 4 empresas (de las 9 no pertenecientes al top 5) iniciaron sus actividades comerciales: FGR Perú Ajustadores de Seguros (año 2013), Baukost Ajustadores y Peritos de Seguros (año 2014), GD Ajustadores de Seguros S.A.C. (año 2012) y Perú Veritas Ajustadores de Seguros S.A.C. (año 2013).

Dado que el presente análisis pretende estimar una proyección de ventas, se ha utilizado como referencia a las 4 empresas que iniciaron sus operaciones entre el 2011 y 2015. De esta manera la proyección está fundamentada con datos reales del mercado, evitándose la subjetividad en la determinación de los resultados obtenidos. Sin embargo como el análisis considera un enfoque sumamente riguroso, las dos empresas con mayor crecimiento desde su implementación (FGR Perú Ajustadores de Seguros y Baukost Ajustadores y Peritos de Seguros) han sido excluidas del análisis.

Es importante señalar que la exclusión de FGR Perú Ajustadores de Seguros y Baukost Ajustadores y Peritos de Seguros, se ha realizado con el único propósito de mantener un 
enfoque riguroso (a fin de ser lo más realistas posibles); pues en el particular caso de FGR Perú, su crecimiento ha sido notable (7\% de participación en el mercado al 2015) y por tal razón se le ha considerado en las estrategias a seguir (Ver Análisis FODA del Capítulo II).

Tras la exclusión de las 2 empresas con mayor crecimiento, la muestra referencial se compone de las empresas: GD Ajustadores de Seguros SAC y Perú Veritas Ajustadores de Seguros SAC, las cuales han tenido una participación inicial de $0.876 \%$ y $0.736 \%$ respectivamente. Por lo tanto, para determinar la participación inicial se ha escogido un indicador representativo de ambas participaciones iniciales, siendo este indicador: el promedio.

Por consiguiente la participación inicial de la empresa será:

(Participación: GD Ajustadores de

Seguros S.A.C. en el año 2012)

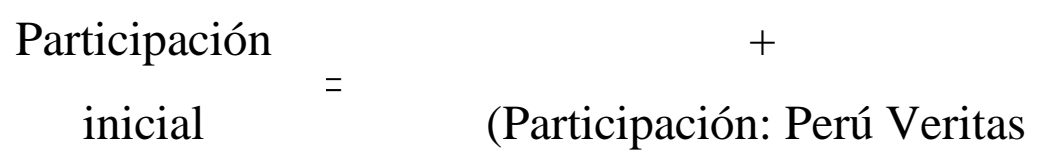

Ajustadores de Seguros S.A.C. en

el año 2013)

Es decir:

$$
\text { Participación Inicial }=\frac{0.876 \%+0.736 \%}{2}
$$

Participación Inicial $=0.806 \%$ 
Respecto a la participación en los años siguientes, la estimación considera la pendiente (indicador matemático que evalúa la razón del incremento de un conjunto de datos) de la empresa que menos creció (nuevamente con el propósito de considerar un escenario estricto y realista), entre las 2 que componen la muestra referencial: GD Ajustadores de Seguros SAC y Perú Veritas Ajustadores de Seguros SAC.

\section{Tabla 3.2. Pendiente de las empresas que iniciaron sus operaciones} entre los años 2011 y 2015

\begin{tabular}{|c|c|c|c|c|c|c|}
\hline PROVEEDORES & 2011 & 2012 & 2013 & 2014 & 2015 & $\begin{array}{l}\text { Pendiente de } \\
\text { Crecimiento }\end{array}$ \\
\hline HERRERA D.K.P. - AJUSTADORES DE SEGUROS & $37.0 \%$ & $42.3 \%$ & $35.3 \%$ & $41.7 \%$ & $32.5 \%$ & - \\
\hline CRAWFORD PERU S.A. AJUSTADORES Y PERITOS DE SEGUROS & $23.5 \%$ & $18.8 \%$ & $23.5 \%$ & $19.6 \%$ & $21.4 \%$ & - \\
\hline W. MOLLER AJUSTADORES Y PERITOS DE SEGUROS S.A.C. & $6.0 \%$ & $7.1 \%$ & $10.4 \%$ & $6.9 \%$ & $7.9 \%$ & - \\
\hline FGR PERU AJUSTADORES DE SEGUROS & - & - & $0.4 \%$ & $4.9 \%$ & $7.5 \%$ & $3.5 \%$ \\
\hline IRIARTE Y ASOCIADOS S.A. AJUSTADORES Y PERITOSDE SEGUROS & $7.1 \%$ & $7.2 \%$ & $6.3 \%$ & $5.7 \%$ & $7.2 \%$ & - \\
\hline BAUKOST AJUSTADORES Y PERITOS DE SEGUROS & - & - & - & $2.0 \%$ & $4.9 \%$ & $2.9 \%$ \\
\hline MCLARENS TOPLIS PERU AJUSTADORES Y PERITOS DE SEGUROS S.A. & $10.0 \%$ & $9.8 \%$ & $6.9 \%$ & $4.7 \%$ & $3.7 \%$ & - \\
\hline BISI \& ROMERO ASOCIADOS S.A. AJUSTADORES DE SEGUROS & $3.1 \%$ & $2.3 \%$ & $1.7 \%$ & $3.1 \%$ & $2.8 \%$ & - \\
\hline BARRON AJUSTADORES DE SEGUROS S.A.C. & $5.6 \%$ & $3.3 \%$ & $3.5 \%$ & $2.8 \%$ & $2.2 \%$ & - \\
\hline GD AJUSTADORES DE SEGUROS S.A.C. & - & $0.9 \%$ & $1.9 \%$ & $1.8 \%$ & $2.0 \%$ & $0.3 \%$ \\
\hline OSBERK AJUSTADORES DE SEGUROS S.A. & $2.2 \%$ & $2.6 \%$ & $4.4 \%$ & $1.1 \%$ & $1.8 \%$ & - \\
\hline PERU VERITAS AJUSTADORES DE SEGUROS S.A.C. & - & - & $0.7 \%$ & $1.2 \%$ & $1.3 \%$ & $0.3 \%$ \\
\hline ACM AJUSTADORES Y PERITOS DE SEGUROS S.A.C. & $1.4 \%$ & $1.5 \%$ & $1.0 \%$ & $0.9 \%$ & $1.0 \%$ & - \\
\hline TOTAL & $100.0 \%$ & $100.0 \%$ & $100.0 \%$ & $100.0 \%$ & $100.0 \%$ & \\
\hline
\end{tabular}

Fuente: Superintendencia de Banca, Seguros y Administradoras de Fondos de Pensiones, 2017, Intermediarios y Auxiliares de Seguros. Recuperado de https://www.sbs.gob.pe/app/stats_net/stats/EstadisticaBoletinEstadistico.aspx?p=26\#.

Elaboración propia.

Por lo tanto, el crecimiento de la empresa será considerando una pendiente de $0.3 \%$ por año (Ver Tabla 3.2).

Finalmente aplicaremos una función lineal que defina el comportamiento de la participación en los 5 primeros años de la empresa.

Dado que toda función lineal posee la forma:

$$
Y=m X+b
$$


Donde:

$\mathrm{m}=$ pendiente

$\mathrm{X}=$ el valor que asume la variable independiente (este caso los años)

$\mathrm{b}=\mathrm{el}$ punto inicial

Hallaremos el valor de 'b' reemplazando en la fórmula el valor de participación inicial (cuando $\mathrm{X}=1$ ) y la pendiente $=0.3 \%$ :

Siendo el resultado para $b=0.52 \%$.

Por lo tanto la función que define la proyección de ventas, basada en el porcentaje de participación del mercado será:

$$
\text { Partipación por Año }=0.3 \% X+0.52 \%
$$

Donde $\mathrm{X}$ asume los valores para los años 1, 2, 3,4 y 5 .

Como resultado se tiene la siguiente participación por años:

Tabla 3.3. Proyección de participación en el mercado de la empresa para los primeros 5 años

\begin{tabular}{cc}
\hline Año & $\begin{array}{c}\text { Participación en el } \\
\text { Mercado }\end{array}$ \\
\hline 1 & $0.806 \%$ \\
2 & $1.095 \%$ \\
3 & $1.384 \%$ \\
4 & $1.673 \%$ \\
5 & $1.962 \%$ \\
\hline
\end{tabular}

Fuente: Elaboración propia. 
Por lo tanto, considerando que los 5 primeros comprende el periodo 2017-2021; tenemos la siguiente proyeccion de ventas: 
Tabla 3.4. Proyección de Ventas.

\begin{tabular}{|c|c|c|c|c|c|c|c|c|c|}
\hline \multirow{2}{*}{$\begin{array}{l}\text { Año } \\
2011\end{array}$} & $\begin{array}{c}\text { Primas de } \\
\text { Seguros } \\
\text { (En } \\
\text { Millones) } \\
\text { (A) } \\
\end{array}$ & \multirow{2}{*}{$\begin{array}{c}\begin{array}{c}\text { Siniestralidad / } \\
\text { Primas }\end{array} \\
\text { (B) } \\
40 \%\end{array}$} & \multicolumn{2}{|c|}{ 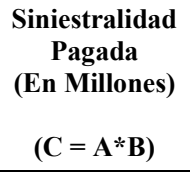 } & \multirow{2}{*}{$\begin{array}{c}\begin{array}{c}\text { Ratio para el } \\
\text { Mercado de } \\
\text { Ajustadores } \\
\text { (D) }\end{array} \\
1.2 \%\end{array}$} & \multirow{2}{*}{$\begin{array}{c}\begin{array}{c}\text { Ingresos para } \\
\text { el Mercado de } \\
\text { Ajustadores }\end{array} \\
\text { (E = C*D) } \\
\text { S/. 18,988,084 }\end{array}$} & \multirow[t]{2}{*}{$\begin{array}{c}\% \text { de } \\
\text { Participación } \\
\text { Estimada } \\
\text { (F) } \\
\end{array}$} & \multicolumn{2}{|c|}{$\begin{array}{c}\text { Ingresos para la } \\
\text { Empresa } \\
\left(\mathbf{G}=\mathbf{E}^{*} \mathbf{F}\right)\end{array}$} \\
\hline & S/. $\quad 3,805$ & & $\mathrm{~S} /$. & 1,520 & & & & & \\
\hline 2012 & S/. $\quad 4,230$ & $45 \%$ & $\mathrm{~S} /$. & 1,891 & $1.0 \%$ & S/. 19,335,127 & & & \\
\hline 2013 & S/. $\quad 4,885$ & $46 \%$ & $\mathrm{~S} /$. & 2,264 & $1.0 \%$ & S/. 23,454,468 & & & \\
\hline 2014 & S/. $\quad 5,225$ & $40 \%$ & $\mathrm{~S} /$ & 2,112 & $1.4 \%$ & S/. 29,573,104 & & & \\
\hline 2015 & S/. $\quad 6,126$ & $42 \%$ & $\mathrm{~S} /$. & 2,558 & $1.2 \%$ & S/. 31,620,239 & & & \\
\hline 2016 & S/. $\quad 6,143$ & $44 \%$ & $\mathrm{~S} /$. & 2,727 & & & & & \\
\hline 2017 & $\mathrm{~S} / . \quad 6,841$ & $43 \%$ & $\mathrm{~S} /$. & 2,937 & $1.2 \%$ & S/. 34,909,040 & $0.806 \%$ & $\mathrm{~S} /$. & 281,496 \\
\hline 2018 & S/. $\quad 7,348$ & $43 \%$ & $\mathrm{~S} /$. & 3,154 & $1.2 \%$ & S/. 37,492,371 & $1.095 \%$ & $\mathrm{~S} /$. & 410,604 \\
\hline 2019 & S/. $\quad \mathbf{7 , 8 5 4}$ & $43 \%$ & $\mathrm{~S} /$. & 3,371 & $1.2 \%$ & S/. 40,075,703 & $1.384 \%$ & S/. & 554,633 \\
\hline 2020 & $\mathrm{~S} / . \quad \mathbf{8 , 3 6 0}$ & $43 \%$ & $\mathrm{~S} /$. & 3,588 & $1.2 \%$ & S/. 42,659,035 & $1.673 \%$ & $\mathrm{~S} /$. & 713,583 \\
\hline 2021 & S/. $\quad 8,866$ & $43 \%$ & $\mathrm{~S} /$. & 3,806 & $1.2 \%$ & S/. 45,242,366 & $1.962 \%$ & $\mathrm{~S} /$. & 887,454 \\
\hline
\end{tabular}

Fuente: Superintendencia de Banca, Seguros y Administradoras de Fondos de Pensiones, 2017, Boletín Estadístico de Seguros. Recuperado de https://www.sbs.gob.pe/app/stats_net/stats/EstadisticaBoletinEstadistico.aspx?p=25\#

Asociación Peruana de Empresas de Seguros, 2017, Siniestros de Primas de Seguros Netas. Recuperado de http://www.apeseg.org.pe/php/sicsa/sinianual.php

Elaboración propia.

Elaboración propia. 


\section{CAPÍtULO IV}

\section{Plan De Operaciones}

Para Heizer J. y Render B. (2009) la administración de operaciones es el conjunto de actividades que crean valor en forma de bienes y servicios al transformar insumos a productos terminados. Estas actividades se realizan y suceden en todas las organizaciones. Estos autores plantean 03 puntos críticos en la elaboración de un plan de operaciones: "Estrategia de localización", "Estrategia de distribución de instalaciones" y "Recursos humanos y diseño de trabajo".

En el presente capitulo presentará el plan de operaciones del proyecto en el que se explican estas 03 decisiones crítica y el cómo se han sustentado para las decisiones de la empresa.

\subsection{UBICACIÓN GEOGRÁFICA}

El presente sub capitulo desarrolla el análisis de la ubicación ideal del presente proyecto, considerando para ello, las operaciones de la empresa, los stakeholders, los locales disponibles y los factores locacionales considerados relevantes para nuestro análisis.

\subsubsection{Macro localización}

Nuestro proyecto se enfoca en el Lima Metropolitana, dentro de dicha zona, se ha seleccionado el distrito de Pueblo Libre, toda vez que en el distrito se concentra la mayor posibilidad de oficinas acorde a nuestro requerimiento. Asimismo, el 
Distrito de Pueblo Libre nos permite acceder o estar muy cerca de la ubicación de nuestros clientes, los cuales se ubican en el Distrito de San Isidro.

Figura 4.1. Mapa Distrital de Lima

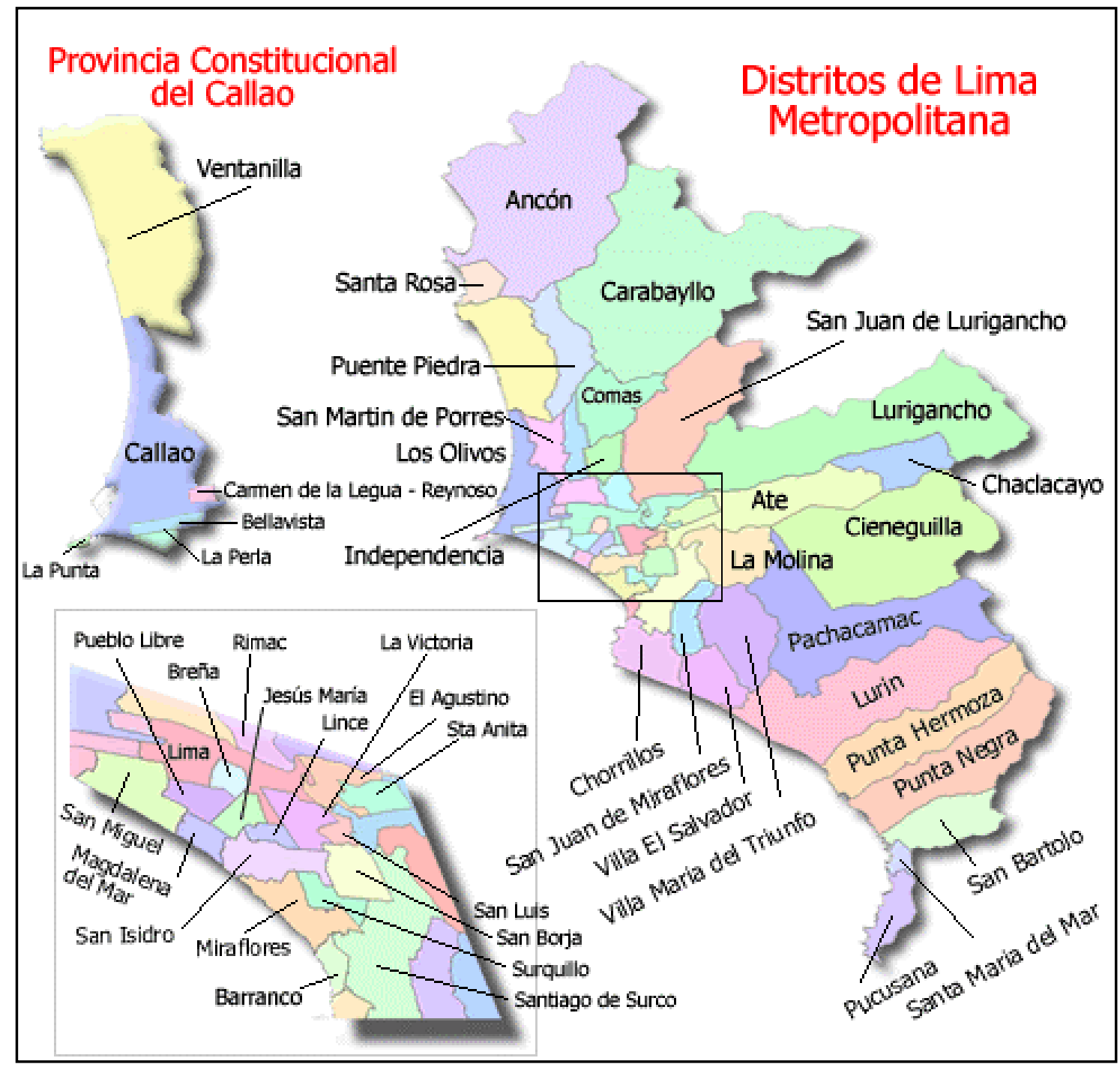

En el distrito de San Isidro se encuentran ubicadas las principales compañías de seguros: Rímac Seguros, Pacifico Seguros, Mapfre y La Positiva.

Fuente: Extracción de cartografía Lima (2012). 


\subsubsection{Micro localización}

El análisis de micro localización busca determinar la ubicación específica idónea para la empresa ajustadora de seguros, para lo cual se toman en cuenta las operaciones de la empresa frente a las empresas de seguros, empresas aseguradas, proveedores y personal; asimismo evalúa los principales factores de localización que afectan al proyecto.

\section{a. Alternativas de localización}

A continuación se analizan las alternativas actualmente disponibles de locales en alquiler.

Para la identificación de los locales alternativos se recurrió a fuentes como la información inmobiliaria publicada en la página web del Diario El Comercio, se contactó con referidos, para que nos identifique locales disponibles en las zonas de interés y se realizaron asimismo visitas a las zonas de Pueblo Libre.

\section{Tabla 4.1. Locales disponibles para alternativas de localización}

\begin{tabular}{|c|l|c|c|c|c|c|}
\hline Opciòn & Ubicaciòn Distrito de Pueblo Libre & Areas $\mathbf{M}^{2}$ & Ambientes & Alquiler mensual & Anunciante & Fecha \\
\hline 1 & Calle Clovis -Cdra. 11 Av. Bolívar & 155 & 4 & US\$ 750.00 & URBANIA & 30-ene-17 \\
\hline 2 & Cdra. 16 Av. Bolívar & 290 & 4 & US\$3500.00 & URBANIA & 01-feb-17 \\
\hline 3 & José Morelos 210 & 200 & 6 & US\$ 600.00 & REFERIDO & 01-feb-17 \\
\hline 4 & Av. Brasil 2610- 3er Piso & 110 & 5 & US\$1100.00 & LOCANTO & 25 -ene-17 \\
\hline 5 & Calle Belgrano 180 & 320 & 4 & US\$1400.00 & MERCADO LIBRE & 28 -ene-17 \\
\hline 6 & Carlos VidaL- Cdra. 1 de La Mar & 285 & 5 & US\$2500.00 & TROVIT & 01-feb-17 \\
\hline
\end{tabular}

Fuente: Elaboración propia. 


\section{b. Factores de localización}

Con el fin de seleccionar entre las alternativas de local disponible para la empresa aseguradora, se analizaron previamente los criterios más importantes sobre los cuales realizar la evaluación de cada alternativa.

\section{- Relevancia de la ubicación del local}

Nuestra empresa y sus operaciones, nos permite ubicarnos en cualquier local que cuente con la infraestructura requerida. Nuestro trabajo para la captación de clientes se realiza en el campo, es decir fuera de ella. Sin embargo para iniciar las operaciones requerimos de un local adecuado en lugar y precio. Razón por la cual se prefiere la zona de Pueblo Libre.

Se realizaron varias visitas de inspección al distrito de Pueblo Libre para identificar locales alternativos, asimismo se recurrió a las distintas fuentes de información para identificar locales tales como periódicos, revistas especializadas, páginas web inmobiliarias, referidos.

\section{- Seguridad}

La seguridad empresarial es un asunto de principal importancia para todos, en tal sentido una ubicación que involucre una menor exposición a zonas de delincuencia, violencia, peligro vehicular será más 
adecuada y preferida por las potenciales empresas a asegurar.

Para la evaluación de este factor se consideró como zonas de menor seguridad las cercanas a Magdalena, Lince, Av., La Marina y las de mayor seguridad como las zonas residenciales, las cercanas a establecimientos comerciales reconocidos, a la municipalidad, comisaría y en donde se puede observar mayor orden y tranquilidad, según las visitas realizadas al distrito.

Por otro lado, se tiene en cuenta la zonificación por compatibilidad de uso que efectúa la municipalidad del distrito.

\section{- Accesibilidad}

La accesibilidad está referida a la facilidad para los clientes, empresas, proveedores, la cercanía a avenidas principales contribuye con este factor, su importancia en la evaluación de la localización sería menor respecto al factor seguridad.

Una consideración adicional respecto a la accesibilidad podría tener en cuenta la predisposición de los clientes para desplazarse hasta la zona, sin embargo es preciso indicar que los factores de localización en este análisis pretenden determinar la mejor ubicación dentro del distrito de Pueblo Libre, por lo que esta consideración sólo se analiza al 
momento de determinar las estratégicas para captar al personal idónea para la empresa.

\section{- Baja contaminación ambiental y acústica}

La contaminación acústica como el sonido de las bocinas de los carros, el transporte público y negocios cuyas actividades impliquen distracción a los colaboradores perjudicaría directamente el desarrollo de las actividades, reuniones dificultando las labores.

Por otro lado la contaminación ambiental que pudiera presentarse en la localización seleccionada también debe incorporarse como un factor negativo en el análisis.

Dada estas razones se consideró finalmente locales cercanos a Parques.

\section{- Costo del Alquiler del local}

Aparte de considerar aspectos cualitativos que permiten ofrecer una mayor comodidad y seguridad a los clientes y colaboradores, lo cual contribuye de manera positiva a la preferencia de la zona, es necesario incorporar en la evaluación el factor relacionado a la inversión requerida en el alquiler y remodelación del local para su funcionamiento como empresa. 
De los resultados obtenidos se concluye que la opción 3 ubicada en la cuadra 3 de la Av. Sucre, en Jr. Gral. Artigas, presenta las mejores características, siendo la accesibilidad, seguridad y el costo del alquiler del local los factores que influencian en mayor medida la decisión final.

\section{- Ubicación de principales empresas competidoras}

A fin de conocer la concentración de empresas competidoras en el distrito se identificó sus respectivas localizaciones.

A continuación se presenta un detalle con la ubicación de las principales empresas de la competencia.

\section{Tabla 4.2. Ubicación de principales empresas competidores}

\begin{tabular}{|l|l|c|}
\hline \multicolumn{1}{|c|}{ Empresas Ajustadoras de Seguros } & \multicolumn{1}{c|}{ Ubicaciòn } & Distrito \\
\hline HERRERA - DKP & Av. Carlos Gonzales 275 Of. 203 & SAN MIGUEL \\
\hline CRAWFORD PERU S.A. & Av. Paseo de la Republica Nro. 3195 Int. 801 & SAN ISIDRO \\
\hline W.MOLLER ORG.INT.AJUST.PERIT. DE SEG.SAC & Cal. Porta Nro. 107 Int. 302 & MIRAFLORES \\
\hline FGR PERU AJUSTADORES DE SEGUROS SA & Av. Paseo de la Republica Nro. 3195 Int. 702 & SAN ISIDRO \\
\hline IRIARTE \& ASOCIADOS S.CIVIL DE R.L. & Jr. Miro Quesada Nro. 191 Int. 510 & LIMA \\
\hline BAUKOST AJUSTADORES Y PERITOS DE SEGUROS SAC & Jr. Monserrate Nro. 381- Urb. Las Gardenias & SURCO \\
\hline
\end{tabular}

Fuente: Elaboración propia.

\section{c. Resumen}

El local seleccionado está ubicado en la Cuadra 3 de la Av. Sucre, en José Morellos 210, en el Distrito de Pueblo Libre.

Cuenta con la mejor accesibilidad por ubicarse en una avenida amplia y de fácil acceso tanto en transporte público como en transporte particular, la cual posee una 
vía alterna que facilita el estacionamiento. Además se encuentra en una zona residencial compatible con el uso de empresas, frente a un Parque y con establecimientos como Starbucks, Bembos, Tay Loy y restaurantes cercanos. Muy cerca se está construyendo un Mall.

\subsection{INFRAESTRUCTURA}

Además del punto anterior (localización), es importante definir con cuidado la distribución interna de la empresa, esto con la finalidad de lograr una disposición ordenada y eficiente del mobiliario y equipo, alineado a los movimientos lógicos del día a día. Esto maximizará el uso del equipo, el tiempo y las aptitudes de los trabajadores.

Las instalaciones necesarias para una empresa de este giro incluyen, entre otras, las siguientes áreas:
a. Gerencia General
b. Staff de Ajustadores y Peritos
c. Asistente de Operaciones

Para determinar la infraestructura de la empresa, debemos primero determinar el tamaño de la misma, considerando:
a. Cantidad de personal
b. Cantidad de empresas atender
c. Cantidad de visitas a recibir
d. Cantidad de proveedores 
Figura 4.2. Distribución interna de la empresa:

\begin{tabular}{|c|c|c|c|c|c|c|}
\hline \multicolumn{4}{|c|}{ ESTACIONAMIENTOS } & \multicolumn{2}{|c|}{$\begin{array}{l}\text { GERENCIA } \\
\text { GENERAL }\end{array}$} & \multirow{2}{*}{ 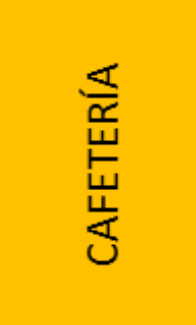 } \\
\hline 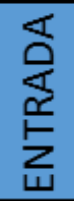 & 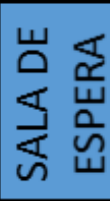 & 竞 & 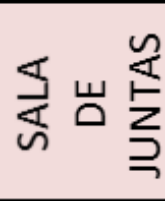 & $\sum_{i}^{\dot{\alpha}}$ & 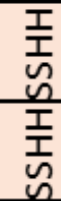 & \\
\hline & \multicolumn{3}{|c|}{ ESTACIONAMIENTOS } & \multicolumn{2}{|c|}{$\begin{array}{c}\text { STAFF DE } \\
\text { AJUSTADORES }\end{array}$} & $\mathrm{DE}$ \\
\hline
\end{tabular}

Fuente: Elaboración Propia

Tabla 4.3. Requerimiento de espacio para áreas de la empresa

\begin{tabular}{|c|c|c|c|}
\hline AREA & PERSONAS & OFICINAS & CARACTERISTICA \\
\hline GERENCIA GENERAL & 1 & 1 & PERSONAL \\
\hline ASISTENTE DE OPERACIONES & 1 & & \\
\hline STAFF DE AJUSTADORES & 2 & 1 & COMPARTIDA 2 \\
\hline SALA DE REUNIONES Y USOS & & & \\
\hline MULTIPLES & & 1 & PERSONAL \\
\hline BAÑOS & & 2 & PERSONAL \\
\hline TOTAL OFICINAS & 4 & 5 & \\
\hline
\end{tabular}

Fuente: Elaboración Propia

\subsection{PROCESO PRODUCTIVO}

El Proceso de ajuste de siniestros tiene las siguientes actividades:

a. Recibe el nombramiento de la compañía de seguros.

b. Inspección el siniestro y analiza sus circunstancias, contexto y/o antecedentes.

c. Se genera un reporte básico y/o preliminar a la aseguradora.

d. Se pide vía carta al asegurado la documentación correspondiente para el estudio del Siniestro. 
e. Se pide vía carta al corredor la información y/o documentación necesaria para el estudio del siniestro.

f. En caso sea necesario envía recordatorios de la solicitud de información a ambas partes.

g. Revisa la cobertura del siniestro.

h. Calcula y define la pérdida y monto indemnizable.

i. Realiza la liquidación del siniestro (convenio de ajuste).

Figura 4.3. Flujo de actividades en un proceso de Ajuste

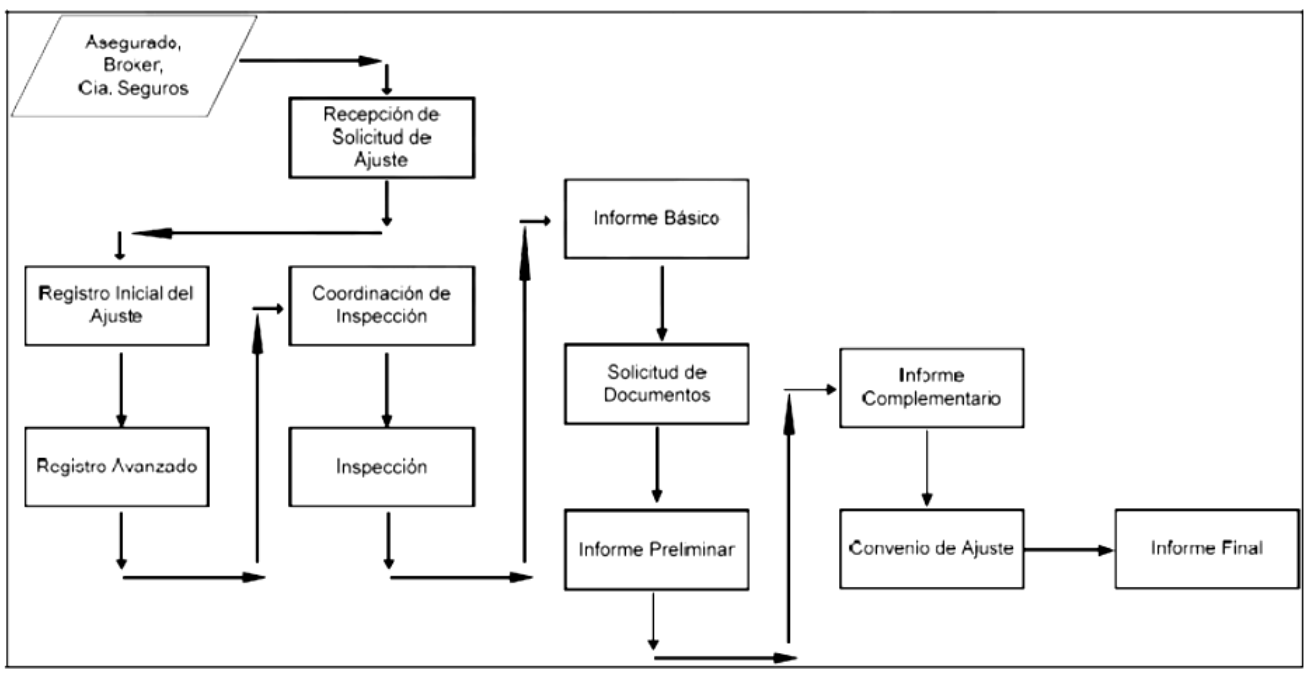

Fuente: García, Iván. Análisis, Diseño e Implementación de una Plataforma Web de Apoyo a la Gestión de Casos de Ajuste de Riesgos Generales. 2011. p 8.

\subsection{REGULACIÓN DE LICENCIAS Y POLÍTICAS}

\subsubsection{Análisis del marco legal}

De acuerdo a la información reflejada en la Asociación de Supervisores de Seguros de América Latina (2016):

En el Perú, el proceso de desregulación se inició en el año 1991 y fue con el Decreto Legislativo $N^{\circ} 770$ "Ley General de Instituciones Bancarias, Financieras y de Seguros" de octubre de 1993, que se liberalizó el 
mercado de seguros. A partir de entonces, se estableció la libertad de contratar seguros en el extranjero, la libertad de fijar las tarifas y el contenido de las pólizas, se eliminó el monopolio del reaseguro y se contribuyó a la creación de un mercado competitivo, que también propició la inversión extranjera.

En diciembre de 1996, fue promulgada la Ley $\mathrm{N}^{\circ}$ 26702, actual Ley General del Sistema Financiero y del Sistema de Seguros y Orgánica de la SBS, que incorporó disposiciones reguladoras de la actividad aseguradora y los requisitos de solvencia necesarios para desarrollar la actividad, incluyendo además, la posibilidad de constituir como subsidiarias a una empresa financiera y/o a una empresa prestadora de salud.

Asimismo, en noviembre de 2012, fue promulgada la Ley N 29946 - Ley de Contrato de Seguro, mediante la cual se buscó establecer un marco legal claro y específico sobre los derechos y obligaciones de las partes que intervienen en un contrato de seguros (asegurados y compañías de seguros), a fin de otorgar un trato justo y equitativo para los contratantes. Cabe mencionar que el marco jurídico que regulaba al contrato de seguro era el Código de Comercio Peruano de 1902. 
En el marco de la Ley de Contrato de Seguro se emitieron, posteriormente, las siguientes normas: Reglamento de Transparencia de Información y Contratación de Seguros (Resolución SBS N ${ }^{\circ} 3199$ 2013), Reglamento del Pago de Primas de Pólizas de Seguro (Resolución SBS N³198-2013), Reglamento para el Uso de Pólizas de Seguro Electrónicas (Resolución SBS N 3201-2013), Reglamento para la gestión y pago de siniestros (Resolución SBS N $3202-$ 2013) y Reglamento de la Reserva de Siniestros ( Resolución SBS N 4095-2013).

De esta forma, acorde con los estándares internacionales, la Superintendencia de Banca, Seguros y Administradoras Privadas de Fondos de Pensiones vienen ejerciendo una supervisión especializada, integral y discrecional. Especializada, debido a que propicia una supervisión en función al tipo de riesgos que enfrentan las entidades supervisadas; integral, por la apreciación global y cualitativa del análisis y manejo de riesgos; y discrecional, en función a los problemas propios que pudieran enfrentar dichas empresas.

Este esquema de supervisión basado en la identificación, evaluación y control de los riesgos que enfrentan las empresas del sistema de seguros pone especial énfasis en el análisis de los riesgos de seguros, inversiones, reaseguros, operacional y lavado de activos. 
La SBS es la institución encargada de regular el mercado de seguros: Compañías de Seguros, Corredores de Seguros y Ajustadores de Seguros.

\subsubsection{Forma societaria}

A través de la Resolución SBS N 1797-2011 se aprueba el REGLAMENTO DEL REGISTRO DE INTERMEDIARIOS Y AUXILIARES DE SEGUROS, que regula el funcionamiento y organización de las empresas ajustadoras de seguros. Entre las principales características de las formas societarias que se puede adoptar se encuentran:

\begin{tabular}{|c|c|c|c|c|}
\hline \multicolumn{2}{|c|}{ Código Civil } & D. Ley 21621 & \multicolumn{2}{|c|}{ Ley General de Sociedades 26887} \\
\hline $\begin{array}{l}\text { Asociación } \\
\text { Civil }\end{array}$ & $\begin{array}{c}\text { Empresa Individual de } \\
\text { Responsabilidad } \\
\text { Limitada E. I. R. L. }\end{array}$ & $\begin{array}{c}\text { Sociedad Comercial } \\
\text { de Responsabilidad } \\
\text { Limitada S. R. L. }\end{array}$ & Sociedad Anónima S.A. & $\begin{array}{l}\text { Sociedad Anónima } \\
\text { Cerrada S. A. C. }\end{array}$ \\
\hline $\begin{array}{l}\text { Organización estable } \\
\text { personas } \\
\text { jurídicas, o naturales }\end{array}$ & 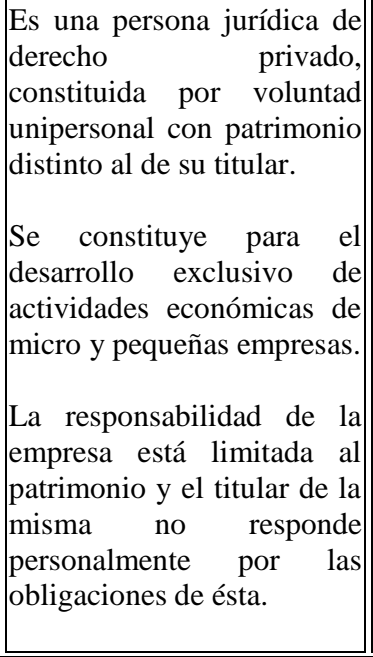 & 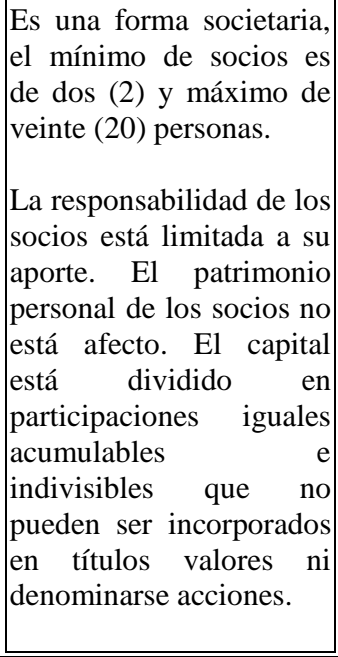 & 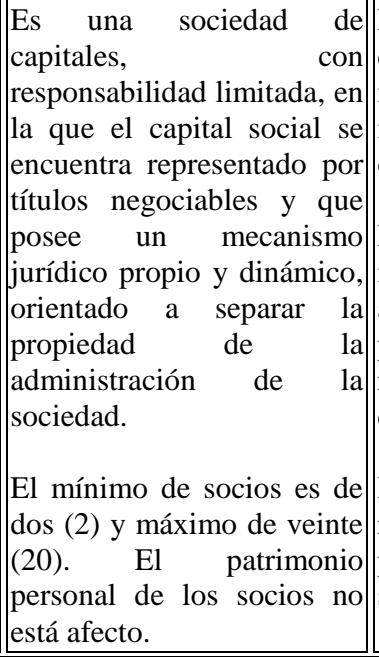 & 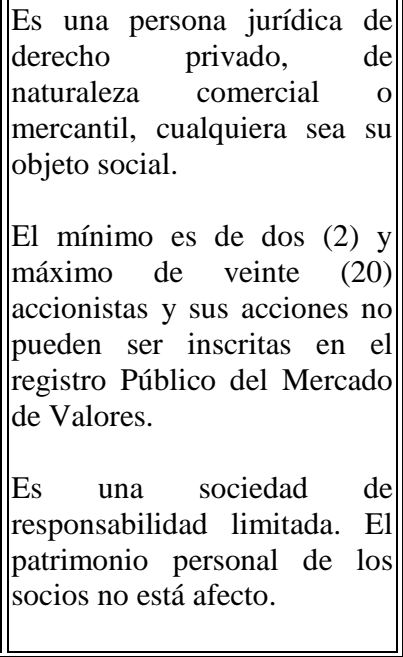 \\
\hline
\end{tabular}

\section{Tabla 4.4. Formas societarias de constitución empresarial}




\begin{tabular}{|c|c|c|c|c|}
\hline \begin{tabular}{||lrr} 
Asamblea & General & de \\
Asociados, & órgano \\
supremo de & asociación \\
compuesta & por & los \\
asociados. & \\
Consejo Directivo, el \\
estatuto de la Asociación \\
fija los miembros del \\
consejo & directivo, \\
presidente y funciones.
\end{tabular} & \begin{tabular}{|l} 
Titular: órgano máximo de \\
la empresa que tiene a su \\
cargo la decisión de los \\
bienes y actividades \\
Gerencia: órgano que tiene \\
a su cargo la administración \\
y representación de la \\
empresa, es designado por \\
el titular. El titular, puede \\
asumir el cargo de gerente, \\
en cuyo caso tendrá las \\
facultades, deberes \\
responsabilidades de ambos \\
cargos, debiendo \\
denominársele \\
Gerente. Titular
\end{tabular} & \begin{tabular}{|llr} 
Junta & General & de \\
Socios: representa & a \\
todos los socios de la \\
empresa \\
Gerente General.: es el \\
encargado de la dirección \\
y administración de la \\
sociedad, goza de las \\
facultades generales y \\
especiales \\
representante procesal \\
Sub-Gerente: reemplaza \\
al gerente en caso de \\
ausencia.
\end{tabular} & 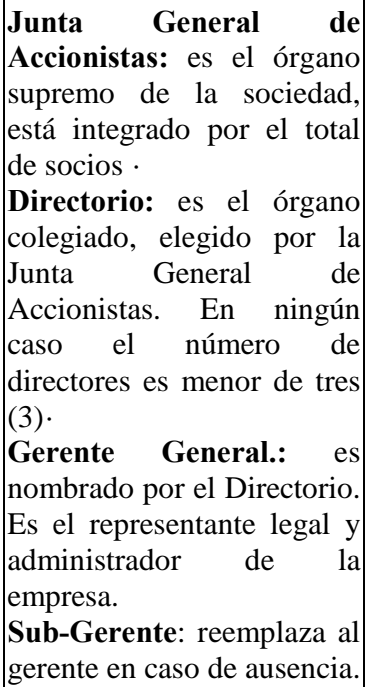 & \begin{tabular}{|l} 
Junta General \\
Accionistas: es el órgano \\
supremo de la sociedad, está \\
integrado por el total de \\
socios que conforman la \\
empresa. \\
Gerente General.: es la \\
persona en quién recae la \\
representación legal y de \\
gestión de la sociedad, es \\
quién convoca a la Junta de \\
Accionistas \\
Sub-Gerente: reemplaza al \\
gerente en caso de ausencia. \\
El Directorio: es facultativo \\
(según la LGS).
\end{tabular} \\
\hline
\end{tabular}

Fuente: Constitución de empresas. Lima Produce, 2005. Recuperado de

http://www.produce.gob.pe/industria/competitividad/constitucion.php

La forma societaria que se adopta es la Sociedad Anónima Cerrada, bajo la denominación de "Moreno \& Pacora Ajustadores de Seguros." como razón social.

La Razón por la que se eligió una S.A.C. para fundar la empresa radica en que esta puede funcionar sin un directorio, con el que actualmente no se podría contar, además de que no se tienen acciones inscritas en el Registro Público del Mercado de Valores pero no se ve limitada con la posibilidad de manejar grandes capitales.

El proceso de constitución de la sociedad es como sigue:

Tabla 4.5. Proceso de constitución de la sociedad

\begin{tabular}{cll}
\hline Ámbito & \multicolumn{1}{c}{ Ítems } & \multicolumn{1}{c}{ Costo } \\
\hline Tramite Interno & Orientación y asesoría & $\mathrm{S} /$. \\
Tramite Interno & Reunir requisitos & - \\
Tramite Interno & Elaboración de la minuta &
\end{tabular}




\begin{tabular}{lll} 
Tramite Interno & $\begin{array}{l}\text { Suscripción de la minuta } \\
\text { por un abogado y los } \\
\text { socios de la empresa }\end{array}$ \\
Notaria & $\begin{array}{l}\text { Escritura Pública } \\
\text { Tarifa social reducida }\end{array}$ & $\mathrm{S} / .300$ \\
Notaria & $\begin{array}{l}\text { Inscripción en el Registro } \\
\text { Mercantil }\end{array}$ & $\mathrm{S} / .35$ \\
SUNARP & RUC & $\mathrm{S} /$. \\
SUNAT & $\begin{array}{l}\text { Comprobante de Pago } \\
\text { SUNAT }\end{array}$ & $\mathrm{S} / .178,38$ \\
Municipalidad & $\begin{array}{l}\text { Licencia Funcionamiento } \\
\text { Notaria }\end{array}$ & \begin{tabular}{l} 
Legalización de libros \\
\multicolumn{2}{c}{ Costo de Constitución }
\end{tabular} \\
\hline
\end{tabular}

\subsubsection{Creación y funcionamiento}

Para la creación de la empresa es necesario cumplir con las exigencias de la SBS, por otro lado una vez constituida la empresa, deberá cumplirse con los requisitos del municipio de Pueblo Libre para su funcionamiento.

\subsubsection{Requisitos para postular al Registro de Intermediarios y} Auxiliares de Seguros - SBS Y AFP

Para la Superintendencia de Banca, Seguros y AFP (2017) los requisitos para postular al registro de intermediarios y auxiliares de seguros pasan por presentar la solicitud proporcionada por la Superintendencia, indicando si van a operar en seguro marítimo y/o generales, adjuntando los siguientes documentos:

- Llenar la solicitud de inscripción 
- Proyecto de minuta de constitución social consignando como objeto social exclusivo la prestación de servicios de ajuste de siniestros y/o peritaje de seguros, con un capital social íntegramente suscrito y pagado en efectivo no menor de cinco (5) Unidades Impositivas Tributarias vigentes a la fecha de presentación de la solicitud.

- Currículum vitae documentado con referencia a la experiencia laboral y estudios en seguros, de los accionistas, socios, directores, gerentes y del representante legal que actuará como gerente general, el cual deberá estar inscrito en el Registro como ajustador de siniestros y/o perito de seguros persona natural, según la actividad para la que se solicita autorización de inscripción. El gerente general actuará como representante legal en todos aquellos actos que guarden relación directa con la actividad autorizada.

- Declaración Jurada de las personas antes mencionadas, de no encontrarse incursos en los impedimentos señalados en el Artículo $4^{\circ}$ de la Resolución S.B.S. № 1797-2011 Reglamento del Registro de Intermediarios y Auxiliares de Seguros.

- Copia del Documento Nacional de Identidad, Carnet de Extranjería o pasaporte de los socios, accionistas, directores, gerentes o titular gerente y de los representantes de la persona jurídica solicitante.

La documentación completa deberá ser entregada en la mesa de partes de las Oficinas de la Superintendencia a 
nivel nacional, con el fin de que puedan ser considerados como postulantes.

- Se verifica el cumplimiento de los requisitos establecidos.

- Se verifica en la Central de Riesgo de la SBS que los accionistas, directores, gerentes y el representante legal directa o indirectamente, no tengan créditos vencidos por más de ciento veinte (120) días, cuya cobranza haya sido requerida o que hayan ingresado a cobranza judicial, con alguna empresa supervisada por la Superintendencia.

- Se verifica que el proyecto de minuta esté de acuerdo con las disposiciones establecidas en el Reglamento del Registro de Intermediarios y Auxiliares de Seguros; en la Ley General del Sistema Financiero y del Sistema de Seguros y Orgánica de la SBS y de la Ley General de Sociedades, pudiendo realizar observaciones que deberán ser subsanadas en el plazo correspondiente.

- Una vez que la empresa en organización (postulante) haya subsanado las observaciones realizadas a la minuta, se le comunica mediante Oficio que puede proceder a inscribirla en los Registros Públicos, debiendo remitir una copia simple del Testimonio (no fotocopia) con la respectiva ficha de inscripción registral.

- Luego el solicitante deberá publicar su solicitud de registro en el diario oficial "El Peruano" y en otro diario de circulación nacional, por lo cual la Superintendencia entrega un modelo de aviso oficial. Durante los 15 días calendario siguientes a la publicación, se podrán presentar tachas a la solicitud de la empresa postulante, los mismo 
que de ser el caso deberán ser absueltos dentro del plazo otorgado, con la finalidad de pasar el expediente para su aprobación.

- Después de haberse aprobado a la empresa, se le indicará mediante Oficio el monto proporcional de la contribución que debe pagar y presentar la constancia de estar inscrito en el registro único de contribuyentes; remitiendo copias tanto del comprobante de pago de la contribución y del RUC.

- Posteriormente se emitirá la Resolución Autoritativa respectiva, la cual debe ser publicada por cuenta de la nueva empresa auxiliar de seguros en el diario oficial "El Peruano", remitiendo copia de la publicación, dentro de los diez (10) días de recibido el Oficio.

\subsubsection{Requisitos del Municipio de Pueblo Libre}

De acuerdo al Texto Único de Procedimientos Administrativos (TUPA 2016) de la Municipalidad Distrital de Pueblo Libre, para obtener la Licencia Municipal de Funcionamiento se debe presentar lo siguiente:

a. Formato de solicitud y Declaración Jurada.

b. Certificado de zonificación, conformidad de establecimiento y certificado de seguridad básica de Defensa Civil.

c. Copia de escritura pública de constitución (persona jurídica)

d. Adjuntar copia de RUC.

\section{Legislación}


a. Ley $\mathrm{N}^{\circ}$ 28976, Ley de Marco de Licencia de Funcionamiento

b. D.S. $\mathrm{N}^{\circ}$ 058-2014-PCM Reglamento de Inspecciones Técnicas de Seguridad en Edificaciones

c. Ordenanza $\mathrm{N}^{\circ} 261-\mathrm{MPL}$

d. Ordenanza $\mathrm{N}^{\circ} 486-\mathrm{MPL}$

e. Sección del TUPA referente al procedimiento de Licencias de Funcionamiento (Requisitos, Costos y Plazos)

f. Procedimiento Conjunto - Licencia de funcionamiento y anuncio de publicidad sencillo (Características)

g. Relación de autorizaciones sectoriales exigidas como requisitos previos para el otorgamiento de la licencia de funcionamiento, de acuerdo a la Ley $\mathrm{N}^{\circ} 28976$ - Ley Marco de Licencia de Funcionamiento.

\section{Procedimientos}

a. Estructura de costos del derecho (Licencias de Funcionamiento)

b. Clases de inspecciones de seguridad en Defensa Civil y criterios de evaluación

c. Índice de Usos - Ordenanza No 1017-MML (No incluye zona monumental) $(*)$

d. Plano de Zonificación - Ordenanza N N 1017-MML (Concordar con el plano de zona monumental)

e. Plano de Zonificación - Ordenanza Nº 1192-MML (zona monumental)

f. Índice de Usos - Ordenanza No 1192-MML (zona monumental): 
- Zona ZT1

- Zona ZT2

\subsubsection{Resumen de Resultados}

La empresa se constituirá como una Sociedad Anónima Cerrada bajo la razón social: "Moreno \& Pacora Ajustadores de Seguros S. A. C". De acuerdo a la normatividad vigente será sujeto al Impuesto a la Renta. La empresa será gravada con tributos como el Impuesto General a las Ventas, Impuesto Predial.

\subsection{COSTOS DE PRODUCCIÓN}

De acuerdo al Instituto Nacional del Emprendedor (2017), el estudio de los costos de operación es la piedra angular en toda clase de negocios, ya que permite no sólo la obtención de resultados satisfactorios, sino evitar que la empresa cometa errores en la fijación de los precios y que esto derive en un resultado negativo.

Es por esto que en la determinación de los costos, se debe tomar en cuenta que su valor cambia por posibles fluctuaciones en los precios o por diversos grados de utilización de la capacidad instalada.

De acuerdo a Horngren Charles (2012) los costos de producción registran el costo de los recursos adquiridos, como materiales, mano de obra y equipo, además de permitir dar un seguimiento a la forma en cómo tales recursos se utilizan para producir y vender los productos o servicios. Horngren C. (2012) menciona que hay dos tipos de patrones del comportamiento de los costos que se 
encuentran en muchos sistemas contables. Un costo variable cambia totalmente en proporción con los cambios relacionados con el nivel de actividad o volumen total. Un costo fijo se mantiene en su totalidad durante cierto periodo de tiempo a pesar de los amplios cambios en el nivel de actividad o volumen total.

Dado esto es importante particularizar que para este proyecto no se encuentran costos variables como tal, ya que no existen materias primas o insumos que vayan variando conforme se genera mayor producción. Lo que sí se presenta es el Costo Fijo independientemente a si haya una producción o no.

A continuación se listan los Costos Fijos propios de la operación:

Tabla 4.6. Costos Fijos

\begin{tabular}{lcc}
\hline \multicolumn{1}{c}{ Ítems } & \multicolumn{1}{c}{ Mensual } & \multicolumn{1}{c}{ Anual } \\
\hline Mano de Obra Directa & S/. 18,760.00 & S/. 225,120.00 \\
Agua & $\mathrm{S} / .100 .00$ & $\mathrm{~S} / .1,200.00$ \\
Luz & $\mathrm{S} / .150 .00$ & $\mathrm{~S} / .1,800.00$ \\
Telefonía Fija & $\mathrm{S} / 200.00$ & $\mathrm{~S} / .2,400.00$ \\
Internet & $\mathrm{S} / .200 .00$ & $\mathrm{~S} / .2,400.00$ \\
Alquiler & $\mathrm{S} / .2,040.00$ & $\mathrm{~S} / .24,480.00$ \\
\multicolumn{1}{c}{ Total } & S/. 21,450.00 & S/. 257,400.00 \\
\hline
\end{tabular}

Fuente: Elaboración propia 


\section{CAPITULO V}

\section{PLAN DE RECURSOS HUMANOS}

\subsection{Organización funcional}

Frederick Taylor (1911) afirmó que la organización lineal no propiciaba la especialización; propuso en su contexto que el trabajo del supervisor se dividiera entre 8 especialistas, uno por cada actividad principal, y que los ocho tuvieran autoridad, cada uno en su propio campo, sobre la totalidad del personal que realiza labores relacionadas con su función.

La idea consiste en dividir el trabajo y establecer la especialización de manera que cada hombre, desde el gerente hasta el obrero, ejecute el menor número posible de Funciones.

La organización por funciones reúne, en un departamento, a todos los que se dedican a una actividad o a varias relacionadas denominadas funciones. Esta estructura aplica el principio de la especialización de las funciones por cada tarea y es probable que la organización funcional sea la forma más lógica y básica de división por departamentos.

Esta estructura es empleada esencialmente por las pequeñas empresas que ofrecen una línea limitada de productos porque posibilita aprovechar con eficiencia los recursos especializados, además de facilitar considerablemente 
la supervisión de que cada gerente (cada uno sólo debe ser experto en un área limitada de conocimientos y habilidades). Adicionalmente facilita el movimiento de los conocimientos y habilidades especializadas para su uso en los puntos donde más se necesitan.

De manera particular, el presente proyecto ha implementado la organización funcional considerando los siguientes criterios:

a. La empresa constará inicialmente de una sola área, integrada por ajustadores de seguros quienes contarán con el conocimiento técnico necesario para realizar el trabajo de campo y las actividades de difusión del servicio. Esta área estará liderada por el Gerente General.

b. La empresa no tendrá en un inicio áreas administrativas ni de soporte técnico, pues estas actividades serán tercerizadas.

Como resultado se tiene la siguiente organización funcional:

Figura 5.1. Organización Funcional de la Empresa

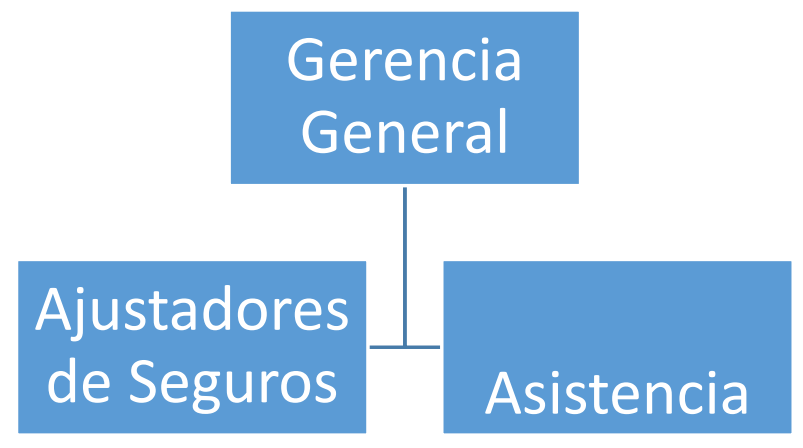

Fuente: Elaboración Propia 


\subsection{Organigrama}

La estructura organizacional de la empresa ajustadora de seguros se debe diseñar tomando en consideración los objetivos estratégicos planteados, así como también respetando las leyes y reglamentos que lo regulan.

Para nuestro proyecto, hemos desarrollado una estructura organizativa de forma funcional la cual se va adaptando al crecimiento de la empresa ajustadora de seguros en el horizonte de tiempo de nuestro proyecto.

A continuación, se muestra el organigrama de la empresa ajustadora de seguros.

Figura 5.2. Organigrama Inicial de Empresa Ajustadora de Seguros

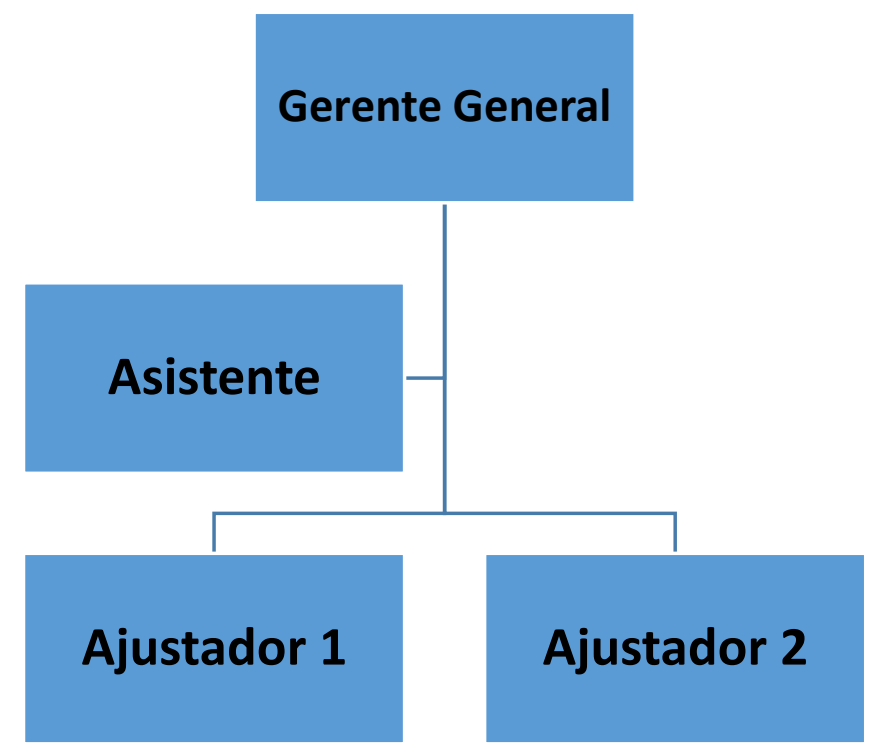

Fuente: Elaboración propia 


\section{Diseño de los perfiles de puestos clave}

La determinación de los perfiles de los puestos claves que se detallan a continuación se basa en los requerimientos del puesto acorde a la estructura organizacional planteada:

\section{Tabla 5.1. Perfil del Gerente General}

\begin{tabular}{|c|c|}
\hline \begin{tabular}{|l|} 
TITULO DEL \\
PUESTO \\
\end{tabular} & GERENTE GENERAL - AJUSTADOR PRINCIPAL \\
\hline REPORTA A & DCIOS \\
\hline FUN & \multirow[b]{2}{*}{$\begin{array}{l}\text { * Realizar los actos de administracion y gestion ordinaria de la } \\
\text { sociedad. } \\
\text { * Representar a la sociedad y apersonarse en su nombre y representacion } \\
\text { ante las autoridades judiciales, administrativas, laborales, municipales, } \\
\text { politicas y policiales, en cualquier lugar de la Republica o en el extranjero. } \\
\text { *Dirigir la contabilidad velando porque se cumplan las normas legales que } \\
\text { la regulan. } \\
\text { * Rendir cuenta justificada de su gestion en los casos senalados por la Ley. } \\
\text { * Vender, arrendar, dar en uso, hipotecar, otorgar fianzas y otras garantias y, } \\
\text { en general, efectuar toda clase de operaciones que impliquen afectacion o } \\
\text { disposicion de los bienes, muebles, inmuebles y de los derechos, de la sociedad, } \\
\text { incluyendo las concesiones de las que esta sea titular y los flujos de la sociedad } \\
\text { hasta por los limitesque se le imponga. } \\
\text { * Abrir, cerrar y administrar cuentas bancarias, sean corrientes, de ahorro, credito } \\
\text { o cualquier otra naturaleza, con o sin garantia. Girar cheque sobre los saldos } \\
\text { acreedores, deudores o en sobregiros autorizados en las cuentas bancarias que } \\
\text { la empresa tenga abiertas en instituciones bancarias de la Republica del Peru o de } \\
\text { otro pais. } \\
\text { * Preparar y presentar los reportes de cumpliemiento de produccion y financiero. } \\
\text { * Velar por la maximizacion de las utilidades de la empresa. } \\
\text { * Aprobar y controlar los presupuestos anuales de la empresa. }\end{array}$} \\
\hline Elaboración & \\
\hline & $\begin{array}{l}\text { * Los daños y perjuicios que ocasione por el incumplimiento de sus obligaciones, } \\
\text { dolo, abuso de facultades y negligencia grave. } \\
\text { * La existencia, regularidad y veracidad de los sistemas de contabilidad, los libros } \\
\text { que la ley ordena llevar a la Sociedad y los demas libros y registros. } \\
\text { * El empleo de los recursos sociales en negocios distintos del objeto de la } \\
\text { Sociedad. }\end{array}$ \\
\hline \begin{tabular}{|c|} 
ESPECIFICACIONES \\
DEL PUESTO \\
\end{tabular} & \multirow{2}{*}{$\begin{array}{l}\text { * Graduado en Administracion de Empresas, Ingenieria Industrial, Ingenieria civil. } \\
\text { o carreras afines. } \\
\text { * Còdigo de la SBS como habilitado para realizar la funciòn de ajustador. } \\
\text { * Estudios de especializacion en seguros o ajuste de siniestros. } \\
\text { * Experiencia de } 05 \text { años en areas de seguros de empresas, ajustadores, Perfil } \\
\text { corredores de seguros o compañias de seguros. } \\
\text { * Ingles nivel Intermedio } \\
\text { * Conocimiento avanzado de Office y Windows }\end{array}$} \\
\hline $1 \mathbf{a b l a}$ & \\
\hline
\end{tabular}




\begin{tabular}{|c|c|}
\hline $\begin{array}{l}\text { TITULO DEL } \\
\text { PUESTO } \\
\end{array}$ & AJUSTADOR DE SEGUROS \\
\hline REPORTA A & COORDINADOR DE OPERACIONES \\
\hline FUNCIONES & $\begin{array}{l}\text { 1. Estimar el valor de los objetos asegurados antes de la ocurrencia del siniestro, en } \\
\text { el caso de que éste se encontrase cubierto por la póliza. }\end{array}$ \\
\hline $\begin{array}{l}\text { Elaboración } \\
\text { propia }\end{array}$ & $\begin{array}{l}\text { 2. Examinar, investigar y determinar las causas conocidas o presuntas del siniestro. } \\
\text { 3. Calificar, informar y opinar si el siniestro se encuentra amparado por las } \\
\text { condiciones de la póliza. } \\
\text { 4. Establecer el monto de las pérdidas o daños amparados por la póliza. } \\
\text { 5. Señalar el importe que corresponde indemnizar con arreglo a las condiciones de } \\
\text { la póliza. } \\
\text { 6. Establecer el valor del salvamento para deducirlo de la cifra de daños, o su } \\
\text { comercialización por la empresa de seguros. El peritaje del ajustador no obliga a las } \\
\text { partes y es independiente a ellos." }\end{array}$ \\
\hline $\begin{array}{l}\text { RESPONSABLE } \\
\text { DE }\end{array}$ & $\begin{array}{l}\text { * Informar y asesorar a clientes, empresas que buscan solucion a su siniestralidad. } \\
\text { * Ofrecer toda la gama de servicios que ofrece la empresa }\end{array}$ \\
\hline $\begin{array}{c}\text { ESPECIFICACIONES } \\
\text { DEL PUESTO } \\
\end{array}$ & $\begin{array}{l}\text { * Bachiller en Administracion de Empresas } \\
\text { * Experiencia de } 2 \text { a } 4 \text { años minimo en el puesto o similares } \\
\text { * Contar con el Certificado de Ajustador de Seguros expedido por la SBS. } \\
\text { * Ingles Intermedio } \\
\text { * Manejo de herramientas tecnologicas Office. }\end{array}$ \\
\hline
\end{tabular}

Fuente: Elaboración propia 


\section{Tabla 5.3. Perfil de Asistente de Operaciones}

\begin{tabular}{|c|c|}
\hline PUESTO & ASISTENTE DE OPERACIONES \\
\hline REPORTA A & COORDINADOR DE OPERACIONES \\
\hline FUNCIONES & * revizar y controlar todos los siniestros asignados por las compañía. \\
\hline $\begin{array}{l}\text { Elaboración } \\
\text { propia }\end{array}$ & $\begin{array}{l}\text { * Revisar la agenda diaria de sus jefes inmediatos, e informar de las actividades del dia. } \\
\text { * Digitar la facturacion de los clientes, proveedores. } \\
\text { * Archivar la documentacion de forma diaria para concretar el orden del area. } \\
\text { * Coordinar con las personas involucradas la recoleccion de la informacion y } \\
\text { documentos necesarios para la elaboracion de los reportes que realiza la Coordinacion } \\
\text { de Operaciones. } \\
\text { * Elaborar los comunicados internos para la empresa, areas. De igual manera, elaborar } \\
\text { los comunicados de cambios a los clientes o proveedores. } \\
\text { * Asistir al jefe directo en la preparacion de reuniones o actividades para el desarrollo } \\
\text { de la buena y asertiva comunicación entre el grupo de trabajo. Efectuar la coordinacion } \\
\text { de dichas actividades. } \\
\text { * Asistir con la informacion a su jefe directo para que los reportes del area se emitan } \\
\text { correctamente. } \\
\text { * Asistir a su jefe directo en momentos en que la operación cuente con alguna baja en el } \\
\text { personal. } \\
\text { * Revisar que la documentacion este en orden. } \\
\text { * Asistir a reuniones con su jefe directo, al igual que encargarse del area en ausencia de } \\
\text { su superior. }\end{array}$ \\
\hline $\begin{array}{l}\text { RESPONSABLE } \\
\text { DE }\end{array}$ & $\begin{array}{l}\text { * Asistir y dar soporte al Coordinador de Operaciones en las funciones diarias. } \\
\text { * Mantener en orden el archivo de documentos. }\end{array}$ \\
\hline $\begin{array}{l}\text { ESPECIFICACIONES } \\
\text { DEL PUESTO } \\
\end{array}$ & $\begin{array}{l}\text { * Bachiller en Administracion de Empresas } \\
\text { * Experiencia de } 2 \text { anos minimo en el puesto o similares } \\
\text { * Ingles Intermedio } \\
\text { * Manejo de herramientas tecnologicas Office. }\end{array}$ \\
\hline
\end{tabular}

Fuente: Elaboración propia 


\subsection{Política de contratación}

En el siguiente cuadro, se detalla la cantidad de personal necesario de acuerdo al horizonte de tiempo del proyecto.

Tabla 5.4. Relación de Puestos

\begin{tabular}{lcccccc}
\hline \multicolumn{1}{c}{ Puesto } & Relación Laboral & Año 1 & Año 2 & Año 3 & Año 4 & Año 5 \\
\hline Gerente General & Planilla & 1 & 1 & 1 & 1 & 1 \\
$\begin{array}{l}\text { Asistente de } \\
\text { Operaciones }\end{array}$ & Planilla & 1 & 1 & 1 & 1 & 1 \\
Ajustador de Seguros & Planilla & 2 & 2 & 3 & 4 & 4 \\
\hline
\end{tabular}

Fuente: Elaboración propia

\subsubsection{Contratación}

El proceso de Vinculación laboral (2017) contempla:

$\checkmark$ Es formalizar con apego a la ley la futura relación de trabajo para garantizar los intereses, derechos, tanto del trabajador como de la empresa.

$\checkmark$ Cuando ya se aceptaron las partes es necesario integrar su expediente de trabajo.

$\checkmark$ La contratación se llevará a cabo entre la organización y el trabajador.

$\checkmark$ La duración del contrato será por tiempo indeterminado o determinado.

$\checkmark$ El contrato deberá ser firmado por el Gerente General, el responsable directo y el trabajador.

$\checkmark$ Generará afiliación al ESSALUD, AFP y de acuerdo a los salarios Impuesto a la renta de 4ta Categoría. 


\subsubsection{Política de Contratación del Personal}

La política de contratación de personal de la empresa Moreno \& Pacora Ajustadores de Seguros S.A.C. se basa en la política de la empresa Servicios Electrónicos para la Industria S.E.I. LTDA (2017), llegando a contemplar los siguientes puntos:

$\checkmark$ La persona a contratar debe cumplir con el perfil de cargo establecido para la vacante.

$\checkmark$ Antes de iniciar con el proceso de reclutamiento, la empresa analizará la posibilidad de realizar alguna promoción o rotación interna acorde a la vacante establecida.

$\checkmark$ Todos los candidatos deberán someterse a entrevista y a los exámenes laborales y deberán obtener resultados satisfactorios de acuerdo a las necesidades de cada caso para ser considerados como aptos para una vacante.

$\checkmark$ No se podrá realizar ninguna contratación de personal que no haya cumplido con el proceso de selección.

$\checkmark$ No es posible contratar a menores de edad.

$\checkmark$ Ningún trabajador se verá discriminado por razones de edad, sexo, estado civil, origen racional o étnico, condición social, religioso o convicciones, ideas políticas, orientación sexual, afiliación o no a un sindicato, discapacidad, así como por razón de lengua.

$\checkmark$ El trabajador debe guardar absoluta discreción con la información confidencial. 
$\checkmark$ El trabajador no podrá efectuar negociaciones relacionadas con los activos de la empresa en los cuales pueda tener un interés real o potencial.

$\checkmark$ No tener antecedentes judiciales y penales.

$\checkmark$ La administración será responsable de integrar los expedientes de personal y manejar confidencialmente su información, así como de elaborar los contratos respectivos, solicitando para tal efecto la siguiente documentación: Hoja de vida con las certificaciones laborales acorde a la experiencia acreditada, certificaciones que avalen los estudios realizados, carta de no antecedentes penales, presentar la documentación que le solicite la empresa para verificar su capacidad para el empleo.

$\checkmark$ Los datos y referencias que proporcionen los trabajadores serán verificados por la empresa, quedando entendido que de comprobarse la falsedad de los mismos, no será admitido en el trabajo, o, si ya estuviese trabajando, le podrá ser rescindido el contrato Individual del trabajo, sin responsabilidad alguna de la empresa.

$\checkmark$ Toda persona contratada para realizar una función en la empresa, deberá firmar un contrato de trabajo, que contenga todas las informaciones requeridas por la ley y según las políticas internas, la empresa podrá contratar de manera temporal a un trabajador que por la naturaleza del trabajo, sólo dure una parte del año. este tipo de contratos se denomina "por cierto tiempo" y termina sin responsabilidad por parte de la empresa en la fecha de término estipulada en el mismo. 
$\checkmark$ Una vez suscrito el contrato, el empleado, queda comprometido con la empresa, a prestar sus servicios personales, en el nivel que le corresponda en la organización, cumpliendo las cláusulas del contrato y las leyes laborales y reglamentos que regulan las relaciones de trabajo. La inducción al puesto será impartida y coordinada por la Administrador(a), a través de proyección de una presentación, folleto y evaluación escrita, en donde se dará a conocer aspectos generales de la empresa, del puesto, y de los sistemas de calidad y ambiental así como aspectos de seguridad establecidos para el buen desarrollo de cada una de las actividades desarrolladas por la organización.

$\checkmark$ Todo empleado nuevo será sometido a un período probatorio, este será de tres meses, al finalizar este período el jefe directo inmediato deberá hacer la evaluación y recomendará o no su contratación, a la gerencia técnica y/o administración, para fines de confirmación en el cargo.

La Administración, dentro de sus funciones de Gestión de Recursos Humanos para la selección de los funcionarios tendrá como principio la búsqueda de personal de la más alta calidad profesional, cuyas competencias se encuentren en concordancia con las exigencias y objetivos institucionales, a través de procedimientos técnicos, transparentes y no discriminatorios, basados en el mérito y la excelencia.

$\checkmark$ Como norma general no se acepta contratar personas que sean familiares del personal hasta cuarto grado de 
consanguineidad o segundo grado de afinidad. Para casos excepcionales deberá ser aprobado, siempre y cuando :

$\checkmark$ El candidato sea el más calificado para cubrir la vacante

$\checkmark$ En ningún caso podrá ser supervisado directa o indirectamente por ningún miembro de su familia ni se encuentre dentro de la línea de la mando. No afecte la imagen institucional interna ni externamente.

Ninguna persona podrá ser contratada por debajo ni por encima de la categoría salarial correspondiente para la posición que ocupa. Para la ubicación dentro del rango de la categoría salarial se tomará en cuenta el histórico salarial del postulante.

$\checkmark$ Es obligatorio para toda contratación presentar el file completo del nuevo trabajador y los formatos requeridos.

$\checkmark$ Antes de toda contratación nueva, se deberá emitir el Reporte del Filtro Antiterrorista y realizar la verificación de sus referencias laborales.

$\checkmark$ Ningún trabajador podrá laborar sin haber firmado su contrato de trabajo cuando dicha formalidad sea exigible legalmente. En caso de encontrarse laborando sin contrato escrito y éste fuese legalmente exigible, el/la Supervisor(a) responsable de la posición será quien asuma la multa ante el Ministerio de Trabajo.

$\checkmark$ Toda nueva contratación tendrá periodo de prueba, según la legislación laboral. Antes de concluir el periodo de prueba y para determinarse la continuidad de la persona el (la) supervisor(a) deberá evaluar al trabajador, darle retroalimentación necesaria y entregarle una copia de su 
evaluación. La otra copia firmada será enviada a recursos humanos.

$\checkmark$ Todo reingreso deberá tomar en cuenta las referencias del supervisor jerárquico, supervisor funcional y recursos humanos.

$\checkmark \quad$ No se podrá contratar en planilla a consultores que un mes anterior hayan emitido recibos de honorarios.

\subsection{Política salarial}

\subsubsection{Consideraciones de la Política Salarial}

De acuerdo a Pérez D. (2015) se debe considerar lo siguiente al momento de evaluar una política salarial:

$\checkmark$ Toda persona que realiza una labor busca ser remunerado económicamente y que esta compensación sea justa. El salario satisface las necesidades básicas de los trabajadores y los integrantes de su familia y también es uno de los principales costos de producción de un empresario, en la mayoría de los casos.

$\checkmark$ Para mantener el equilibrio es necesario un manejo adecuado. Contar con una política salarial justa, constituye un factor clave para administrar las finanzas.

$\checkmark$ La política salarial es el conjunto de orientaciones que tienen como finalidad distribuir equitativamente las cantidades asignadas para retribuir al personal, haciendo hincapié en la habilidad, responsabilidad, méritos, eficacia y educación requerida para el desarrollo eficiente 
de las tareas que exige un puesto de trabajo en la organización.

$\checkmark$ También se puede decir que una política salarial es el conjunto de reglas y normas que rigen el sistema de retribución de los asalariados de una empresa. Muchas veces esta expresada en la formulación de un ordenamiento mayor o a veces vía convenciones colectivas. Cuando cuenta con un sistema de incentivos bien formulados es una herramienta de gestión fundamental, que contribuye a la mejora de la productividad, la competitividad de las instituciones y/o establecimientos y a la motivación de los trabajadores. Es decir, que es la estructura organizacional quien determina el pago y los beneficios que recibirá cada empleado de acuerdo a la función que desempeñen dentro de la empresa.

\section{Figura 5.3. Componentes de la Política Salarial}

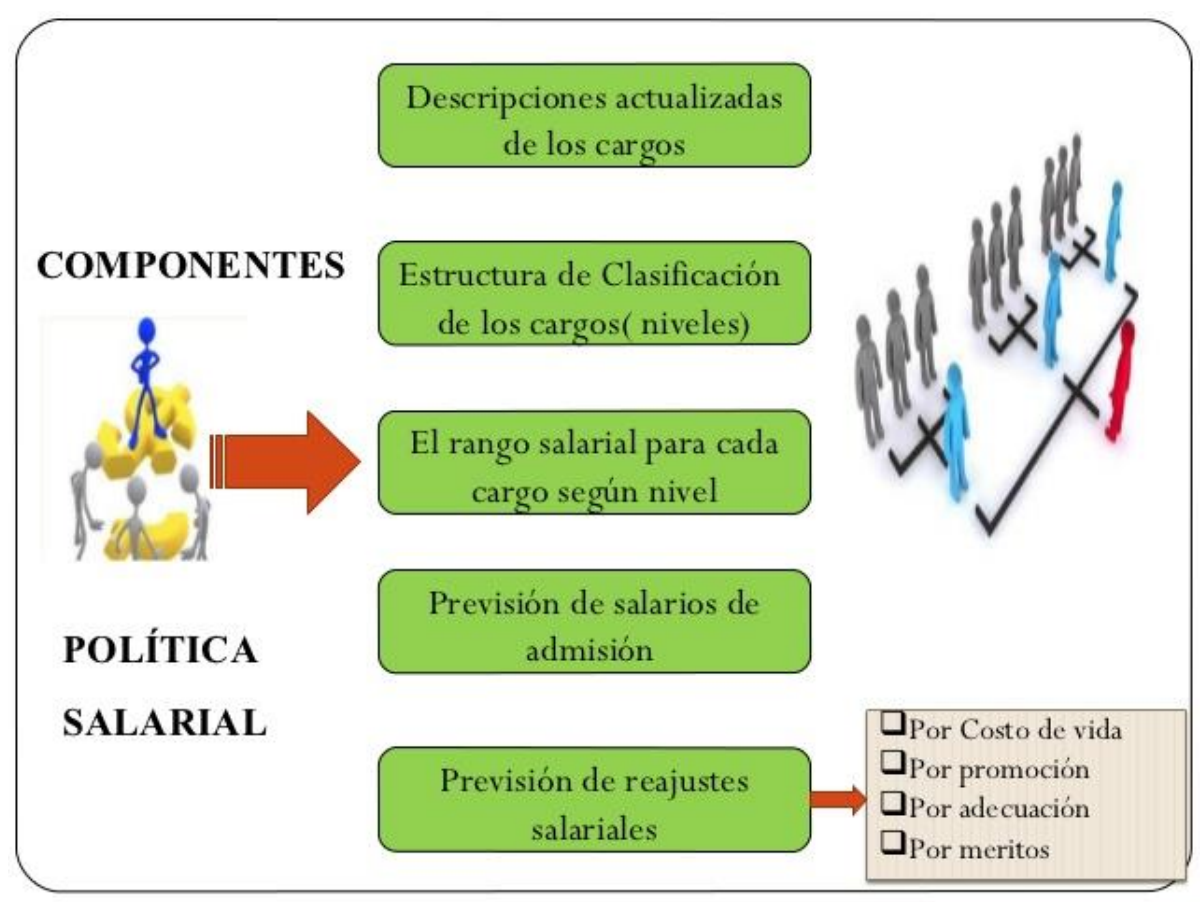


Fuente: Figura 5.2. Componentes de la Política Salarial, 2012. Recuperado de https://es.slideshare.net/Emerson19835/politica-salarial

\subsubsection{Escala Salarial}

A continuación se detalla la escala Salarial de la empresa

Tabla 5.5. Salarios de Empresa Ajustadora de Seguros

\begin{tabular}{lc}
\hline \multicolumn{1}{c}{ Nombre del Puesto } & Sueldo Mensual \\
\hline Gerente General - Ajustador & 6,000 \\
Asistente de Operaciones & 2,000 \\
Ajustador de Seguros & 4,000 \\
Total & 12,000 \\
\hline
\end{tabular}

Fuente: Elaboración propia

\subsubsection{Políticas Salariales}

Moreno \% Pacora, ajustadora de seguros, basa sus políticas salariales en las extraídas de la empresa en marcha World Service LTDA. (2017), extrayendo los siguientes puntos:

1. Los Términos de contratación y los niveles de remuneración se fijarán de acuerdo a un estudio referencial de competitividad de mercado, disponibilidades presupuestarias y a la hoja de vida del candidato seleccionado.

2. Los sueldos se pagarán mensualmente mediante depósito en la cuenta corriente o de ahorros de cada empleado.

3. Los empleados con contrato indefinido, podrán solicitar un anticipo de sueldo siempre y cuando no exceda el total 
de su remuneración mensual. Este anticipo será descontado en su totalidad en el rol de pagos a la finalización de dicho mes.

4. Moreno \& Pacora, Ajustadora de Seguros, podrá conceder préstamos de emergencia a sus empleados con contrato de trabajo indefinido, siempre y cuando éste no tenga deudas con la empresa y sean solicitados por motivos justificados. El préstamo no podrá ser mayor a tres veces su sueldo mensual en un plazo no mayor a 10 meses.

5. Cualquier excepción podrá ser autorizada únicamente por el Gerente General.

6. Del sueldo mensual de los empleados se descontarán los siguientes rubros:

a. Aportaciones al ESSALUD, AFP

b. Impuesto a la renta

c. Retenciones judiciales ordenadas por la autoridad competente

d. Aportes de los valores correspondientes a los beneficios adicionales

e. Deudas a la empresa, reconocidas y autorizadas por el empleado

f. Valor de útiles, materiales, equipos, muebles, cuya posesión indebida, pérdida o destrucción dolosa sea comprobada. 
7. En caso de tener que realizar trabajos para Moreno \& Pacora, Ajustadora de Seguros., en un lugar distinto al de su trabajo habitual, la empresa se hará cargo de los gastos de alojamiento y subsistencia durante el período que el empleado se encuentre en esta locación.

8. El pago de viáticos y subsistencias se efectuará de acuerdo a las TABLA DE VIÁTICOS vigentes.

9. Moreno \& Pacora, Ajustadora de Seguros, se hará cargo del pago de pasajes aéreos, marítimos o terrestres que se requiere para el traslado de los empleados hacia el lugar de trabajo. Estos gastos deberán constar con la aprobación del supervisor inmediato del cargo y la Gerencia General.

10. Moreno \& Pacora, Ajustadora de Seguros, no pagará a sus empleados horas suplementarias o extras debido a la naturaleza no programada del trabajo. 


\section{CAPÍTULO VI}

\section{PLAN FINANCIERO}

\subsection{Inversiones}

A continuación se detalla cada rubro de la Inversión inicial en la que se incurrirá con el proyecto.

\subsubsection{Inversiones en activo fijo}

Se lista los ítems que corresponden a los activos fijos que se necesitarán en el horizonte del proyecto en cuestión:

\section{Tabla 6.1. Inversión en Activo Fijo}

\begin{tabular}{lcccccc}
\hline \multicolumn{1}{c}{ Ítems } & Unidad de Medida & Año 1 & Año 2 & Año 3 & Año 4 & Año 5 \\
\hline PC & Unidad & 4 & - & 1 & 1 & - \\
Muebles de Oficina & Unidad & 4 & - & 1 & 1 & - \\
Equipos de Oficina & Unidad & 4 & - & 1 & 1 & - \\
Sala de Reuniones & Unidad & 1 & - & - & - & - \\
Televisor & Unidad & 1 & - & - & - & - \\
$\quad$ TOTAL & - & 14 & - & 3 & 3 & - \\
\hline
\end{tabular}

Fuente: Elaboración propia

Adicionalmente se detalla el nivel de la inversión asociada al primer año de funcionamiento para establecer la inversión inicial:

Tabla 6.2. Inversión en Activo Fijo

\begin{tabular}{|c|c|c|c|}
\hline Ítems & Cantidad & Valor Unitario & Valor Total \\
\hline $\mathrm{PC}$ & 4 & S/. 1,500.00 & $\mathrm{S} / .6,000.00$ \\
\hline Muebles de Oficina & 4 & $\mathrm{~S} / .400 .00$ & S/. 1,600.00 \\
\hline Equipos de Oficina & 4 & S/. 200.00 & S/. 800.00 \\
\hline Sala de Reuniones & 1 & S/. 1,200.00 & S/. 1,200.00 \\
\hline Televisor & 1 & S/. 2,500.00 & S/. 2,500.00 \\
\hline TOTAL & 14 & $\mathrm{~S} / . \mathbf{5 , 8 0 0 . 0 0}$ & $\mathrm{S} / . \mathbf{1 2 , 1 0 0 . 0 0}$ \\
\hline
\end{tabular}

Fuente: Elaboración propia 


\subsubsection{Inversiones en Capital de Trabajo}

Considerando un capital de trabajo que cubre los 03 primeros meses del inicio del proyecto, se construye el siguiente cuadro detallando su composición:

\section{Tabla 6.3. Cálculo de Capital de trabajo}

\begin{tabular}{lc}
\hline \multicolumn{1}{c}{ Ítems } & Monto (3 meses) \\
\hline Efectivo en Caja & $\mathrm{S} / .20,000.00$ \\
Pagos al personal & $\mathrm{S} / .48,000.00$ \\
Mantenimiento & $\mathrm{S} / .255 .00$ \\
Movilidades & $\mathrm{S} / .3,060.00$ \\
Viajes y Viáticos & $\mathrm{S} / .3,708.00$ \\
Gastos Fijos / Indirectos & $\mathrm{S} / .8,070.00$ \\
\multicolumn{1}{c}{ Capital de Trabajo } & S/. 83,093 \\
\hline
\end{tabular}

Fuente: Elaboración propia

\subsubsection{Inversiones en Activos Intangibles}

Los activos de constitución legal de la empresa conforman aquellos activos propios de los intangibles:

Tabla 6.4. Activos intangibles

\begin{tabular}{|c|c|c|c|}
\hline Ámbito & Ítems & & \\
\hline Tramite Interno & Orientación y asesoría & \multirow{4}{*}{$\mathrm{S} /}$. & \multirow{4}{*}{ - } \\
\hline Tramite Interno & Reunir requisitos & & \\
\hline Tramite Interno & Elaboración de la minuta & & \\
\hline Tramite Interno & $\begin{array}{l}\text { Suscripción de la minuta por un abogado y } \\
\text { los socios de la empresa }\end{array}$ & & \\
\hline Notaria & Escritura Pública & \multirow{2}{*}{$\mathrm{S} /}$. & \multirow{2}{*}{300} \\
\hline Notaria & Tarifa social reducida & & \\
\hline SUNARP & Inscripción en el Registro Mercantil & $\mathrm{S} /$. & 35 \\
\hline SUNAT & RUC & \multirow{2}{*}{$\mathrm{S} /}$. & \multirow{2}{*}{ - } \\
\hline SUNAT & Comprobante de Pago & & \\
\hline Municipalidad & Licencia Funcionamiento & $\mathrm{S} /$. & 178.38 \\
\hline \multirow[t]{2}{*}{ Notaria } & Legalización de libros & $\mathrm{S} /$. & 50 \\
\hline & Costo de Constitución & $\mathbf{S} /$. & 563 \\
\hline
\end{tabular}

Fuente: Elaboración propia

La inversión del proyecto ascendería a S/. 95,756 distribuyéndose en los rubros de los cuadros anteriores: 
Tabla 6.5. Inversión del proyecto

\begin{tabular}{llr} 
& \multicolumn{1}{c}{ Componente de la Inversión } & \multicolumn{1}{c}{ Monto } \\
\cline { 2 - 3 } & I.M.E. & S/. 12,100.00 \\
Constitución Legal & S/. 563 \\
& $\begin{array}{l}\text { Capital de Trabajo } \\
\text { Inversión Inicial }\end{array}$ & S/. 83,093 \\
Fuente: Elaboración propia & S5,756 \\
\cline { 2 - 2 }
\end{tabular}

\subsection{Financiamiento}

Para el caso de la composición de la inversión inicial y sus fuentes de financiamiento se han considerado la siguiente partición:

\section{Tabla 6.6. Financiamiento del proyecto}

\begin{tabular}{lccc}
\hline \multicolumn{1}{c}{ Items } & Aporte & Préstamo & Total \\
\hline Inversión Inicial & $\mathrm{S} / .28,726.91$ & $\mathrm{~S} / .67,029.47$ & $\mathrm{~S} / .95,756.38$ \\
En Porcentaje & $\mathbf{3 0 \%}$ & $\mathbf{7 0 \%}$ & $\mathbf{1 0 0 \%}$ \\
\hline \multicolumn{2}{c}{ Fuente: Elaboración propia } & &
\end{tabular}

\subsubsection{Costo de Oportunidad}

Se ha utilizado el modelo Capital Asset Pricing Model (CAPM en adelante) para estimar el costo de Oportunidad que se utilizará como Tasa de descuento de los flujos de cajas.

El modelo CAPM tiene como objetivo calcular el costo de capital desapalancado, el cual se define como la tasa esperada de retorno que se obtendría en el mercado de capitales por inversiones con similar riesgo (Sapag, 2011). A continuación se lista la fórmula de cálculo del mismo y se pasa a detallar cada variable en la expresión: 


$$
K_{e}=\left\{\left[R_{f}+\beta\left(R_{m}-R_{f}\right)+R_{p}\right] \times\left(\frac{\pi_{P e r u ́}}{\pi_{U s a}}\right)\right\}
$$

$K_{e}$ : Costo del Capital / Tasa de Descuento

$R_{f}$ : Tasa de rendimiento libre de riesgo

$\beta$ : Coeficiente de volatilidad Beta sin apalancamiento

$R_{m}$ : Tasa de rendimiento esperado del mercado

$R_{p}:$ Riesgo País

$\pi_{\text {Perú }}$ : Inflación de los últimos 12 meses Perú

$\pi_{U s a}$ : Inflación de los últimos 12 meses USA.

$F_{c}:$ Factor de Corrección

Entendiéndose en el presente proyecto que la Tasa libre de riesgo es equivalente al cupón de los bonos soberanos hacia el 2023, el coeficiente Beta utilizado es el del mercado de seguros en Estados Unidos, el riesgo país es el último disponible en información (abril 2017) y el factor de corrección situado para empresas nuevas alrededor del $6 \%$.

Para el caso puntual de la Tasa de rendimiento esperado se define como el valor de la mejor alternativa posible a la que uno deja de percibir para llevar a cabo un proyecto de inversión por lo que se estima como la Tasa de Interés más alta que nos estaría brindando una entidad financiera por un depósito a plazo mayor a 1 año sobre nuestra inversión calculada.

En este escenario se extrae la lista de tasas de interés por depósitos desde la misma web de la SBS del proyecto: 
Figura 6.1. Listados de Tasas Pasivas Anuales

\begin{tabular}{|c|c|c|c|c|c|c|c|c|}
\hline \multirow{2}{*}{ Tasa Anual (\%) } & \multirow{2}{*}{$\begin{array}{l}\text { Depósitos } \\
\text { de Ahorro }\end{array}$} & \multicolumn{5}{|c|}{ Depósitos a Plazo } & \multirow{2}{*}{$\begin{array}{l}\text { Depósitos } \\
\text { a Plazo }\end{array}$} & \multirow{2}{*}{$\begin{array}{l}\text { Depósitos } \\
\text { CTS }\end{array}$} \\
\hline & & $\begin{array}{c}\text { Hasta } 30 \\
\text { dias }\end{array}$ & $31-90$ dias & $91-180$ dias & $181-360$ dias & $\begin{array}{c}\text { Más de } 360 \\
\text { dias }\end{array}$ & & \\
\hline Continental & 0.76 & 4.01 & 3.76 & 4.51 & 4.48 & 4.94 & 4.05 & 2.08 \\
\hline Comercio & 1.39 & 0.91 & 2.48 & 1.28 & 5.76 & 6.55 & 4.62 & 5.00 \\
\hline Crédito & 0.19 & 4.04 & 4.40 & 4.73 & 4.34 & 5.05 & 4.06 & 1.97 \\
\hline Financiero & 0.77 & 4.02 & 4.45 & 4.94 & 5.45 & 5.79 & 4.51 & 5.03 \\
\hline BIF & 1.17 & 4.19 & 4.45 & 4.78 & 4.85 & 5.81 & 4.20 & 4.06 \\
\hline Scotiabank & 0.72 & 3.95 & 2.91 & 4.34 & 4.68 & 3.79 & 3.93 & 2.36 \\
\hline Citibank & 0.34 & 3.36 & 3.93 & 3.70 & - & - & 3.40 & - \\
\hline Interbank & 0.34 & 4.17 & 4.30 & 4.39 & 4.76 & 2.62 & 4.14 & 3.01 \\
\hline Mibanco & 0.31 & 4.30 & 4.93 & 5.23 & 5.37 & 5.58 & 4.68 & 5.83 \\
\hline GNB & 4.14 & 4.43 & 4.61 & 5.08 & 5.51 & 6.07 & 4.82 & 4.25 \\
\hline Falabella & 2.46 & 4.09 & 4.47 & 4.46 & 5.07 & 5.73 & 4.62 & 5.36 \\
\hline Santander & 0.50 & 4.24 & 4.54 & 4.88 & 4.85 & 4.80 & 4.29 & - \\
\hline Ripley & 0.75 & 3.14 & 3.56 & 4.36 & 5.47 & 5.97 & 5.14 & 6.57 \\
\hline Azteca & 1.00 & 1.80 & 2.50 & 3.25 & 3.85 & 4.15 & 3.48 & - \\
\hline Cencosud & - & 5.94 & 7.66 & 5.16 & 5.79 & 7.08 & 6.90 & 6.59 \\
\hline ICBC & - & 4.38 & 4.47 & - & - & - & 4.40 & - \\
\hline Promedio & 0.46 & 4.07 & 4.18 & 4.66 & 4.81 & 4.60 & 4.11 & 3.33 \\
\hline
\end{tabular}

Fuente: Figura 6.1. Listado de Tasas Pasivas Anuales. Recuperado. Superintendencia de Banca, Seguros y AFP, Recuperado de: http://www.sbs.gob.pe/app/pp/EstadisticasSAEEPortal/Paginas/TIPasivaDeposito

Como se aprecia el mejor rendimiento que se encuentra en el Sistema Financiero es de $7.0 \%$ perteneciente al Banco Cencosud, por lo que se estará utilizando esta tasa como el Rendimiento esperado del mercado.

Calculando con la información estimada tendríamos:

$$
\begin{gathered}
K_{e}=\left\{[5.20 \%+0,71(7.0 \%-5.20 \%)+1.49 \%] \times\left(\frac{1.89 \%}{2.20 \%}\right)\right\}+6 \% \\
K_{e}=12.85 \%
\end{gathered}
$$

\subsubsection{Costo de la Deuda}

El costo de la Deuda es calculado y extraído desde la SBS en el rubro de préstamos empresariales en MN a más de 01 año. Esta TEA para el caso del Banco BBVA Continental se encuentra aproximadamente en $13.30 \%$. 
Con la Tasa mencionada el párrafo anterior se realiza el cronograma de amortizaciones e intereses generados para el pago de la Deuda en 03 años:

Tabla 6.7. Detalle del financiamiento

\begin{tabular}{|c|c|c|}
\hline Ítems & & \\
\hline Monto del Préstamo & $\mathrm{S} /$. & $67,029.47$ \\
\hline Plazo (En meses) & & 36 \\
\hline Interés Anual (\%) & & $13.30 \%$ \\
\hline Interés Mensual (\%) & & $1.046 \%$ \\
\hline
\end{tabular}

Tabla 6.8. Cronograma de Amortizaciones

\begin{tabular}{|c|c|c|c|}
\hline $\mathrm{N}^{\mathbf{0}}$ & Interés & Amortización & Saldo \\
\hline$\overline{1}$ & S/. 701.13 & S/. 1,542.92 & S/. $65,486.55$ \\
\hline 2 & S/. 684.99 & S/. 1,559.06 & S/. 63,927.49 \\
\hline 3 & S/. 668.69 & S/. 1,575.37 & $\mathrm{S} / .62,352.12$ \\
\hline 4 & S/. 652.21 & S/. 1,591.85 & S/. 60,760.27 \\
\hline 5 & S/. 635.56 & S/. 1,608.50 & S/. 59,151.78 \\
\hline 6 & S/. 618.73 & S/. 1,625.32 & S/. 57,526.45 \\
\hline 7 & S/. 601.73 & S/. 1,642.32 & S/. 55,884.13 \\
\hline 8 & S/. 584.55 & S/. 1,659.50 & S/. 54,224.63 \\
\hline 9 & S/. 567.19 & S/. 1,676.86 & S/. 52,547.77 \\
\hline 10 & S/. 549.65 & S/. 1,694.40 & S/. $50,853.37$ \\
\hline 11 & S/. 531.93 & S/. 1,712.12 & S/. 49,141.25 \\
\hline 12 & S/. 514.02 & S/. 1,730.03 & $\mathrm{S} / .47,411.21$ \\
\hline 13 & S/. 495.92 & S/. 1,748.13 & S/. 45,663.09 \\
\hline 14 & S/. 477.64 & S/. 1,766.41 & S/. 43,896.67 \\
\hline 15 & S/. 459.16 & S/. 1,784.89 & S/. 42,111.78 \\
\hline 16 & S/. 440.49 & S/. $1,803.56$ & S/. 40,308.22 \\
\hline 17 & S/. 421.63 & S/. $1,822.43$ & S/. 38,485.79 \\
\hline 18 & $\mathrm{~S} / .402 .56$ & S/. 1,841.49 & S/. 36,644.30 \\
\hline 19 & S/. 383.30 & S/. $1,860.75$ & S/. $34,783.55$ \\
\hline 20 & S/. 363.84 & S/. 1,880.22 & S/. 32,903.34 \\
\hline 21 & S/. 344.17 & S/. $1,899.88$ & $\mathrm{~S} / .31,003.45$ \\
\hline 22 & S/. 324.30 & S/. 1,919.76 & S/. 29,083.70 \\
\hline 23 & S/. 304.22 & S/. 1,939.84 & S/. 27,143.86 \\
\hline 24 & S/. 283.93 & S/. 1,960.13 & S/. $25,183.73$ \\
\hline 25 & S/. 263.42 & S/. 1,980.63 & $\mathrm{S} / .23,203.10$ \\
\hline 26 & S/. 242.71 & S/. 2,001.35 & S/. 21,201.76 \\
\hline 27 & S/. 221.77 & S/. 2,022.28 & S/. $19,179.48$ \\
\hline 28 & S/. 200.62 & S/. 2,043.44 & S/. 17,136.04 \\
\hline 29 & S/. 179.24 & S/. 2,064.81 & S/. $15,071.23$ \\
\hline 30 & S/. 157.65 & S/. 2,086.41 & S/. 12,984.82 \\
\hline 31 & S/. 135.82 & S/. 2,108.23 & S/. $10,876.59$ \\
\hline 32 & S/. 113.77 & S/. 2,130.28 & S/. 8,746.31 \\
\hline
\end{tabular}




\begin{tabular}{llcc}
33 & S/. 91.49 & S/. $2,152.57$ & S/. $6,593.74$ \\
34 & S/. 68.97 & S/. $2,175.08$ & S/. $4,418.66$ \\
35 & S/. 46.22 & S/. $2,197.83$ & S/. 2,220.82 \\
36 & S/. 23.23 & S/. $2,220.82$ & S/. - \\
\hline
\end{tabular}

Fuente: Elaboración propia

\subsection{Presupuesto Base}

El presupuesto Base a diseñar se compone de las estructuras de Requerimiento de Personal, Costos indirectos al servicio, Gastos de Administración, Gastos de Ventas y Cálculo de Depreciación.

\subsubsection{Requerimiento de Personal}

Del personal requerido para el presente proyecto el Gerente General / Ajustador Principal y los Ajustadores de Seguros pertenecen al cálculo de la Mano de Obra Directa; mientras que el Asistente se posiciona en el cálculo de Gastos de Administración:

\section{Tabla 6.9. Personal requerido en el horizonte del proyecto}

\begin{tabular}{lccccc}
\hline \multicolumn{1}{c}{ Trabajador } & Año 1 & Año 2 & Año 3 & Año 4 & Año 5 \\
\hline Gerente General / Ajustador Principal & 1 & 1 & 1 & 1 & 1 \\
Ajustador de Seguros & 2 & 2 & 3 & 4 & 4 \\
Asistente de Operaciones & 1 & 1 & 1 & 1 & 1 \\
\hline
\end{tabular}

Fuente: Elaboración propia

Calculando el Costo para un año del Gerente General y un Ajustador se tendría:

Tabla 6.10. Cálculo anual de MOD

\begin{tabular}{|c|c|c|c|c|c|}
\hline Cargos & $\mathbf{N}^{\circ}$ & Sueldo M & nsual & & eldo Anual \\
\hline Gerente General & 1 & $\mathrm{~S} /$. & $6,000.00$ & $\mathrm{~S} /$. & $72,000.00$ \\
\hline Ajustador de Seguros & 1 & $\mathrm{~S} /$. & $4,000.00$ & $\mathrm{~S} /$. & $48,000.00$ \\
\hline Gratificaciones & & $\begin{array}{l}\text { SALUD Anual } \\
(9 \%)\end{array}$ & & TS & Costo Anual \\
\hline $12,000.00$ & $\mathrm{~S} /$. & $6,480.00$ & $\mathrm{~S} / \mathrm{s}$ & $6,000.00$ & $96,480.00$ \\
\hline $8,000.00$ & S/. & $4,320.00$ & S/. & $4,000.00$ & $64,320.00$ \\
\hline
\end{tabular}


Finalmente se realiza la proyección del costo el MOD para los 05 años de evaluación del proyecto tomando en cuenta el requerimiento de personal en cada año:

\section{Tabla 6.11. Proyección de la MOD}

\begin{tabular}{lccccc}
\hline \multicolumn{1}{c}{ Ítems } & Año 1 & Año 2 & Año 3 & Año 4 & Año 5 \\
\hline $\begin{array}{l}\text { Costo Anual } \\
\text { en MOD }\end{array}$ & S/. 225,120.00 & S/.225,120.00 & S $/ .289,440.00$ & S $/ .353,760.00$ & S $/ .353,760.00$ \\
\hline
\end{tabular}

Fuente: Elaboración propia

\subsubsection{Costos Indirectos al Servicio}

A continuación se lista una serie de Ítems que conforman la estructura de Costos Indirectos del presente proyecto con sus respectivos montos mensuales y anuales:

\section{Tabla 6.12. Cálculo de costos indirectos}

\begin{tabular}{|c|c|c|c|c|c|}
\hline Items & Año 1 & Año 2 & Año 3 & Año 4 & 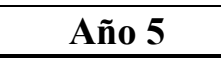 \\
\hline Man & S/. $\quad 1,020.00$ & S/. $1,020.00$ & S/. $\quad 1,020.0$ & $\mathrm{~S} / . \quad 1,020.00$ & S/. $1,020.0$ \\
\hline Tel & $\mathrm{S} / . \quad 3, \mathrm{C}$ & $\mathrm{S} / .3$, & S/ & & S/. \\
\hline Agua & S/. 1,2 & S/. 1, & S/. 1, & $\mathrm{~S} /$. & S/. 1, \\
\hline 117 & S/. $\quad 1,8$ & S/. 1, & $\mathrm{~S} / . \quad 1, \mathrm{~S}$ & $\mathrm{~S} /$. & $\mathrm{S} /$. \\
\hline & $\mathrm{S} / . \quad 2,40$ & S/. 2,47 & $\mathrm{~S} / . \quad 2,5$ & $\mathrm{~S} / . \quad 2, \mathrm{C}$ & S/. 2, \\
\hline & S/. $\quad 2,40$ & S/. $\quad 2,47$ & S/. 2,5 & S/. 2,6 & $\mathrm{~S} / . \quad 2$, \\
\hline & S/. 24,48 & S/. 26,92 & S/. 29,6 & S/. 32, & S/. 35, \\
\hline & $\mathrm{S} / .12$ & S/. 12,2 & S/. 15, & $\mathrm{S} / .1$ & S/. $18,000.00$ \\
\hline & .1 & S/. 1 & $5 \% 15$ & & S/. 16, \\
\hline stros $V$ arios & S/. $14,400.00$ & S/. $14,832.00$ & S/. 15,276.96 & S/. 15,735.27 & S/. 16,207.33 \\
\hline
\end{tabular}

Fuente: Elaboración propia

Como se puede apreciar los costos indirectos crecen a un ritmo de la inflación de 3\% al año; con excepción del Alquiler que se 
incrementa en $10 \%$ de su valor cada año y la Telefonía Móvil que depende de la cantidad de Ajustadores en la empresa.

Finalmente y al igual que con la MOD se realiza la proyección para los 05 años del periodo de evaluación:

Tabla 6.13. Proyección de costos indirectos

\begin{tabular}{cccccc}
\hline Ítems & Año 1 & Año 2 & Año 3 & Año 4 & Año 5 \\
\hline $\begin{array}{c}\text { Costo Indirecto } \\
\text { Anual }\end{array}$ & S/. 78,372.00 & S/. 81,930.96 & S/. 89,848.05 & S/. 98,068.75 & S/. 102,541.01 \\
\hline Fuente: Elaboración propia & & & &
\end{tabular}

\subsubsection{Gastos de Administración}

Se realiza el cálculo del salario del Asistente de Operaciones:

Tabla 6.14. Cálculo anual del Salario Asistente

\begin{tabular}{cccc}
\hline Cargos & $\mathbf{N}^{\circ}$ & Sueldo Mensual & Sueldo Anual \\
\hline Asist. Operaciones & 1 & S/.2,000.00 & S/.24,000.00 \\
\hline & & & \\
\hline Gratificaciones & ESSALUD & CTS & Costo Anual \\
\hline S/.4,000.00 & S/.2,160.00 & S/.2,000.00 & S/.32,160.00 \\
\hline
\end{tabular}

Fuente: Elaboración propia

Adicionalmente se ingresan los costos naturales de la parte administrativa del negocio:

Tabla 6.15. Cálculo de gastos administrativos

\begin{tabular}{lll}
\hline \multicolumn{1}{c}{ Ítems } & \multicolumn{1}{c}{ Mensual } & \multicolumn{1}{c}{ Anual } \\
\hline Contribución SBS & S/. 49.58 & S/. 595.00 \\
Servicio de contabilidad & S/. 500.00 & S/. 6,000.00 \\
Servicio de Limpieza & S/. 8,50.00 & S/. 10,200.00 \\
\hline
\end{tabular}

Fuente: Elaboración propia

Y se evalúa la proyección de gastos administrativos en el periodo correspondiente: 
Tabla 6.16. Proyección de gastos administrativos

\begin{tabular}{cccccc}
\hline Ítems & Año 1 & Año 2 & Año 3 & Año 4 & Año 5 \\
\hline Sueldo Asistente & S/. 32,160.00 & S/. 32,160.00 & S/. 32,160.00 & S/. 32,160.00 & S/. 32, 160.00 \\
Gastos ADM & S/. 16,795.00 & S/. 16,795.00 & S/. 16,795.00 & S/. 16,795.00 & S/. 16,795.00 \\
TOTAL & S/. 48,955.00 & S/. 48,955.00 & S/. 48,955.00 & S/. 48,955.00 & S/. 48,955.00 \\
\hline
\end{tabular}

Fuente: Elaboración propia

\subsubsection{Gasto de Ventas}

Se adicionan en este rubro la elaboración de una Página Web más su respectivo almacenamiento en la web (hosting) más el merchandising propio de la operación del negocio:

Tabla 6.17. Cálculo de gasto de ventas

\begin{tabular}{ccccc}
\hline Ítems & Unidad & Cantidad & Precio Unitario & Gasto total \\
\hline Elaboración Página & Site & 1 & $\mathrm{~S} / .5,100.00$ & $\mathrm{~S} / .5,100.00$ \\
$\begin{array}{c}\text { Web } \\
\text { Merchandising }\end{array}$ & $\begin{array}{c}\text { Unidades } \\
\text { Hosting }\end{array}$ & 12 & $\mathrm{~S} / .1,000.00$ & $\mathrm{~S} / .12,000.00$ \\
$\begin{array}{c}\text { Espacio } \\
\text { mensual }\end{array}$ & 12 & $\mathrm{~S} / .8 .33$ & $\mathrm{~S} / .100 .00$ \\
\hline
\end{tabular}

Fuente: Elaboración propia

Del mismo modo que los anteriores casos y considerando un incremento de inflación para el Merchandising se realiza la proyección del gasto de ventas:

Tabla 6.18. Proyección de gasto de ventas

\begin{tabular}{|c|c|c|c|c|c|}
\hline Ítems & Año 1 & Año 2 & Año 3 & Año 4 & Año 5 \\
\hline $\begin{array}{c}\text { Gastos de } \\
\text { Vtas. }\end{array}$ & S/. 17,200.00 & S/. $12,460.00$ & $\mathrm{~S} / .12,830.80$ & S/. 13,212.72 & S/. 13,606.11 \\
\hline
\end{tabular}




\subsubsection{Cálculo de la Depreciación}

Se utiliza el método de Depreciación en línea recta para realizar el respectivo descuento de valor a los Inmuebles, maquinarias y equipos considerados en el presente proyecto:

Tabla 6.19. Cálculo y proyección de la depreciación

\begin{tabular}{|c|c|c|c|c|c|c|c|c|c|}
\hline Items & Cant. & $\begin{array}{c}\text { Valor } \\
\text { Unitario }\end{array}$ & $\begin{array}{c}\text { Valor a } \\
\text { depreciar }\end{array}$ & Tasa & Año 1 & Año 2 & Año 3 & Año 4 & Año 5 \\
\hline$\overline{\mathrm{PC}}$ & 4 & $\mathrm{~S} / .1,500.00$ & $\mathrm{~S} / .6,000.00$ & $10 \%$ & S/. 600.00 & S/. 600.00 & S/. 750.00 & S/. 900.00 & S/. 900.00 \\
\hline $\begin{array}{l}\text { Muebles } \\
\text { de Oficina }\end{array}$ & 4 & S/.400.00 & S/.1,600.00 & $10 \%$ & S/. 160.00 & S/. 160.00 & S/. 200.00 & S/. 240.00 & S/. 240.00 \\
\hline $\begin{array}{l}\text { Equipos } \\
\text { de Oficina }\end{array}$ & 4 & S/.200.00 & $\mathrm{S} / .800 .00$ & $10 \%$ & S/. 80.00 & S/. 80.00 & S/. 100.00 & S/. 120.00 & S/. 120.00 \\
\hline $\begin{array}{l}\text { Sala de } \\
\text { Reuniones }\end{array}$ & 1 & S/.1,200.00 & S/.1,200.00 & $10 \%$ & S/. 120.00 & S/. 120.00 & S/. 120.00 & S/. 120.00 & S/. 120.00 \\
\hline Televisor & 1 & $\mathrm{~S} / .2,500.00$ & $\mathrm{~S} / .2,500.00$ & $10 \%$ & S/. 250.00 & S/. 250.00 & S/. 250.00 & S/. 250.00 & S/. 250.00 \\
\hline TOTAL & 14 & S/.5,800.00 & S/.12,100.00 & & S/. 1,210.00 & S/. 1,210.00 & S/. $1,420.00$ & S/. 1,630.00 & S/. $1,630.00$ \\
\hline
\end{tabular}

\subsection{Estados financieros proyectados}

A continuación se listan 03 Estados Financieros que permitirán evaluar la factibilidad del presente proyecto y de los cuales se estarán extrayendo los principales indicadores de análisis de rentabilidad. 


\subsubsection{Balance General}

Tabla 6.20. Balance general

Moreno y Pacora Ajustadores de Seguros

Balance General

Del 01.01.2018 al 31-12-218

Expresado en Nuevos Soles

\begin{tabular}{|c|c|c|c|}
\hline \multicolumn{2}{|l|}{ ACTIVO } & \multicolumn{2}{|l|}{ PASIVO Y PATRIMONIO } \\
\hline & TOTAL & & TOTAL \\
\hline ACTIVO CORRIENTE & & PASIVO CORRIENTE & \\
\hline \multirow{2}{*}{ Efectivo (Caja y Bancos) } & $\mathrm{S} / .83,093.00$ & & \\
\hline & & TOTAL PASIVO CTE. & $\mathrm{S} /$. \\
\hline \multirow[t]{2}{*}{ TOTAL ACTIVO CTE. } & $\mathrm{S} / .83,093.00$ & & \\
\hline & & PASIVO NO CORRIENTE & \\
\hline ACTIVO NO CORRIENTE & & Deudas a largo Plazo & S/. $67,029.47$ \\
\hline$\overline{\text { Inmuebles Maquinarias y Equipos }}$ & $\mathrm{S} / .12,100.00$ & & \\
\hline Activos Intangibles & S/. $\quad 563.38$ & TOTAL PASIVO NO CTE. & S/. $67,029.47$ \\
\hline \multirow[t]{4}{*}{ TOTAL ACTIVO NO CTE. } & S/.12,663.38 & $\begin{array}{l}\text { TOTAL PASIVO } \\
\end{array}$ & S/. 67,029.47 \\
\hline & & PATRIMONIO & \\
\hline & & Capital Social & S/. $28,726.91$ \\
\hline & & $\begin{array}{l}\text { TOTAL PATRIMONIO } \\
\end{array}$ & S/. 28,726.91 \\
\hline TOTAL ACTIVO & $\mathrm{S} / .95,756.38$ & TOTAL PASIVO Y PATRIMONIO & S/. $95,756.38$ \\
\hline
\end{tabular}

Fuente: Elaboración propia

Para realizar los siguientes 02 Estados financieros es necesario estimar los ingresos por Ventas de Servicio, basándose en las proyecciones realizadas en la demanda objetivo, para ello se presenta el siguiente cuadro donde se precisa dicho cálculo: 
Tabla 6.21. Proyección de los Ingresos brutos

\begin{tabular}{|c|c|c|c|c|c|}
\hline Años & Año 1 & Año 2 & Año 3 & Año 4 & Año 5 \\
\hline $\begin{array}{l}\text { Monto de } \\
\text { Siniestralidad }\end{array}$ & $\mathrm{S} / .2,936,551,253$ & $\mathrm{~S} / .3,153,861,323$ & S/.3,371,171,392 & $\mathrm{S} / .3,588,481,462$ & $\mathrm{~S} / .3,805,791,531$ \\
\hline $\begin{array}{c}\text { Comisión } \\
(\%)\end{array}$ & $1.189 \%$ & $1.189 \%$ & $1.189 \%$ & $1.189 \%$ & $1.189 \%$ \\
\hline $\begin{array}{l}\text { Siniestralidad } \\
\text { Total de EAS }\end{array}$ & S/.34,909,040 & S/.37,492,371 & S/.40,075,703 & S/.42,659,035 & S/.45,242,366 \\
\hline $\begin{array}{c}\text { Mercado } \\
\text { Objetivo } \\
(\%)^{*}\end{array}$ & $0.81 \%$ & $1.10 \%$ & $1.38 \%$ & $1.67 \%$ & $1.96 \%$ \\
\hline $\begin{array}{c}\text { Ingresos } \\
\text { Brutos }\end{array}$ & $\mathrm{S} / .281,496$ & S/.410,604 & $\mathrm{S} / .554,633$ & $\mathrm{~S} / . \mathbf{7 1 3 , 5 8 3}$ & $\mathrm{S} / . \mathbf{8 8 7 , 4 5 4}$ \\
\hline
\end{tabular}

6.4.2. Estado de Pérdidas y Ganancias Proyectado

Tabla 6.22. Estado de Ganancias y Pérdidas

\begin{tabular}{|c|c|c|c|c|c|}
\hline \multicolumn{6}{|c|}{$\begin{array}{c}\text { Moreno y Pacora Ajustadores de Seguros } \\
\text { Estado de Pérdidas y Ganancias Proyectado } \\
\text { Proyección a } 05 \text { años } \\
\text { Expresado en Nuevos Soles }\end{array}$} \\
\hline Items & Año 1 & Año 2 & Año 3 & Año 4 & Año 5 \\
\hline VENTAS (+) & S/. $281,496.42$ & S/. 410,604.16 & S/. 554,633.03 & S/. 713,583.01 & S/. $887,454.12$ \\
\hline COSTOS DE VENTAS (-) & S/. 257,400.00 & S/. 260,082.00 & S/. 327,335.82 & S/. 394,866.15 & S/. 398,380.14 \\
\hline Costos Variables & S/. - & S/. - & S/. - & S/. - & S/. - \\
\hline Costos Fijos & S/. $257,400.00$ & S/. 260,082.00 & S/. 327,335.82 & S/. $394,866.15$ & S/. 398,380.14 \\
\hline UTILIDAD BRUTA & S/. 24,096.42 & S/. $150,522.16$ & S/. 227,297.21 & S/. $318,716.86$ & S/. $489,073.98$ \\
\hline Gastos ADM. (-) & S/. $48,955.00$ & S/. 48,955.00 & S/. $48,955.00$ & S/. 48,955.00 & S/. 48,955.00 \\
\hline Gastos de Ventas (-) & S/. $17,200.00$ & S/. 12,460.00 & S/. $12,830.80$ & S/. $13,212.72$ & S/. 13,606.11 \\
\hline UTILIDAD OPERATIVA & S/. $-42,058.58$ & S/. 89,107.16 & S/. $165,511.41$ & S/. 256,549.14 & S/. 426,512.88 \\
\hline Gastos Financieros (-) & S/. 7,310.39 & S/. 4,701.17 & S/. 1,744.91 & S/. - & S/. - \\
\hline Depreciación (-) & S/. 1,210.00 & S/. 1,210.00 & S/. 1,420.00 & S/. 1,630.00 & S/. $1,630.00$ \\
\hline Otros Ingresos (+) & S/. - & S/. - & S/. - & S/. - & S/. - \\
\hline Otros Egresos (-) & S/. 46,092.00 & S/. 46,968.96 & S/. 51,952.23 & S/. 56,962.60 & S/. 57,920.87 \\
\hline Ingresos Financieros (+) & S/. - & S/. - & S/. - & S/. - & S/. - \\
\hline UAI & S/. - $96,670.97$ & S/. 36,227.04 & S/. $110,394.27$ & S/. $197,956.54$ & S/. 366,962.00 \\
\hline Impuestos $(29.5 \%)$ & S/. - & S/. 10,686.98 & S/. 32,566.31 & S/. 58,397.18 & S/. $108,253.79$ \\
\hline UTILIDAD NETA & S/. -96,670.97 & S/. 25,540.06 & S/. 77,827.96 & S/. 139,559.36 & S/. 258,708.21 \\
\hline
\end{tabular}

Fuente: Elaboración propia 


\subsubsection{Flujo de Caja}

\section{Tabla 6.23. Flujo de Caja}

Moreno y Pacora Ajustadores de Seguros

Flujo de Caja Proyectado

Proyección a 05 años

Expresado en Nuevos Soles

\begin{tabular}{|c|c|c|c|c|c|c|}
\hline Items & Año 0 & Año 1 & Año 2 & Año 3 & Año 4 & Año 5 \\
\hline INVERSIÓN INICIAL (-) & S/. 95,756.38 & & & & & \\
\hline I.M.E. & S/. $12,100.00$ & & & & & \\
\hline Constitución Legal & S/. 563.38 & & & & & \\
\hline Capital de Trabajo & S/. 83,093.00 & & & & & \\
\hline VALOR DE DESECHO (+) & S/. - & S/. - & S/. - & S/. - & S/. - & S/. 5,000.00 \\
\hline I.M.E. & S/. - & S/. - & S/. - & S/. - & S/. - & S/. 5,000.00 \\
\hline INGRESOS (+) & S/. - & S/. 281,496.42 & S/. 410,604.16 & S/. 554,633.03 & S/. 713,583.01 & S/. $887,454.12$ \\
\hline EGRESOS (-) & S/. - & S/. 369,647.00 & S/. 368,465.96 & S/. $441,073.85$ & S/. 513,996.47 & S/. $518,862.12$ \\
\hline Costos Directos & S/. - & S/. $225,120.00$ & S/. $225,120.00$ & S/. $289,440.00$ & S/. $353,760.00$ & S/. $353,760.00$ \\
\hline Costos Administrativos & $\mathrm{S} / .-$ & S/. 48,955.00 & S/. 48,955.00 & S/. 48,955.00 & S/. 48,955.00 & S/. 48,955.00 \\
\hline Costos de Ventas & S/. - & S/. $17,200.00$ & S/. $12,460.00$ & S/. 12,830.80 & S/. $13,212.72$ & S/. $13,606.11$ \\
\hline Costos indirectos & S/. - & S/. $78,372.00$ & S/. 81,930.96 & S/. 89,848.05 & S/. 98,068.75 & S/. $102,541.01$ \\
\hline Depreciación (-) & S/. - & S/. $1,210.00$ & S/. 1,210.00 & S/. $1,420.00$ & S/. $1,630.00$ & S/. 1,630.00 \\
\hline Impuestos (-) & S/. - & S/. - & S/. 10,686.98 & S/. 32,566.31 & S/. $58,397.18$ & S/. $108,253.79$ \\
\hline Amortización (-) & S/. - & S/. $19,618.25$ & S/. 22,227.48 & S/. $25,183.73$ & S/. - & S/. - \\
\hline Intereses (-) & S/. - & S/. 7,310.39 & S/. 4,701.17 & S/. 1,744.91 & S/. - & S/. - \\
\hline FLUJO NETO & S/. $-95,756.38$ & S/. $-116,289.23$ & S/. 3,312.58 & S/. 52,644.22 & S/. 139,559.36 & S/. 263,708.21 \\
\hline
\end{tabular}

\subsection{Evaluación de la rentabilidad}

Con la finalidad de realizar la evaluación de rentabilidad del proyecto se deben extraer los flujos económicos y financieros correspondientes. Se toma en consideración el impacto de la inflación esperada de $2.88 \%$ (Informe de expectativas inflacionarias, BCRP - Expectativas para el 2017 y 2018) y 
utilizando la fórmula de Fisher relacionando la inflación con la tasa de descuento mencionada en puntos anteriores se obtiene una tasa real de $9.70 \%$.

El Flujo financiero Nominal se compone de los montos calculados en el Flujo de Caja proyectado, mientras que el Flujo económico Nominal se extrae del Estado de ganancias y pérdidas proyectado. Seguido de esto el cálculo de los flujos deflactados descuenta el valor de cada flujo nominal utilizando la inflación esperada mencionada en el párrafo anterior (2.88\%), mostrando el efecto que tiene la inflación esperada a lo largo de los años del horizonte.

Finalmente los Flujos reales se generan aplicando la tasa de descuento de Fisher (9.70\%) hacia los flujos deflactados. Estos últimos flujos permiten generar los indicadores de rentabilidad que se expondrán en los siguientes párrafos.

Tabla 6.24. Cálculo de flujos financieros y económicos

\begin{tabular}{|c|c|c|c|c|c|c|}
\hline Items & Año 0 & Año 1 & Año 2 & Año 3 & Año 4 & Año 5 \\
\hline Flujo Financiero Nominal & S/. $-95,756.38$ & S/. $-116,289.23$ & S/. 3,312.58 & S/. 52,644.22 & S/. $139,559.36$ & S/. 263,708.21 \\
\hline Flujo Económico Nominal & S/. $-95,756.38$ & S/. $-96,670.97$ & S/. 25,540.06 & S/. 77,827.96 & S/. $139,559.36$ & S/. $258,708.21$ \\
\hline Items & $\mathbf{0}$ & 1 & 2 & 3 & 4 & 5 \\
\hline Flujo Financiero Deflactado & S/. $-95,756.38$ & S/. $-113,039.34$ & S/. 3,130.02 & S/. 48,352.75 & S/. $124,600.44$ & S/. $228,862.38$ \\
\hline Flujo Económico Deflactado & S/. $-95,756.38$ & S/. $-93,969.35$ & S/. $24,132.50$ & S/. 71,483.55 & S/. $124,600.44$ & S/. 224,523.07 \\
\hline Items & $\mathbf{0}$ & 1 & 2 & 3 & 4 & 5 \\
\hline Flujo Financiero Real & S/. $-95,756.38$ & S/. $-103,047.61$ & S/. 2,601.14 & S/. 36,630.77 & S/. $86,050.37$ & S/. $144,084.03$ \\
\hline Flujo Económico Real & S/. $-95,756.38$ & S/. $-85,663.25$ & S/. 20,054.82 & S/. $54,154.05$ & S/. 86,050.37 & S/. $141,352.14$ \\
\hline
\end{tabular}

Fuente: Elaboración propia

Una vez detallados los flujos económicos y financieros se seleccionan 03 criterios vitales en la evaluación de proyectos: 


\subsubsection{Valor Actual Neto y Tasa Interna de Retorno (VAN y TIR)}

El VAN o el Valor Actual Neto se calcula actualizando todos los

Flujos de Caja con su respectivo Costo de Oportunidad, de forma que se traen a Valor Presente todos los montos y se comparan contra la Inversión inicial del proyecto. Si el resultado del VAN es mayor a cero se entiende que el Valor del proyecto en el periodo 0 es positivo; mientras que si es menor en un análisis superficial no se considera rentable.

Para evaluar un proyecto utilizando el VAN y TIR es necesario extraer los flujos Financieros y Económicos de los Estados proyectados calculados en el acápite anterior y se generan los siguientes resultados:

\section{Tabla 6.25. Cálculo de VAN y TIR}

\begin{tabular}{lc}
\hline \multicolumn{1}{c}{ Concepto } & Dato \\
\hline VANE & S/. $120,191.75$ \\
TIRE & $72.96 \%$ \\
VANF & S/. $70,562.31$ \\
TIRF & $51.10 \%$ \\
\hline
\end{tabular}

Fuente: Elaboración propia

Analizando estos indicadores se puede apreciar que los económicos (VANE y TIRE) son relativamente altos y por tanto en una primera instancia se recomendaría llevar a cabo el proyecto; adicionalmente a esto se señala que los indicadores financieros muestran resultados positivos y superiores a los criterios de factibilidad de un proyecto.

Es importante mencionar que el préstamo podría estar causando distorsiones en la proyección y podría generar que los indicadores 
financieros sean menores a los económicos, sin embargo la tasa interna de retorno financiera de $51.10 \%$ indica claramente el potencial de crecimiento y rentabilidad que generan las operaciones de la empresa.

El análisis es concluyente desde el punto de vista que los 4 indicadores brindan resultados satisfactorios y es innegable el crecimiento y potencial de los flujos en el periodo de evaluación.

\subsubsection{Período de Recuperación: Pay Back corriente}

El Periodo de Recuperación es un indicador financiero que nos permite estimar el tiempo que nos tomará recuperar la inversión realizada para el proyecto, utilizando los datos del flujo procedemos a estimarla y verificar si se encuentra dentro del periodo de evaluación (05 años):

\section{Tabla 6.26. Cálculo del periodo de recuperación}

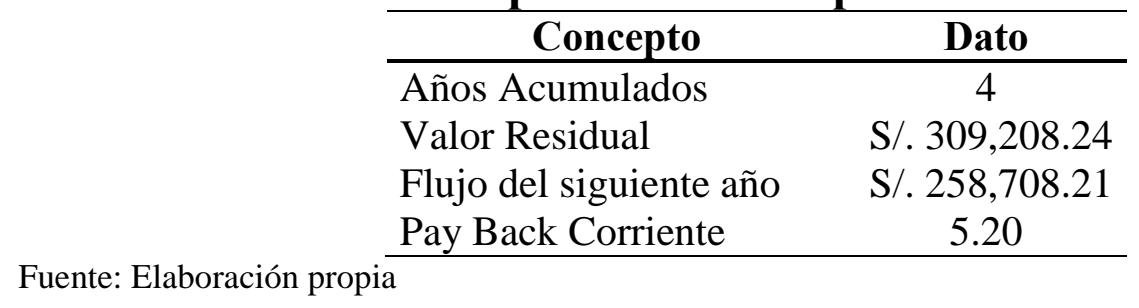

La fórmula utilizada para este cálculo es:

$$
\mathrm{PBC}=\text { Años Acumulados }+\frac{\text { Valor Residual }}{\text { Flujo del siguiente año }}
$$

Con este indicador se puede apreciar que el periodo en el que se recupera la inversión se encuentra dentro del periodo de evaluación financiera de los estados proyectos, por lo tanto en este criterio también es recomendable la realización del presente proyecto. 


\subsection{3. Índice de Rentabilidad o Índice de Deseabilidad}

El índice de Rentabilidad nos permite realizar una comparación entre los Valores presentes de los Flujos Económicos y la Inversión realizada en el periodo inicial, de forma que el ratio puede demostrar si el proyecto tiene rentabilidad o no. A un ratio mayor a 1 se le considera una evaluación positiva.

\section{Tabla 6.27. Cálculo del índice de rentabilidad}

\begin{tabular}{ccc}
\hline Años & Valor Presente \\
\cline { 2 - 3 } & 1 & S/. $-85,663.25$ \\
2 & S/. 20,054.82 \\
3 & S/. 54,154.05 \\
4 & S/. 86,050.37 \\
5 & S/. 141,352.14 \\
VP Total & S/. 215,948.13 \\
Inversión & S/. 95,756.38 \\
IR & S/. 2.26 \\
\hline
\end{tabular}

Fuente: Elaboración propia

La fórmula de cálculo que se ha utilizado para estimar este criterio es:

$$
\mathrm{IR}=\frac{\text { Valor Presente Total }}{\text { Inversión }}
$$

$\mathrm{Al}$ realizar el cálculo de este indicador se obtiene un ratio mayor a la unidad, por lo que también en esta herramienta financiera se concluye que el proyecto tiene potencial de rentabilidad. Este indicador expresa que frente a la inversión se tiene un ratio de 2.26 veces de rentabilidad durante el periodo de evaluación financiera. 


\subsection{Análisis de Sensibilidad}

Se utilizará la comisión como la variable en 03 escenarios distintos para realizar un análisis de sensibilidad del indicador financiero VANE y VANF.

El escenario regular se establece utilizando la misma comisión con la que se ha realizado el análisis financiero detallado líneas arriba, para obtener los resultados del escenario pesimista y optimista se ha restado/sumado respectivamente un 5\% a la comisión. De esta manera se obtiene que la comisión para el escenario pesimista es de $1.129 \%$, mientras que para el optimista sería $1.248 \%$.

\section{Tabla 6.28. Cálculo de VAN en escenarios}

\begin{tabular}{cccc}
\hline Indicador & Esc. Pesimista & Esc. Regular & Esc. Optimista \\
\hline Comisión & $1.070 \%$ & $1.189 \%$ & $1.308 \%$ \\
VANE & S/. 50,148.89 & S/. 120,191.75 & S/. 190,234.62 \\
VANF & S/. 519.45 & S/. 70,562.31 & S/. 140,605.17 \\
\hline Fuente: Elaboración propia & & &
\end{tabular}

Como se puede apreciar en la anterior tabla, ambos indicadores son volátiles a la comisión, pero esto es natural dado que la proyección de ventas depende de los montos de siniestros, los cuales llegan a millones de soles y una variación porcentual ocasiona una considerable diferencia.

Adicionalmente y como se pudo apreciar en la estimación de la demanda, la comisión del mercado obtenida no es un indicador tan cambiante de un periodo a otro, por lo que es mucho más probable que la proyección de ventas se sitúe en el escenario regular y 
mantener niveles similares en el periodo de evaluación sin ocasionar que los indicadores financieros se perjudiquen.

Aun asumiendo que los cambios en las comisiones pudieran darse, el análisis de sensibilidad permite descubrir que en los 03 escenarios se tienen resultados de VANE y VANF bastante aceptables que aseguran la rentabilidad del negocio. 


\section{CAPÍTULO VII}

\section{CONCLUSIONES Y RECOMENDACIONES}

En este capítulo se procederá a presentar y enumerar las conclusiones y recomendaciones a las que se ha llegado luego de realizar y evaluar el proyecto en cuestión.

\subsection{Conclusiones}

A continuación detallaremos las conclusiones a las que hemos llegado a partir de nuestra investigación:

a. El proyecto es plenamente viable, según la investigación realizada.

b. Se concluye que el nivel de rivalidad entre los competidores es moderado debido a que existen 14 ajustadores en el mercado de seguros para la atención de los siniestros, y solo 06 de ellas que han incrementado su participación, además del $76 \%$ del mercado concentrado en las 05 principales.

c. De lo investigado, se concluye que no existen productos sustitutos para el servicio que se busca brindar, puesto que este se basa es actividades muy específicas tanto para la compañía de seguros como para los asegurados.

d. De la segmentación del mercado, podemos observar que los Clientes Grandes y Medianos poseen la necesidad de contar 
con los servicios de las empresas ajustadoras de seguros, motivo por el cual acceden a los servicios dependiendo de las ventajas que ofrece o negocia el ajustador, generándose una frecuencia de consumo.

e. Del análisis de demanda se concluye que:

- El mercado de Primas de Seguros tiene una tendencia creciente.

- Las siniestralidades representan un $43 \%$ en promedio de las Primas Pagadas.

- El ingreso para el mercado de empresas ajustadoras de seguros de roles generales representa un $1.2 \%$ de la siniestralidad pagada.

f. El Índice de Rentabilidad obtenido, mayor a uno (1); nos permite concluir que el proyecto tiene alta viabilidad.

\subsection{Recomendaciones}

A continuación detallaremos las recomendaciones a las que hemos llegado a partir de nuestra investigación:

a. Se recomienda la puesta en marcha del proyecto con su posterior incursión en el mercado de ajustadores de seguros como así lo ha demostrado la presente investigación.

b. Dada la actual situación de los ajustadores de seguros en el Perú se recomienda la puesta en marcha de esta empresa en el menor tiempo posible, por la oportunidad de negocio existente. 
c. El periodo de recuperación se encuentra dentro del periodo de la evaluación financiera, por lo tanto es altamente recomendable la realización del presente proyecto.

d. Una vez iniciadas las operaciones se recomienda llevar a cabo una investigación mediante encuestas a fin de conocer los insights más importantes de nuestros clientes. 


\section{BIBLIOGRAFÍA}

Aguirre, Sánchez, Cooper, Kemp y Velarde (1999). Plan comercial para la implementación de un negocio de seguros personales (Tesis de Postgrado). Universidad San Ignacio de Loyola, Lima, Perú.

Araujo Dejo, M. A., Escudero Casquino, F. A., Palacios Santos, J. (2000). Análisis y propuestas estratégicas para el desarrollo del sector seguros en el Perú (Tesis de Maestría). Universidad ESAN, Lima, Perú.

Asociación de Supervisores de Seguros de América Latina (2017). ASSAL - Mercado Sectorial Peruano. Recuperado de wWw.assalweb.org/docs/merc_asegurador/mercado_asegurador_peru. docx

Banco Central de Reserva del Perú (2017). Informe de Expectativas inflacionarias - Expectativas para el 2017 y 2018. BCRP, Lima Perú.

Banco Central de Reserva del Perú (2017). Índice de Precios al Consumidor a nivel nacional. BCRP, Lima Perú.

Banco Central de Reserva del Perú (2017). Diferencial de Rendimientos del índice de Bonos de Mercados Emergentes (EMBIG) - Perú. BCRP, Lima Perú.

Bureau of Labor Statistics (2017). CPI Detailed Report: Data for April 2017. Estados Unidos de América. 
Crece Negocios (2017). La cadena de valor de Porter. Recuperado de www.crecenegocios.com/la-cadena-de-valor-de-porter

Damodaran Online (2017). Total Betas by Sector. Recuperado de http://pages.stern.nyu.edu/ adamodar/

Díaz J., Pajuelo M. \& Miranda C. (2015). Pacific Credit Rating - Informe Sectorial Perú: Sector Seguros. Recuperado de http://www.ratingspcr.com/uploads/2/5/8/5/25856651/sectorial_segur os_201512.pdf

Frederick Taylor (1911). The Principles of Scientific Management. Harper $\&$ brothers publishers, New york and london.

Fundación MAPFRE (2017). MAPFRE: ¿Quiénes somos?, Misión, visión y principios y Órganos de Gobierno. Recuperado de https://www.fundacionmapfre.org/fundacion/es_es/publica

García, I (2011). Análisis, Diseño e Implementación de una Plataforma Web de Apoyo a la Gestión de Casos de Ajuste de Riesgos Generales (Tesis de Pregrado). Pontificia Universidad Católica del Perú, Lima, Perú.

Horngren Charles (2012). Contabilidad de Costos: Un enfoque de Gerencia. Décimo cuarta edición. Editorial Pearson.

Kotler, Philip y Keller, Kevin (2016). Dirección de Marketing. Decimoquinta edición, México, Pearson Educación. 
Instituto Nacional del Emprendedor (2017). Flujo del proceso productivo y escalas de producción - Determinación de Costos y márgenes de operación. Recuperado de http://www.contactopyme.gob.mx/guiasempresariales/guias.asp?s=14 $\underline{\text { \&guia }=46 \& \text { giro }=1 \& \text { ins }=934}$

Ley N ${ }^{\circ} 26702$ "Ley General del Sistema Financiero y Sistema de Seguros". Diario El Peruano, Lima, Perú, lunes 09 de diciembre de 1996.

Ley N 29946 “Ley del Contrato de Seguros”. Diario El Peruano, Lima, Perú, martes 27 de noviembre de 2012.

Mejía, A. (2000). Estrategias para fidelizar la cartera de clientes de la compañía de seguros Pacifico Vida (Tesis de Postgrado). Universidad San Ignacio de Loyola, Lima, Perú.

Ministerio de Economía y Finanzas (2017). Reporte de Precios de Bonos Soberanos: PEN Soberanos. Lima, Perú.

Ministerio de Economía, Industria y Competitividad (2017). Legislación Básica - Normativa - Mediación en seguros privados de ley. Lima, Perú. 
Ministerio de la Producción (2017). Constitución de empresas. Lima Produce, $2005 . \quad$ Recuperado de http://www.produce.gob.pe/industria/competitividad/constitucion.php

Miyoshi M. (2015). Planeamiento Estratégico para la Empresa PROTECTA S.A.C para su unidad de negocios de microseguros (Tesis de Postgrado). Universidad San Ignacio de Loyola, Lima, Perú.

Morales S. (2013). Plan de Negocio para el lanzamiento del producto de libros orientados al plan lector (Tesis de Postgrado). Universidad San Ignacio de Loyola, Lima, Perú.

Municipalidad Distrital de Pueblo Libre (2017). Texto Único de Procedimientos Administrativo - TUPA (2016). Recuperado de http://www.muniplibre.gob.pe/assets/docs/tupa/TUPA\%202016\%20M $\underline{\text { PL.pdf }}$

Pérez D. (2015). Políticas Salariales: Principios de Orientación y filosofía en la organización. Recuperado de http://psalarialesdiana.blogspot.pe/2015/06/politicas-salariales.html

Philip Kotler (1999). El Marketing según Kotler. Como crear, ganar y dominar los mercados. Barcelona, Ediciones Paidos Iberica y Editorial Paidos.

Porter, Michael (2015). Ventaja Competitiva. Creacion y Sostenibilidad de un Rendimiento Superior. Novena Edición. Madrid, Ediciones Piramide (Grupo Anaya). 
Romero R. (2016). Ajustes, liquidacion y recupero de siniestros. Recuperado de http://docplayer.es/3818532-Ajustes-liquidacion-yrecupero-de-siniestros-ing-rafael-romero.html

Santesmases, Miguel (2012). Marketing Conceptos y Estrategias - Sexta Edición. Madrid, Ediciones Piramide (Grupo Anaya).

Sapag Nassir (2011). Proyecto de Inversion, Formulacion y Evaluacion. Segunda edición. Chile. Pearson Educación.

Sergio R. Ortiz (2003). Visión y Gestión Empresarial. España, THOMPSON.

Servicios Electrónicos para la Industria (2017). Política de Contratación del Personal. Recuperado de http://www.seicolombia.com/index.php?option=com_content\&view=a $\underline{\text { rticle\&id }=167 \& \text { Itemid }=142}$

Superintendencia de Banca, Seguros y AFP (2017). Boletín Estadístico de $\begin{array}{lll}\text { Seguros. } & \text { Recuperado de }\end{array}$ https://www.sbs.gob.pe/app/stats_net/stats/EstadisticaBoletinEstadisti co.aspx?p=25\#

Superintendencia de Banca, Seguros y AFP (2017). Evolución del Sistema Asegurador. Recuperado

de https://www.sbs.gob.pe/app/stats_net/stats/EstadisticaBoletinEstadisti co.aspx?p=27\#

Superintendencia de Banca, Seguros y AFP (2017). Intermediarios y Auxiliares de Seguros. Recuperado de 
https://www.sbs.gob.pe/app/stats net/stats/EstadisticaBoletinEstadisti co.aspx?p=26\#

Superintendencia de Banca, Seguros y AFP (2017). Listado de Tasas Pasivas Anuales. Recuperado de: http://www.sbs.gob.pe/app/pp/EstadisticasSAEEPortal/Paginas/TIPasi vaDeposito

Superintendencia de Banca, Seguros y AFP (2017). Requisitos para postular al registro de intermediarios y auxiliares de seguros. Recuperado de http://www.sbs.gob.pe/principal/categoria/requisitospara-postular-al-registro-de-intermediarios-y-auxiliares-deseguros/2065/c-2065

World Service LTDA. (2017). Políticas de Contratación. Recuperado de https://es.scribd.com/doc/18033900/POLITICAS-DE-contratacion 